\title{
Pholcid spiders from the Lower Guinean region of Central Africa: an overview, with descriptions of seven new species (Araneae, Pholcidae)
}

\author{
Bernhard A. HUBER ${ }^{1,5}$, Philippe LE GALL ${ }^{2,6}$, Jacques François MAVOUNGOU ${ }^{3,4,7}$ \\ ${ }^{1}$ Alexander Koenig Research Museum of Zoology, Adenauerallee 160, 53113 Bonn, Germany \\ E-mail: b.huber@zfmk.de \\ ${ }^{2}$ Laboratoire Evolution, Génomes et Spéciation, UPR 9034, Centre National de la Recherche \\ Scientifique (CNRS), 91198 Gif sur Yvette Cedex, France and Université Paris-Sud 11, \\ 91405 Orsay Cedex, France. E-mail: philippe.le-gall@ird.fr \\ ${ }^{3}$ Institut de Recherche en Ecologie Tropicale, BP: 13354, Libreville, Gabon \\ Email: mavoungoujacques@yahoo.fr \\ ${ }^{4}$ Université des Sciences et Techniques de Masuku, Franceville, Gabon. \\ ${ }^{5}$ urn:1sid:zoobank.org:author:33607F65-19BF-4DC9-94FD-4BB88CED455F \\ ${ }^{6}$ urn:Isid:zoobank.org:author:13F0CC41-6013-49FD-B4C2-0A455C9F8D82 \\ ${ }^{7}$ urn:Isid:zoobank.org:author:E990D817-154C-4B8A-BD6D-740B05879DA0
}

\begin{abstract}
This paper summarizes current knowledge about Central African pholcids. Central Africa is here defined as the area between $10^{\circ} \mathrm{N}$ and $7^{\circ} \mathrm{S}$ and between $6^{\circ} \mathrm{E}$ and $18^{\circ} \mathrm{E}$, including mainly the Lower Guinean subregion of the Guineo-Congolian center of endemism. This includes all of Gabon, Equatorial Guinea, São Tomé and Príncipe, most of Cameroon and Congo Republic, and parts of the neighboring countries. An annotated list of the 14 genera and 79 species recorded from this area is given, together with distribution maps and an identification key to genera. Seven species are newly described: Anansus kamwai sp. nov., Leptopholcus gabonicus sp. nov., Ninetis faro sp. nov., Pholcus punu sp. nov., P. rawiriae sp. nov., Spermophora abibae sp. nov., and S. awalai sp. nov. Additional new records are given for 16 previously described species, including 17 new country records. Distribution and diversity patterns are compared with data on West and East Africa. While West Africa contains a similar set of genera it is significantly less diverse than Central Africa. East Africa is taxonomically more distinct. It has similar levels of diversity as Central Africa, but appears to be less undersampled.
\end{abstract}

Keywords. Pholcidae, Central Africa, Lower Guinea, taxonomy, identification key

Huber B.A., Le Gall P. \& Mavoungou J.F. 2014. Pholcid spiders from the Lower Guinean region of Central Africa: an overview, with descriptions of seven new speices (Araneae, Pholcidae). European Journal of Taxonomy 81: 1-46. http://dx.doi.org/10.5852/ejt.2014.81

\section{Introduction}

Central Africa is home to the world's second largest moist tropical forests, exceeded in area only by the Amazon Basin forests. In contrast to West and East Africa, where only about $10 \%$ of the original tropical moist forests remain (Naughton-Treves \& Weber 2001; Norris et al. 2010), Central African forests may still extend over about half the original area (59.3\% in 1992; Naughton-Treves \& Weber 2001). While 
a high diversity of organisms otherwise concentrated in the tropics is thus expected for Central Africa, available data often fail to reflect this, probably for lack of exploration. Even relatively well-studied groups such as mammals, birds, and amphibians are poorly studied in parts of Africa, in particular in Central Africa (Dowsett-Lemaire \& Dowsett 2001; Grubb 2001; Lawson \& Klemens 2001), where cryptic diversity is probably more frequent than previously thought (Voelker et al. 2013).

Pholcid spiders are among the groups known to be most diverse in tropical and subtropical regions (Huber 2011a, 2011b), with a wide range of body shapes and colors related to different microhabitats (Figs 1-18). However, tropical Africa has long remained poorly explored (Huber 2005). No more than 18 currently valid species had been described from the Lower Guinean subregion of the Guineo-Congolian
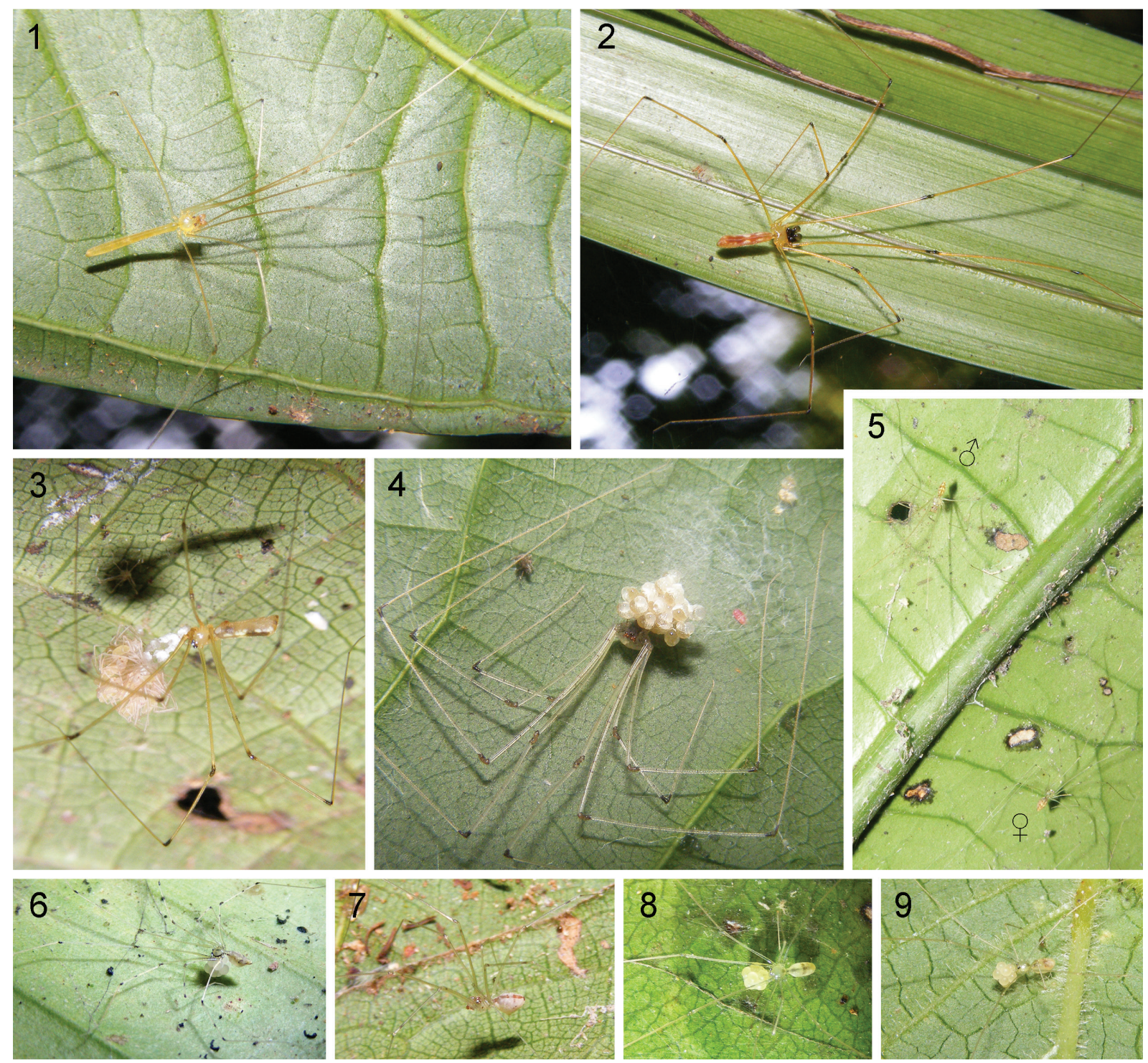

Figs 1-9. Leaf-dwelling Central African pholcids. 1. Leptoholcus gabonicus sp. nov., $\widehat{\jmath}$ from Mayebout, Gabon. 2-3. Pholcus baka Huber, 2011, $\widehat{\jmath}$ from Sahoué (2) and $q$ with juveniles from Mayebout (3), Gabon. 4. Smeringopus cylindrogaster (Simon, 1907), \& with eggsac from Loum, Cameroon. 5-6. Spermophora awalai sp. nov., pair from Nyasoso (5) and a $q$ with eggsac from Attuleh (6), Cameroon. 7. Spermophora akwamu Huber \& Kwapong, 2013, o from NE Makokou, Gabon. 8-9. Quamtana oku Huber, 2003, $q 9$ with eggsacs from Mt. Oku, Cameroon. Photos BAH. 
HUBER B.A. et al., Central African pholcid spiders

center of endemism until 2002, and numbers were similarly low for West Africa (19) and East Africa (29). This situation has changed dramatically within the last decade. Focused arachnological collecting campaigns by a number of individuals from various institutions have resulted in an increase of available
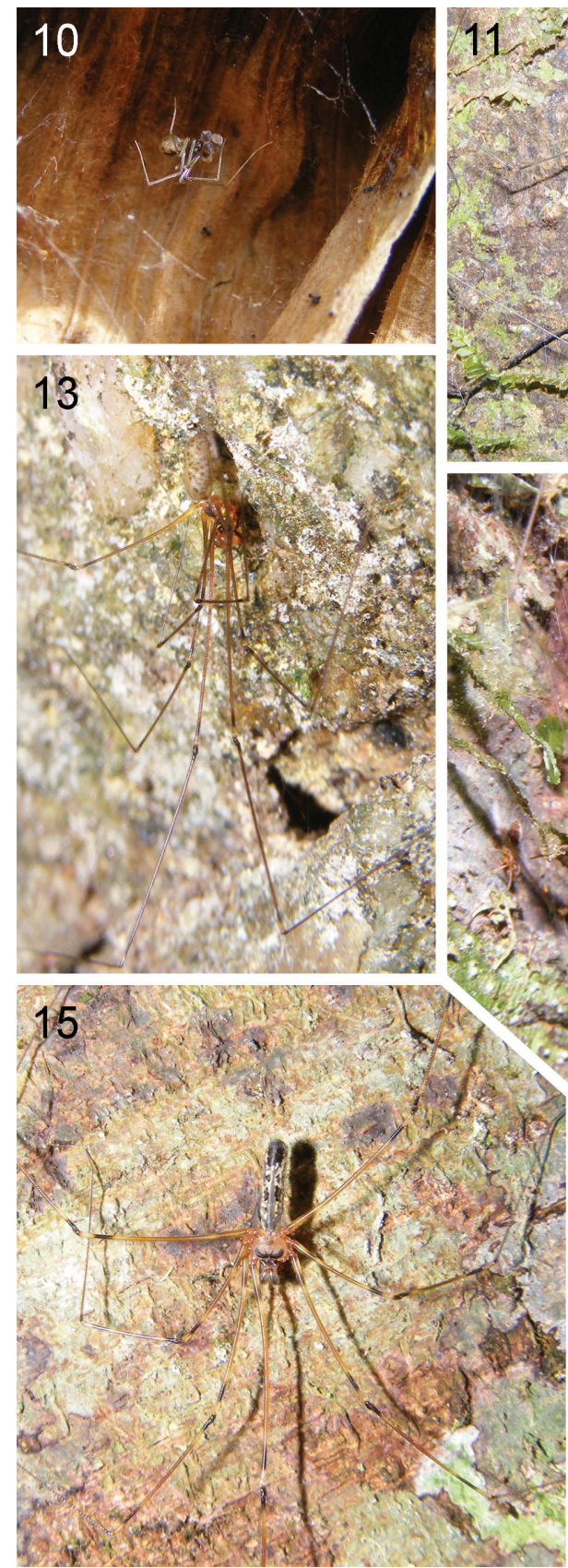
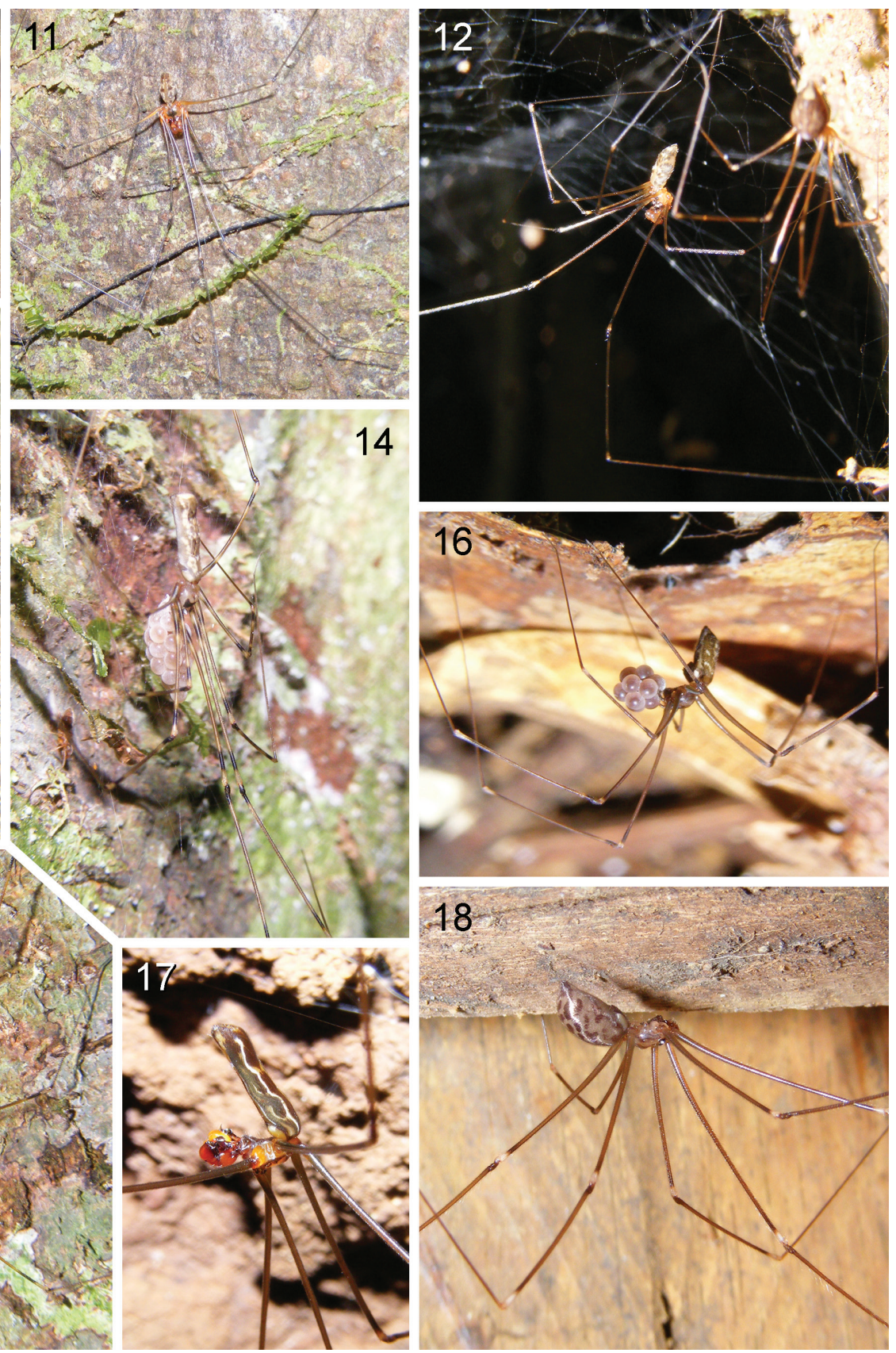

Figs 10-18. Litter, bark and ground-dwelling Central African pholcids. 10. Anansus kamwai sp. nov., with eggsac from near Bamenda, Cameroon. 11. Pholcus moca Huber, 2011, ô from near Ndjole, Gabon. 12-13. Pholcus punu sp. nov., pair from between Mimongo and Yéno (12) and đ̂ from Moudouma (13), Gabon. 14-15. Pholcus rawiriae sp. nov., $\varnothing^{+}$with eggsac (14) and $\hat{\partial}$ from Mohoba, Gabon (15). 16. Smeringopina fang Huber, 2013, $q$ with eggsac from Mayebout, Gabon. 17. Smeringopina belinga Huber, 2013, ô from Monts de Belinga, Gabon. 18. Smeringopus lesserti Kraus, 1957, ô from Mayebout, Gabon. Photos BAH. 
material by about two to three orders of magnitude. Revisions of all major and most minor pholcid genera present in Africa have more than tripled the number of described African species (Huber 2003a, b, c, 2007, 2009, 2011b, 2012, 2013). Even though percentages of new species collected during intensive sampling trips suggest hundreds of undescribed species in tropical Africa (Huber in press), African pholcids can probably be considered fairly well known at the generic level. At least a framework is now available that roughly circumscribes each group in terms of morphology, distribution, and relationships, and that allows old species to be identified and new species to be recognized as such.

Two recent overviews of the Pholcidae from East Africa and West Africa have summarized the available information for each of these regions, including descriptions for species that had not been included in taxonomic revisions (Huber \& Warui 2012; Huber \& Kwapong 2013). The present paper is the last in this trilogy, concentrating of the third part of mainland tropical Africa that has received intensive recent attention both by collectors and in taxonomic revisions.

\section{Material and methods}

A large part of the material studied herein was collected during expeditions to Cameroon (2009) and Gabon (2011). This material is currently deposited at the Zoologisches Forschungsmuseum Alexander Koenig, Bonn (ZFMK). Further material was borrowed from the following institutions: Natural History Museum, London (BMNH); California Academy of Sciences, San Francisco (CAS); Musée royal de
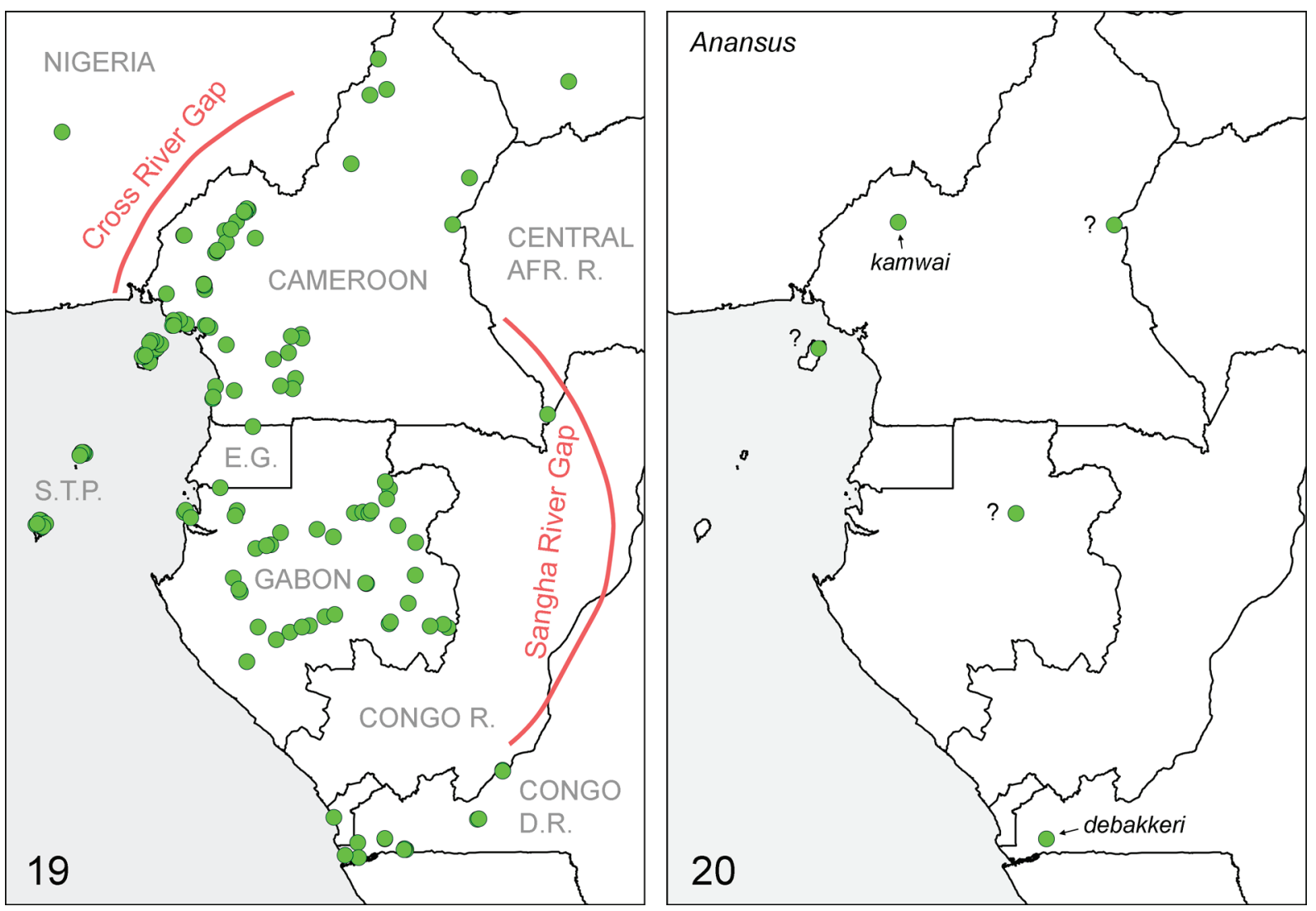

Figs 19-20. All pholcid records known from Central Africa (19) and known distribution of the genus Anansus Huber, 2007 in Central Africa (20). Question marks denote uncertain identifications (females from Bioko and Gabon and one poorly preserved male from eastern Cameroon). E.G. = Equatorial Guinea; S.T.P. $=$ São Tomé and Príncipe. 
l'Afrique Centrale, Tervuren (MRAC); National Museum of Natural History, Washington D.C. (USNM); and Zoological Museum, University of Copenhagen, Copenhagen (ZMUC).

Format, style of descriptions, and terminology are as in recent revisions (e.g., Huber 2011b, 2012, 2013). Measurements are in mm unless otherwise noted. The precision for eye measurements is $c a .5 \mu \mathrm{m}$. Epigyna were cleared in a warm $\mathrm{NaOH}$ solution and stained with chlorazol black. Locality coordinates are in round brackets when copied from labels and original publications or when received directly from collectors, in square brackets when originating from some other source (such as online gazetteers, Google Earth, MRAC database, etc.).

The following abbreviations are used:

$\mathrm{ALE}=$ anterior lateral eyes
$\mathrm{ALS}=$ anterior lateral spinnerets
$\mathrm{AME}=$ anterior median eyes
a.s.l. $=$ above sea level
$\mathrm{L} / \mathrm{d}=$ length/diameter
$\mathrm{PME}=$ posterior median eyes

The geographic area considered here (between $10^{\circ} \mathrm{N}$ and $7^{\circ} \mathrm{S}$; between $6^{\circ} \mathrm{E}$ and $18^{\circ} \mathrm{E}$; Fig. 19) encompasses mainly the Lower Guinean subregion of the Guineo-Congolian center of endemism (White 2001). The western and eastern limits of this subregion are somewhat controversial. In the west, the main current gap (Dahomey Gap; $\sim 0-3^{\circ} \mathrm{E}$ ) is not always congruent with distribution limits of taxa, which in many cases are further east (Cross River Basin of eastern Nigeria, $\sim 8^{\circ} \mathrm{E}$ ) (Dowsett-Lemaire \& Dowsett 2001; Lawson \& Klemens 2001; Maley 2001). In the east, both the Gabon-Congo watershed and the Sangha-Ubangui Rivers have been proposed as limits (Dowsett-Lemaire \& Dowsett 2001). For the present overview, however, the exact western and eastern limits are fairly irrelevant since the pholcid faunas of Nigeria and Congo Republic remain largely unknown. The southern and northern limits were chosen to include western Congo D.R. (with the excellent collections from Luki Forest Reserve in MRAC) and all known pholcid records from Cameroon (no record from beyond $10^{\circ} \mathrm{N}$ is known to us).

\section{Results}

Class Arachnida Cuvier, 1812

Order Araneae Clerck, 1757

Family Pholcidae C.L. Koch, 1851

\section{Annotated list of Central African genera and species}

Pholcidae described from Central Africa as defined herein, with countries, references, and new records.

Anansus Huber, 2007

Anansus is endemic and widely distributed in tropical Africa (Huber 2007; Huber \& Warui 2012; Huber \& Kwapong 2013), with two nominal species currently known from Central Africa (Fig. 20). Females in this genus are difficult to distinguish, and female specimens from Bioko (Pico Basilé) in CAS and from Gabon (Ntenkélé) in ZFMK (Ar 11886) might represent further undescribed species.

1. Anansus debakkeri Huber, 2007. Congo D.R. (Huber 2007).

\section{New records}

CONGO D.R.: Bas Congo: 4 $\partial^{1}, 14+q+$ + juvs (5 vials) in MRAC (224305-306 part, 309-311 part),

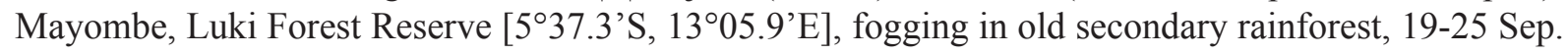




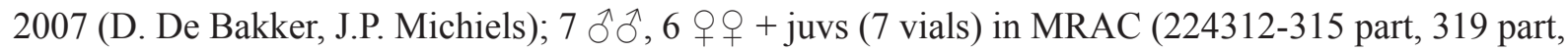
234844-845), same locality, fogging in primary rainforest, 25 Sep.-4 Oct. 2007 (D. De Bakker, J.P. Michiels); 5 ふふ, 4 웅 (6 vials) in MRAC (222190 part, 223021, 223039, 223120 part, 223457 part, 223679 part), same locality, beating in old secondary rainforest, 17-23 Sep. 2007 (D. De Bakker, J.P.

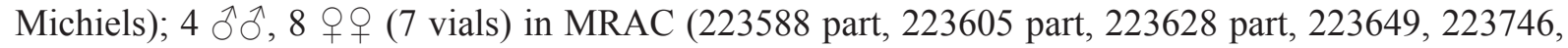
223804, 223835), same locality, beating in primary rainforest, 26 Sep.-3 Oct. 2007 (D. De Bakker, J.P. Michiels); 1 O , 1 ㅇ in MRAC (222019), same locality, sweeping along trail in primary rainforest, 11 Nov. 2006 (D. De Bakker, J.P. Michiels); 1 đ in MRAC (222753), same locality, pitfalls in primary rainforest, 13-23 Sep. 2007 (D. De Bakker, J.P. Michiels).

2. Anansus kamwai sp. nov. (see below). Cameroon.

\section{Crossopriza Simon, 1893}

Only the pantropical synanthropic C. lyoni (Blackwall, 1867) occurs in Central Africa (Fig. 21). It is common but has apparently not been recorded previously from the area considered here.

3. Crossopriza lyoni (Blackwall, 1867). Newly recorded for Cameroon, Chad, and Gabon.

\section{New records}

CAMEROON: North Region: 2 + 9,2 juvs in MRAC (148259), Touroua [ $\left.9^{\circ} 04.7^{\prime} \mathrm{N}, 12^{\circ} 58.4^{\prime} \mathrm{E}\right], 8-9$ Jan. 1976 (F. Puylaert). 4 우 in MRAC (221386), Faro Game Reserve [8²4'N, 1249'E], in hut, 5 May 2007 (R. Jocqué et al.).
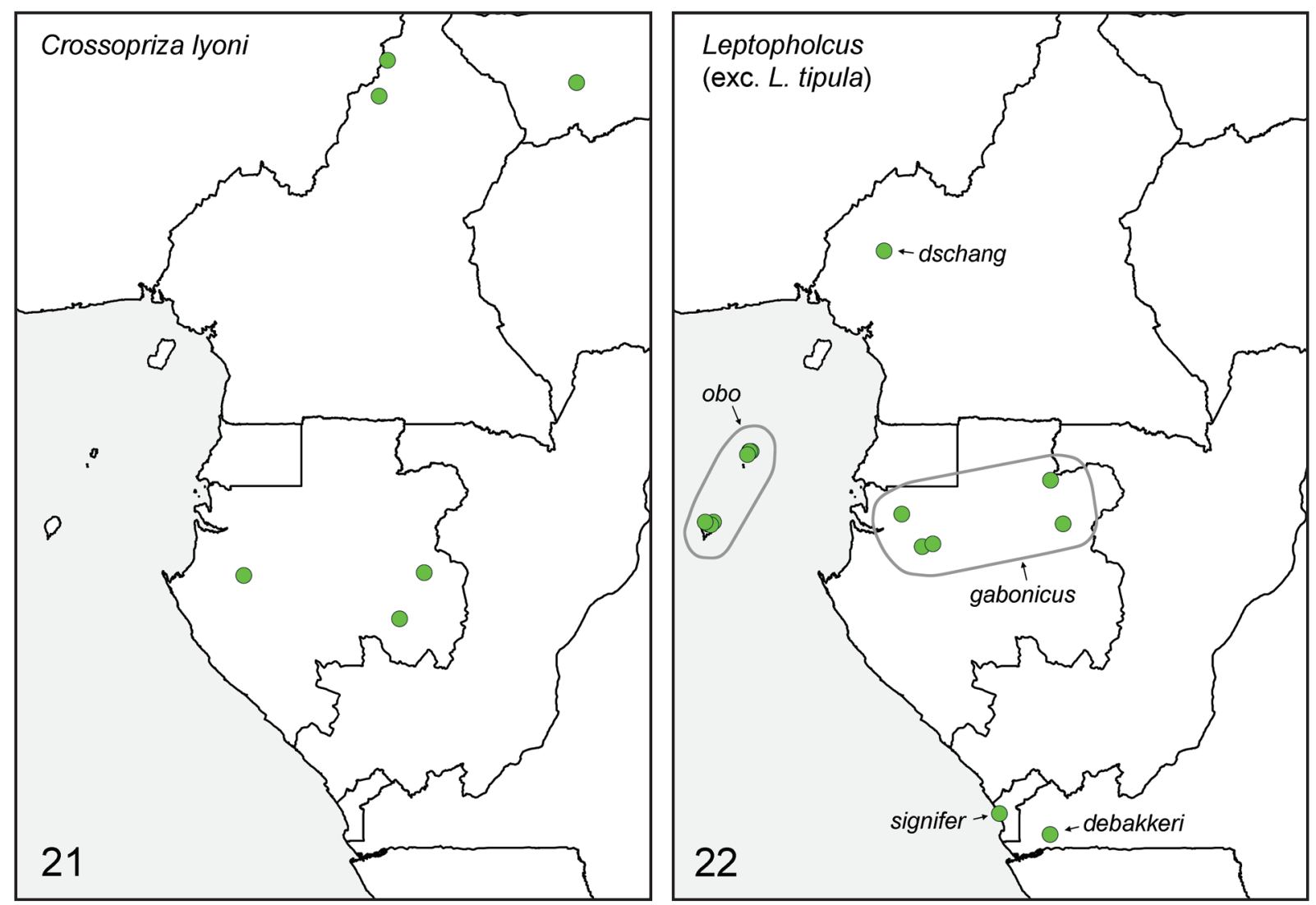

Figs 21-22. Known distributions of Crossopriza lyoni (Blackwall, 1867) and of the genus Leptopholcus Simon 1893 [except L. tipula (Simon, 1907); see Fig. 23] in Central Africa. 
CHAD: Logone Oriental: 1 đ̂, 3 우, 3 juvs in MRAC (151455), Bébédjia, near Moundou [840.6’N, 16³4.5’E], 1-10 Jul. 1977 (G. Ruella).

GABON: Haut Ogooué: 1 i in ZFMK (Ar 11887), Mouanda (1³2.3'S, 13²12.6'E), $410 \mathrm{~m}$ a.s.1., in building, 20 Aug. 2011 (B.A. Huber). 2 ○े $^{\top}$ in ZFMK (Ar 11888), Okondja ( $0^{\circ} 39^{\prime}$ S, $\left.13^{\circ} 40.5^{\prime} \mathrm{E}\right), 350 \mathrm{~m}$ a.s.1., in building, 17 Aug. 2011 (B.A. \& S.R. Huber). Moyen-Ogooué: 1 Ô, 1 juv. in ZFMK (Ar 11889), Lambaréné (042.2’S, 10¹4.4'E), 30 m a.s.1., at building, 27 Aug. 2011 (B.A. Huber).

Leptopholcus Simon, 1893

Of the ten species of Leptopholcus currently known from mainland Africa (Huber 2011b; Huber \& Kwapong 2013), six occur in Central Africa (Figs 22-23). Of these, four are endemic to Central Africa (L. dschang Huber, 2011; L. obo Huber, 2011; L. debakkeri Huber, 2011; L. gabonicus sp. nov.); the fifth [L. tipula (Simon, 1907)] occurs throughout the entire Guineo-Congolian rainforest (Huber 2011b). The type species L. signifer Simon, 1893 was described from Central Africa (Cabinda, Angola) but its actual range is dubious (Huber 2011b).

4. Leptopholcus debakkeri Huber, 2011. Congo D.R. (Huber 2011b).

5. Leptopholcus dschang Huber, 2011. Cameroon (Huber 2011b).

6. Leptopholcus gabonicus sp. nov. (see below). Gabon.

7. Leptopholcus obo Huber, 2011. São Tomé and Príncipe (Huber 2011b).
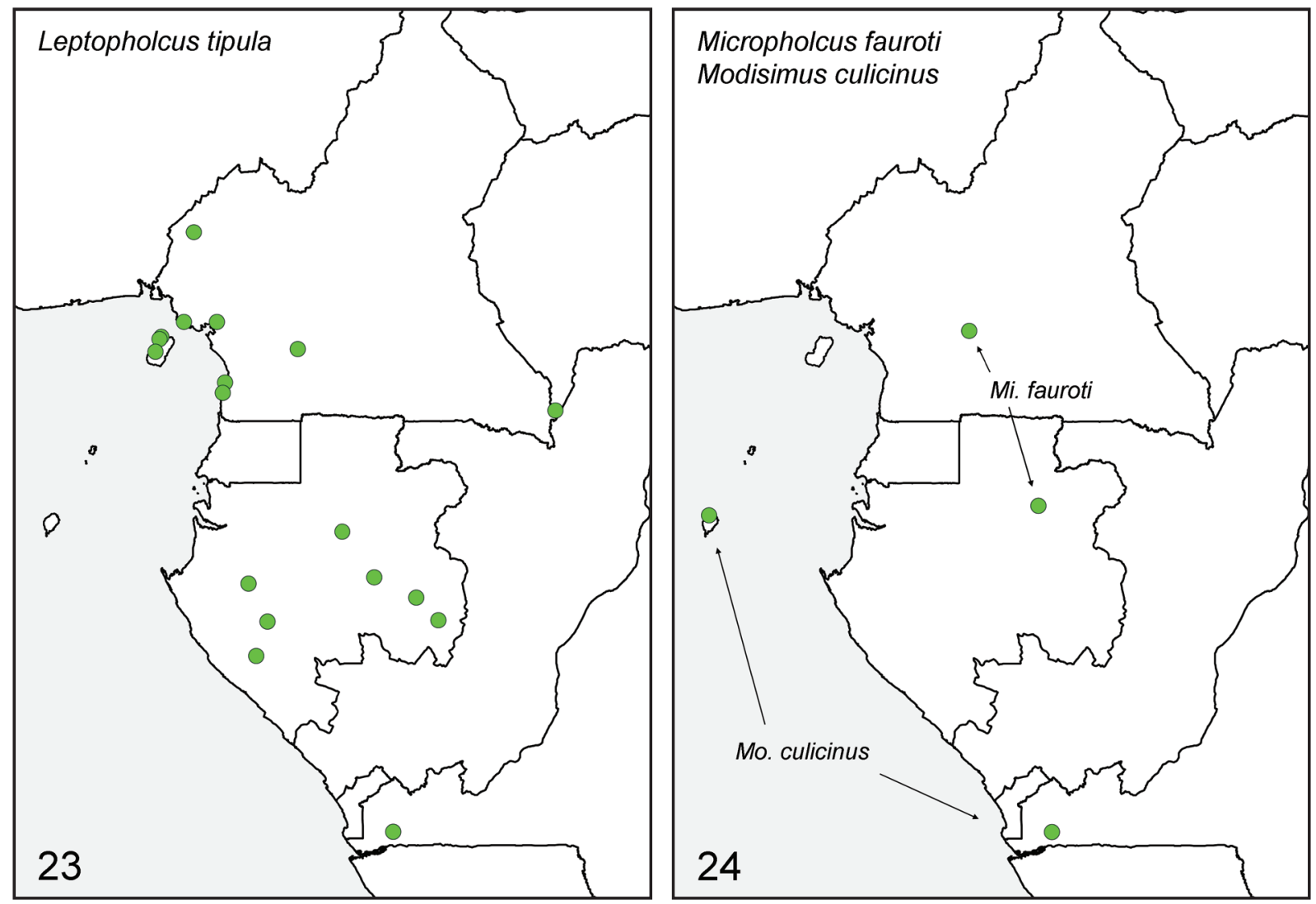

Figs 23-24. Known distributions of Leptopholcus tipula (Simon, 1907), Micropholcus fauroti (Simon, 1887), and Modisimus culicinus (Simon, 1893) in Central Africa. 
8. Leptopholcus signifer Simon, 1893. Angola (Cabinda) (Simon 1893).

9. Leptopholcus tipula (Simon, 1907). Equatorial Guinea (Bioko) (Simon 1907; Huber 2009); Cameroon, Central African Republic, Congo D.R., Gabon (Huber 2009).

New records

GABON: Ngounié: $1{ }^{\AA}, 1$ in ZFMK (Ar 11890), near Moulandoufouala $\left(1^{\circ} 38.1^{\prime} \mathrm{S}, 1^{\circ} 42.5^{\prime} \mathrm{E}\right), 110$ $\mathrm{m}$ a.s.1., forest along road, 27 Aug. 2011 (B.A. \& S.R. Huber). Ogooué-Lolo: $3 \overbrace{}^{\Uparrow}, 3$ q $q$ in ZFMK (Ar

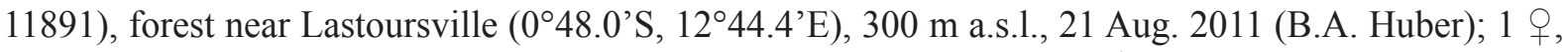
2 juvs in pure ethanol, in ZFMK (Gab 219), same data. Haut Ogooué: 1 đ in ZFMK (Ar 11892), forest at Lékoni River (1 ${ }^{\circ} 10.7^{\prime}$ S, $\left.13^{\circ} 32.3^{\prime} \mathrm{E}\right), 305$ m a.s.l., 18 Aug. 2011 (B.A. \& S.R. Huber); 1 juv. in pure ethanol, in ZFMK (Gab 211), same data. 3 우 in ZFMK (Ar 111893), forest near Bongoville (1'36.7'S, 13⒌ $4^{\prime} \mathrm{E}$ ), 600-650 m a.s.1., 20 Aug. 2011 (B.A. Huber); 1 ㅇ, 2 juvs in pure ethanol, in ZFMK (Gab 206), same data.

Micropholcus Deeleman-Reinhold \& Prinsen, 1987

Only the synanthropic M. fauroti (Simon, 1887) occurs in Central Africa (Huber 2011b) (Fig. 24). It is probably more common than suggested by the few records.

10. Micropholcus fauroti (Simon, 1887). Cameroon (Huber 2011b); newly recorded for Gabon.

\section{New record}

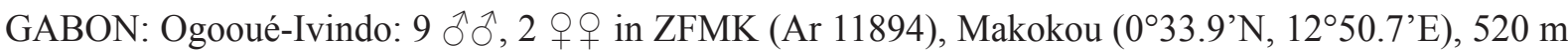
a.s.l., in building, 13 Aug. 2011 (B.A. \& S.R. Huber).

Modisimus Simon, 1893

Of this otherwise New World genus, only the pantropical M. culicinus (Simon, 1893) occurs in Africa. It is probably common throughout the region, but rare in collections due to its small size and cryptic lifestyle.

11. Modisimus culicinus (Simon, 1893). Newly recorded for Central Africa [Fig. 24; Lessert's (1938) record - sub Hedypsilus lawrencei - from Kananga, Congo D.R., is outside the area considered here].

New records

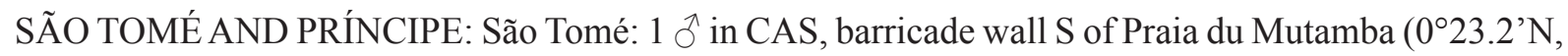
6³5.7’E), 3 May 2001 (J.M. Ledford).

CONGO D.R.: Bas Congo: 1 q in MRAC (128843), Mayombe, Luki [5³9'S, 1304'E], in Cubitermes [Termitidae] nest, 20 Sep. 1956 (A. Bouillon).

Ninetis Simon, 1890

This only African (and probably only Old World) genus of the subfamily Ninetinae is widely distributed from Namibia to the Arabian Peninsula, including Madagascar (Huber 2000, 2002; Huber \& El Hennawy 2007). The new species described below is the first representative of the genus (and subfamily) recorded from Central Africa (Fig. 25).

12. Ninetis faro sp. nov. (see below). Cameroon. 
Nyikoa Huber, 2007

Nyikoa is a monotypic genus with the leaf-dwelling N. limbe Huber, 2007 widely distributed in the western subregions of the Guineo-Congolian rainforest (Upper and Lower Guinea) (Huber 2007, 2009; Huber \& Kwapong 2013).

13. Nyikoa limbe Huber, 2007. Cameroon (Huber 2007, 2009), Congo D.R. (Huber 2007); newly recorded for Gabon and Equatorial Guinea (Fig. 26).

\section{New records}

CAMEROON: Central Region: 1 i in USNM, $6.5 \mathrm{~km}$ SSE of Yaounde ( $\left.3^{\circ} 48.4^{\prime} \mathrm{N}, 1^{\circ} 32.4^{\prime} \mathrm{E}\right)$, Mbalmayo Rd., patch of forest, 715 m a.s.1., 8 Jan. 1992 (J. Coddington et al.).

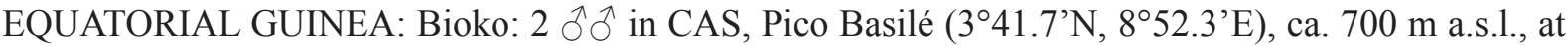
night, 17 Oct. 1998 (D.K. Dabney, D. Ubick). 1 ㅇ in CAS, $3.5 \mathrm{~km} \mathrm{~N}$ of Luba (3²8.9’ N, 8³5.0’E), swampy forest, 13 Oct. 1998 (M. Boko et al.).

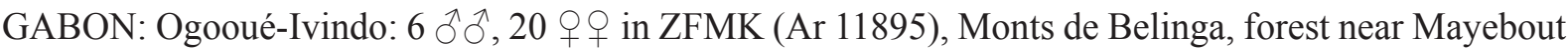
$\left(1^{\circ} 06.7^{\prime} \mathrm{N}, 13^{\circ} 06.6^{\prime} \mathrm{E}\right), 500 \mathrm{~m}$ a.s.1., 13-14 Aug. 2011 (B.A. \& S.R. Huber); 3 우 in pure ethanol, in ZFMK (Gab 201), same data. 1 i in pure ethanol, in ZFMK (Gab 204), Monts de Belinga ( $0^{\circ} 58.7^{\prime} \mathrm{N}$, $\left.13^{\circ} 11.5^{\prime} \mathrm{E}\right), 860 \mathrm{~m}$ a.s.1., forest with large rocks, 13 Aug. 2011 (B.A. \& S.R. Huber). 2 o $^{\lambda}, 7$ 우 in ZFMK (Ar 11896), near Djidji $\left(0^{\circ} 12.8^{\prime} \mathrm{N}, 11^{\circ} 49.3^{\prime} \mathrm{E}\right), 470 \mathrm{~m}$ a.s.1., forest, 12 Aug. 2011 (B.A. \& S.R. Huber); 2 + $q$ in pure ethanol, in ZFMK (Gab 238), same data. 2 우 in USNM, Makokou, CNRS
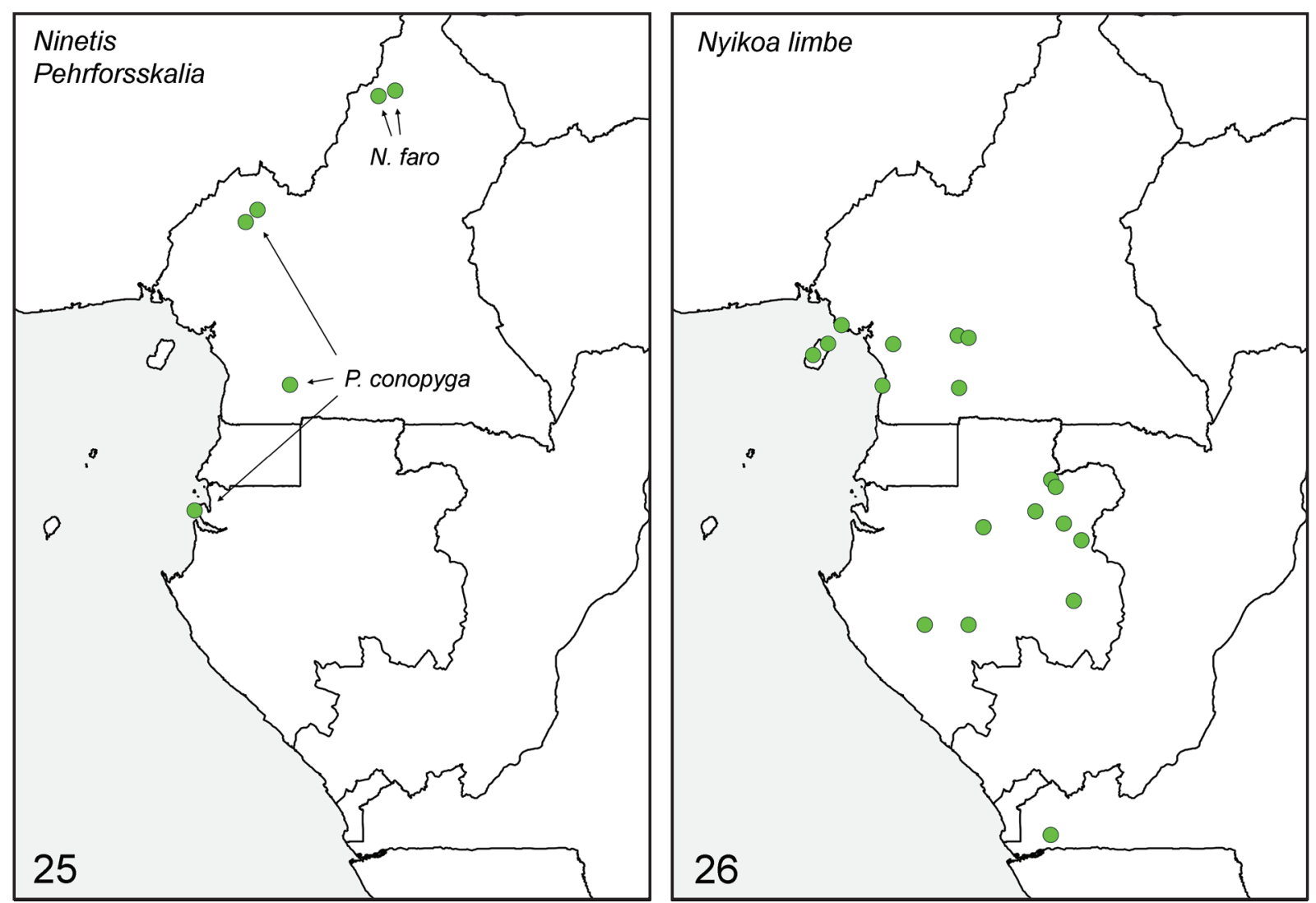

Figs 25-26. Known distributions of the genera Ninetis Simon, 1890 and Pehrforsskalia DeelemanReinhold \& van Harten, 2001, and of Nyikoa limbe Huber, 2007 in Central Africa. 
[0 $0^{\circ} 30.8^{\prime} \mathrm{N}, 12^{\circ} 48.2^{\prime} \mathrm{E}$; not $0^{\circ} 04^{\prime} \mathrm{N}, 12^{\circ} 08^{\prime} \mathrm{E}$ as on label], Sep.-Nov. 1976 (A.L. Rypstra). 1 q in ZFMK (Ar 11897), near Mohoba Mozeye ( $\left.0^{\circ} 16.8^{\prime} \mathrm{N}, 13^{\circ} 20.9^{\prime} \mathrm{E}\right), 510 \mathrm{~m}$ a.s.l., forest along road, 17 Aug. 2011 (B.A. \& S.R. Huber). 1 q in ZFMK (Ar 11898), N Tébé ( $\left.0^{\circ} 02.3^{\prime} S, 13^{\circ} 40.9^{\prime} \mathrm{E}\right), 550 \mathrm{~m}$ a.s.1., forest along

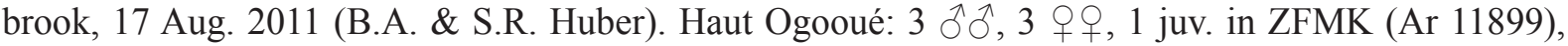
forest at Lékoni River (1 ${ }^{\circ} 10.7^{\prime}$ S, 13³2.3’E), 305 m a.s.1., 18 Aug. 2011 (B.A. \& S.R. Huber). Ngounié:

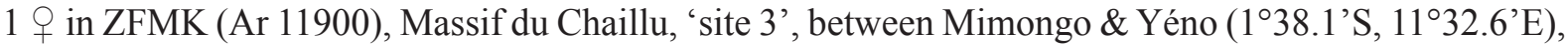

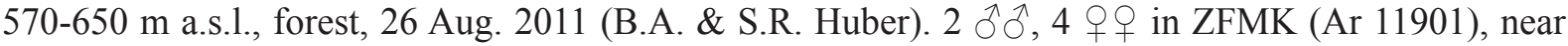
Moulandoufouala ( $\left.1^{\circ} 38.1^{\prime} \mathrm{S}, 10^{\circ} 42.5^{\prime} \mathrm{E}\right), 110 \mathrm{~m}$ a.s.1., forest along road, 27 Aug. 2011 (B.A. \& S.R. Huber); 1 juv. in pure ethanol, in ZFMK (Gab 185), same data.

CONGO D.R.: Bas Congo: $\sim 45$ $\widehat{\jmath}, 43$ 9 + + juvs (8 vials) in MRAC (parts of 224303-307, 309-311),

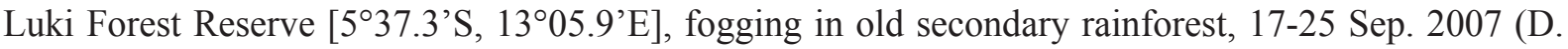
De Bakker, J.P. Michiels); 76 ○ิ ${ }^{\lambda}, 47$ 우 + + juvs (8 vials) in MRAC (parts of 224312-319), same data

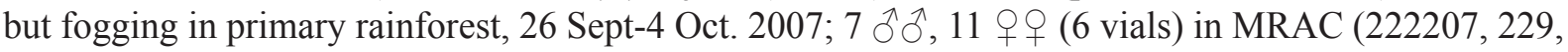
994, 223096 part, 223123, 684), same locality, beating in old secondary rainforest, 17-25 Sep. 2007 (W.

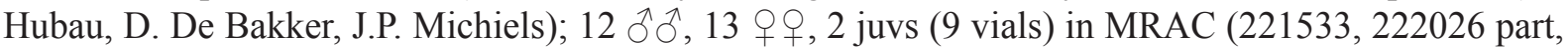
222061, 222798, 223635 part, 223587, 223732, 223819, 223831), same locality, beating in primary rainforest, 6-11 Nov. 2006, 26 Sep.-3 Oct. 2007 (D. De Bakker, J.P. Michiels); $1{ }^{\Uparrow}$ in MRAC (221546), same locality, sieving, 7 Nov. 2006 (D. De Bakker, J.P. Michiels).

Pehrforsskalia Deeleman-Reinhold \& van Harten, 2001

Pehrforsskalia includes three described species (Huber 2011b). Only the widely distributed P. conopyga Deeleman-Reinhold \& van Harten, 2001 occurs in Central Africa (Fig. 25).

14. Pehrforsskalia conopyga Deeleman-Reinhold \& van Harten, 2001. Cameroon, Gabon (Huber 2009).

Pholcus Walckenaer, 1805

Of the 29 operational species groups in Pholcus identified in Huber (2011b), only three occur in Central Africa: (1) the bamboutos group, with four of its nine species in Central Africa (Fig. 27; a fifth species, P. kakum Huber, 2009, is likely to occur in Lower Guinea but has not yet been documented from there); (2) the circularis group, which is largely endemic to the area considered here (Fig. 28; only P. leruthi occurs further west, in Congolia and East Africa); (3) the debilis group, which is largely endemic to the area considered here (Fig. 29; only P. baka ranges into Congolia). While the monophyly of the debilis group is well supported, the relationships within and among the other groups remain largely obscure (Huber 2011b; Dimitrov et al. 2013).

15. Pholcus attuleh Huber, 2011. Cameroon (Huber 2011b).

\section{New record}

CAMEROON: Southwest Region: 1 in ZMUC, Mt. Koupé above Nyasoso (450'N, 941'E), forest, 1200-1600 m a.s.1., 16-19 Feb. 1992 (C.E. Griswold, N. Scharff, C. Wanzie, S. Larcher, Masongo).

16. Pholcus baka Huber, 2011. Cameroon, Central African Republic, Gabon (Huber 2011b).

New records

GABON: Ogooué-Ivindo: 1 đ, 2 + $\bigcirc$ in ZFMK (Ar 11902), Monts de Belinga, forest near Mayebout $\left(1^{\circ} 06.7^{\prime} \mathrm{N}, 13^{\circ} 06.6^{\prime} \mathrm{E}\right), 500 \mathrm{~m}$ a.s.1., 13-14 Aug. 2011 (B.A. \& S.R. Huber); 1 i in pure ethanol, in ZFMK (Gab 196), same data. $2 \widehat{\partial} \widehat{\jmath}, 2$ q $q$ in ZFMK (Ar 11903), Monts de Belinga, NE Makokou $\left(0^{\circ} 47.0^{\prime} \mathrm{N}, 13^{\circ} 08.3^{\prime} \mathrm{E}\right), 530 \mathrm{~m}$ a.s.1., degraded forest along road, 15 Aug. 2011 (B.A. \& S.R. Huber). 1 ㅇ in ZFMK (Ar 11904), Ivindo N.P. near Simintang ( $\left.0^{\circ} 32.2^{\prime} \mathrm{N}, 12^{\circ} 41.3^{\prime} \mathrm{E}\right), 545 \mathrm{~m}$ a.s.l., forest, 16 


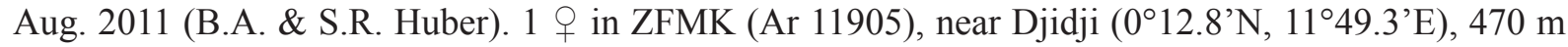
a.s.1., forest, 12 Aug. 2011 (B.A. \& S.R. Huber). Haut Ogooué: 2 đ̃, 1 q, 2 juvs in ZFMK (Ar 11906),

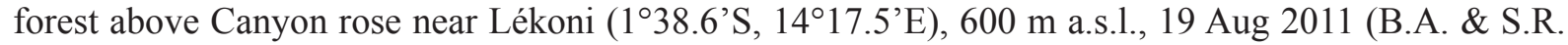

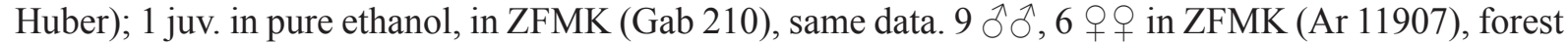
at Lékoni River ( $1^{\circ} 10.7^{\prime}$ S, $\left.13^{\circ} 32.3^{\prime} \mathrm{E}\right), 305 \mathrm{~m}$ a.s.l., 18 Aug. 2011 (B.A. \& S.R. Huber); 1 , 1 juv. in pure ethanol, in ZFMK (Gab 212), same data. 3 q 9,1 juv. in ZFMK (Ar 11908), forest along Lékoni River (1³4.6'S, 14¹2.1'E), 450 m a.s.1., 20 Aug. 2011 (B.A. \& S.R. Huber). Moyen-Ogooué: 1 đo, 1

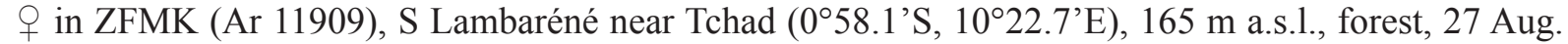

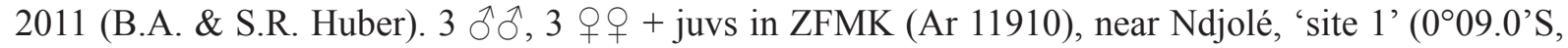
$\left.10^{\circ} 40.0^{\prime} \mathrm{E}\right), 120 \mathrm{~m}$ a.s.1., forest near brook, 11 Aug. 2011 (B.A. \& S.R. Huber); 1 ` , 4 q $q, 1$ juv. in pure ethanol, in ZFMK (Gab 228), same data. Estuaire: 2 $\lesssim, 4$ 우, 2 juvs in ZFMK (Ar 11911), forest near Sahoué, N Libreville ( $\left.0^{\circ} 34.6^{\prime} \mathrm{N}, 9^{\circ} 20.4^{\prime} \mathrm{E}\right), 30 \mathrm{~m}$ a.s.1., 28 Aug. 2011 (B.A. \& S.R. Huber); 2 $q$ in pure ethanol, in ZFMK (Gab 181), same data.

17. Pholcus bakweri Huber, 2011. Cameroon, Equatorial Guinea (Huber 2011b).

18. Pholcus bamboutos Huber, 2011. Cameroon (Huber 2011b).

\section{New record}

CAMEROON: Northwest Region: $2 \partial^{\lambda}{ }^{\jmath}, 2$ juvs in ZMUC, near Lake Oku $\left(6^{\circ} 12^{\prime} \mathrm{N}, 10^{\circ} 27^{\prime} \mathrm{E}\right)$, forest at 2150 m a.s.1., 7-13 Feb. 1992 (C. Griswold, S. Larcher, N. Scharff, C. Wanzie).
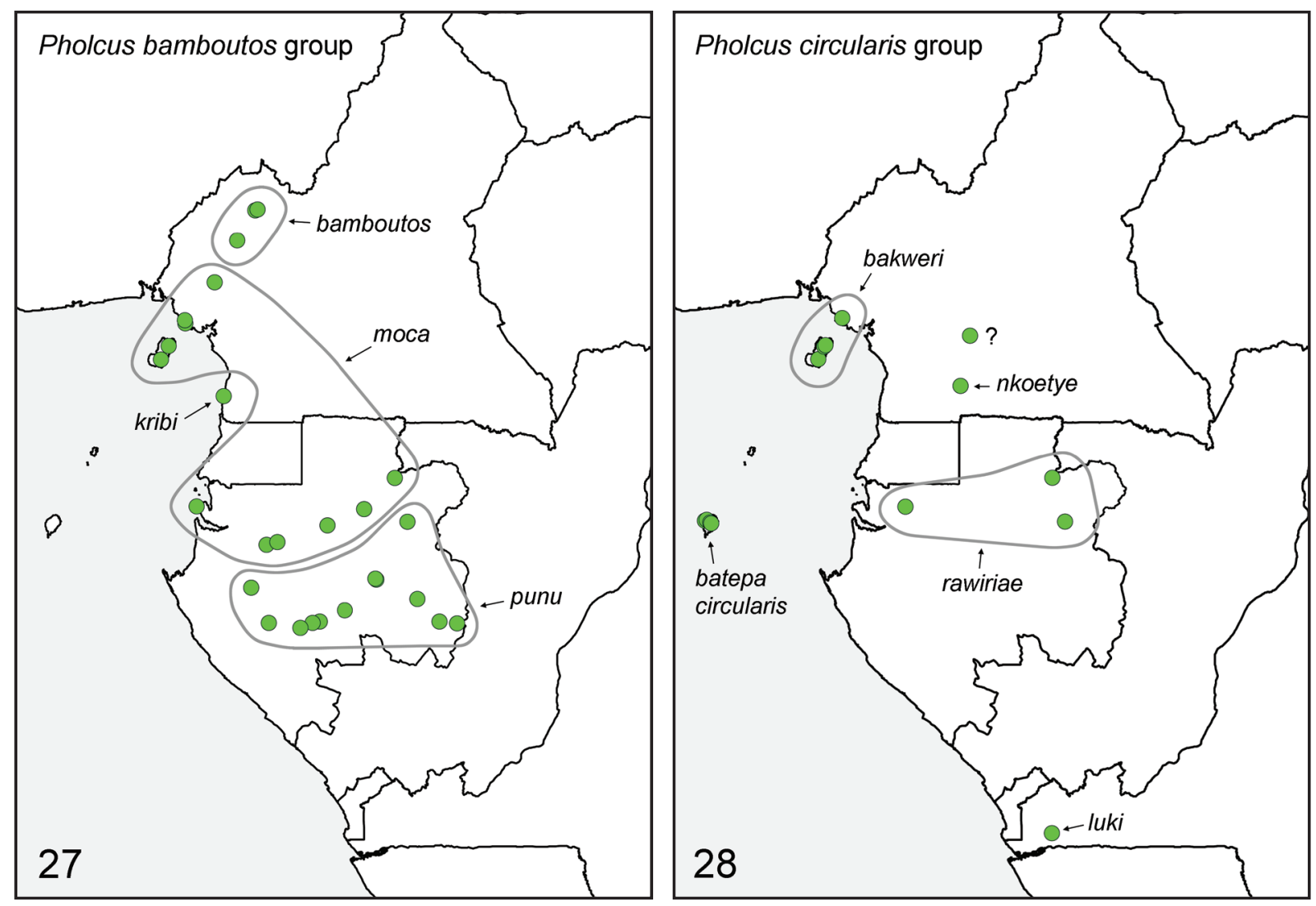

Figs 27-28. Known distributions of the bamboutos and circularis species groups (sensu Huber 2011b) of Pholcus Walckenaer, 1805 in Central Africa. The question mark denotes an undescribed species represented by a single male in USNM. 
19. Pholcus batepa Huber, 2011. São Tomé and Príncipe (Huber 2011b).

20. Pholcus circularis Kraus, 1957. São Tomé and Príncipe (Kraus 1957; Huber 2011b).

21. Pholcus debilis (Thorell, 1899). Cameroon, Equatorial Guinea (Bioko) (Thorell 1899; Huber 2011b).

Note

The CAS has a single female specimen from Bioko (Pico Basilé) that may represent an additional (undescribed) species within the debilis group sensu Huber (2011b).

22. Pholcus kribi Huber, 2011. Cameroon (Huber 2011b).

23. Pholcus luki Huber, 2011. Congo D.R. (Huber 2011b).

24. Pholcus moca Huber, 2011. Cameroon, Equatorial Guinea (Bioko) (Huber 2011b); newly recorded from Gabon.

\section{New records}

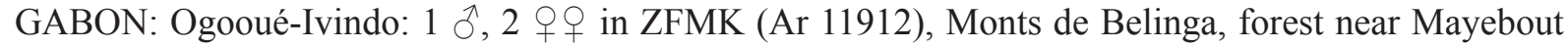
( $\left.1^{\circ} 06.7^{\prime} \mathrm{N}, 13^{\circ} 06.6^{\prime} \mathrm{E}\right), 500 \mathrm{~m}$ a.s.1., 13-14 Aug. 2011 (B.A. \& S.R. Huber). 1 đo in ZFMK (Ar 11913), near Djidji $\left(0^{\circ} 12.8^{\prime} \mathrm{N}, 11^{\circ} 49.3^{\prime} \mathrm{E}\right), 470 \mathrm{~m}$ a.s.l., forest, 12 Aug. 2011 (B.A. \& S.R. Huber); 1 , 1 juv. in pure ethanol, in ZFMK (Gab 240), same data. 1 \& in pure ethanol, in ZFMK (Gab 237), near Ntenkélé $\left(0^{\circ} 31.4^{\prime} \mathrm{N}, 12^{\circ} 31.5^{\prime} \mathrm{E}\right), 550 \mathrm{~m}$ a.s.l., forest, 12. Aug. 2011 (B.A. \& S.R. Huber). Moyen-Ogooué: 1 ô, 2 우 in ZFMK (Ar 11914), near Ndjolé, 'site 1' $\left(0^{\circ} 09.0^{\prime} \mathrm{S}, 10^{\circ} 40.0^{\prime} \mathrm{E}\right), 120 \mathrm{~m}$ a.s.l., forest near brook,

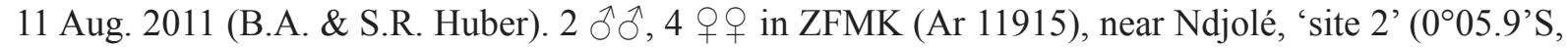
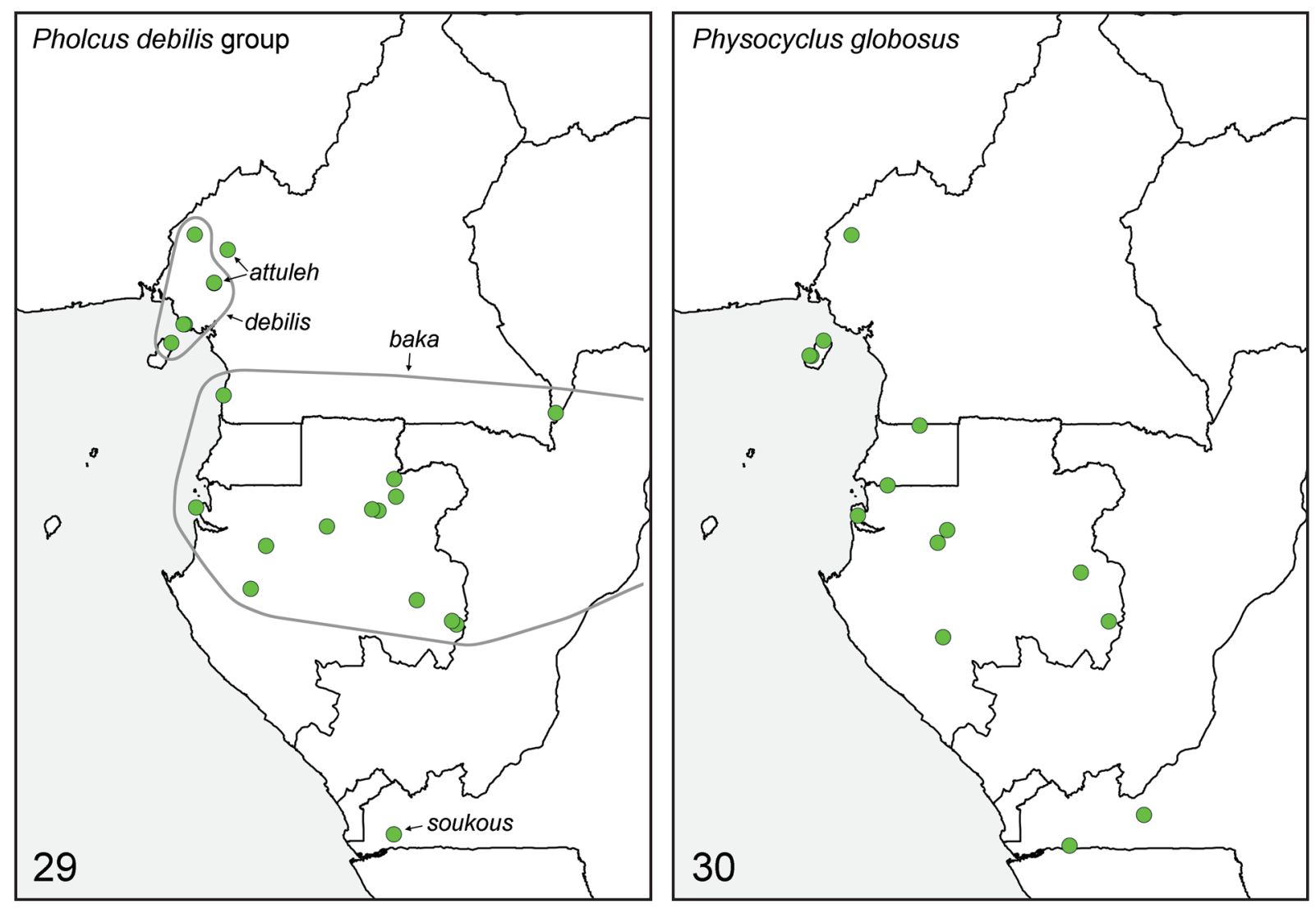

Figs 29-30. Known distributions of the debilis species group (sensu Huber 2011b) of Pholcus Walckenaer, 1805 and of Physocyclus globosus (Taczanowski, 1874) in Central Africa. 
1052.4'E), $140 \mathrm{~m}$ a.s.1., forest near brook, 11 Aug. 2011 (B.A. \& S.R. Huber). Estuaire: 1 o in ZFMK (Ar 11916), forest near Sahoué, N Libreville (0³4.6’N, 9²0.4'E), 30 m a.s.1., 28 Aug. 2011 (B.A. \& S.R. Huber); 1 , 2 juvs in pure ethanol in ZFMK (Gab 180), same data.

25. Pholcus nkoetye Huber, 2011. Cameroon (Huber 2011b).

\section{Note}

The USNM has a single male specimen of a very similar undescribed species from Cameroon, SSE of

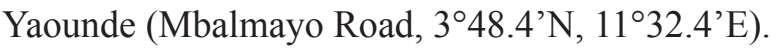

26. Pholcus punu sp. nov. (see below). Gabon.

27. Pholcus rawiriae sp. nov. (see below). Gabon.

28. Pholcus soukous Huber, 2011. Congo D.R. (Huber 2011b).

\section{Physocyclus Simon, 1893}

Physocyclus is a New World genus. Only the pantropical synanthropic P. globosus (Taczanowski, 1874) occurs in Central Africa (Fig. 30). It seems that this widespread species has not previously been recorded from the area considered here. Only Simon's (1877) Pholcus claviger (transferred and synonymzed in Huber 2011b) from "Congo" might be a previous record.

29. Physocyclus globosus (Taczanowski, 1874). Newly recorded for Cameroon, Equatorial Guinea, and Gabon.

\section{New records}

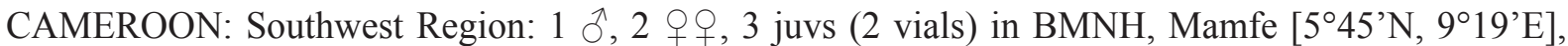
in houses in clearing in forest, 13 Mar.-30 Apr. 1933 (Percy Sladen Trust Exped., I.T. Sanderson). Unidentified locality: 1 ô, 1 9, 2 juvs (2 vials) in CAS, "Mabete Victoria Div.", 24 May-7 June 1949 (B. Malkin).

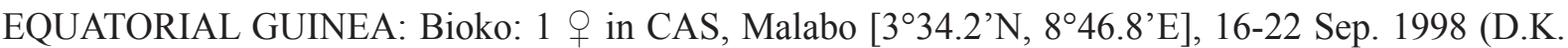

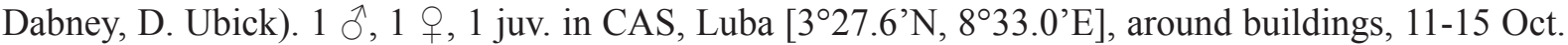

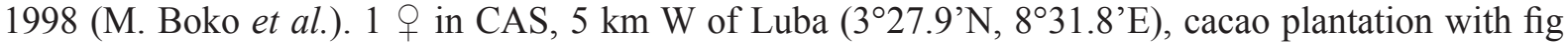
trees, 12-14 Oct. 1998 (D.K. Dabney, D. Ubick). Centro Sur(?): 1 q in MRAC (170225), between Mibonde and Elon $\left[\sim 1.0^{\circ} \mathrm{N}, 10.0^{\circ} \mathrm{E}\right]$, rocky outcrop, by hand, $23 \mathrm{Jul} .1989$ (M. Alderweireldt). 1 ๙, 3 우 in MRAC (169989), Micomeseng [Mecomeseng, $2^{\circ} 08.7^{\prime} \mathrm{N}, 10^{\circ} 37.0^{\prime} \mathrm{E}$ ], in house, by hand, $8 \mathrm{Jul}$. 1989 (M. Alderweireldt); 1 , 1 juv. in MRAC (170155, 164), same data but 9-11 Jul. 1989, gardens.

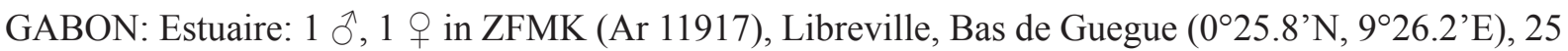
m a.s.l., in building, 29 Aug. 2011 (B.A. Huber). Haut Ogooué: 1 q, 1 juv. in ZFMK (Ar 11918), under bridge over Lékoni River (1³4.6'S, 14²12.1'E), 450 m a.s.1., 19 Aug. 2011 (B.A. \& S.R. Huber). 2

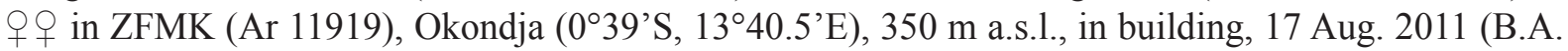
\& S.R. Huber). Ngounié: 1 ô $^{\top}, 1$ in ZFMK (Ar 11920), Mouila (1 $\left.{ }^{\circ} 52.4^{\prime} \mathrm{S}, 11^{\circ} 03.3^{\prime} \mathrm{E}\right), 80 \mathrm{~m}$ a.s.1., in building, 26 Aug. 2011 (B.A. \& S.R. Huber). Ogooué-Ivindo: 1 q in ZFMK (Ar 11921), near Abébéa ( $0^{\circ} 09^{\prime} \mathrm{N}, 11^{\circ} 08^{\prime} \mathrm{E}, 300 \mathrm{~m}$ a.s.1.), in building, 12 Aug. 2011 (B.A. \& S.R. Huber). Moyen Ogooué: $1{ }^{\Uparrow}$ in MRAC (172778), Petit-Okano [005’S, 1057’E], Sep. 1985 (J.M. Weill, A. Pauly).

CONGO D.R.: Bas Congo: $4 \hat{\jmath} \hat{\jmath}, 13$ 9 ㅇ, juvs (13 vials) in MRAC (1170, 1206-13, 26833, 26835-45,

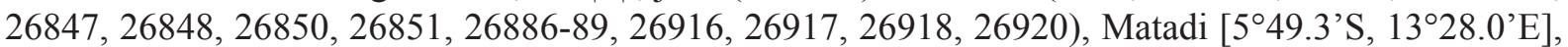
Feb. 1937 (E. Dartevelle). 1 \& in MRAC (74564), Thysville [=Mbanza-Ngungu; 5 15'S, 1452'E, 600 m a.s.1.], 1953 (J. Sion). 
Quamtana Huber, 2003

Quamtana is highly diverse in southern Africa, but a few species occur further north in tropical Africa (Huber 2003c; Huber \& Warui 2012; Huber \& Kwapong 2013). In Central Africa, only Q. oku Huber, 2003 from Cameroon was previously known. The widespread Q. kitahurira Huber, 2003 (previously known from West and East Africa and from Angola) was expected to occur in Central Africa and is here newly reported for the region (Fig. 31).

30. Quamtana kitahurira Huber, 2003. Newly recorded for Central Africa.

\section{New records}

CONGO D.R.: Bas Congo: 19 $\widehat{\jmath}, 11$ q $q, 2$ juvs (9 vials) in MRAC (219851 part, 219850 part, 219855 part, 224312 part, 224313 part, 224314 part, 224315 part, 224317 part, 224319 part), Mayombe, Luki Forest Reserve [ $\left.5^{\circ} 37.3^{\prime} \mathrm{S}, 13^{\circ} 05.9^{\prime} \mathrm{E}\right]$, fogging in primary rainforest, 4-13 Nov. 2006 and 26 Sep.-4 Oct. 2007 (D. De Bakker, J.P. Michiels); 1 i in MRAC (220006), same locality, beating along trail near guest house, 14 Nov. 2006 (D. De Bakker, J.P. Michiels); 2 § $\widehat{ }$, 6 q $q$ (3 vials) in MRAC (224305 part, 224308 part, 224310 part), fogging in old secondary rainforest, 19-24 Sep. 2007 (D. De Bakker, J.P. Michiels). 1 O , 6 우 (2 vials) in MRAC (224301 part, 224302 part), fogging in young secondary rainforest, 14-16 Sep. 2007 (D. De Bakker, J.P. Michiels).

31. Quamtana oku Huber, 2003. Cameroon (Huber 2003c).
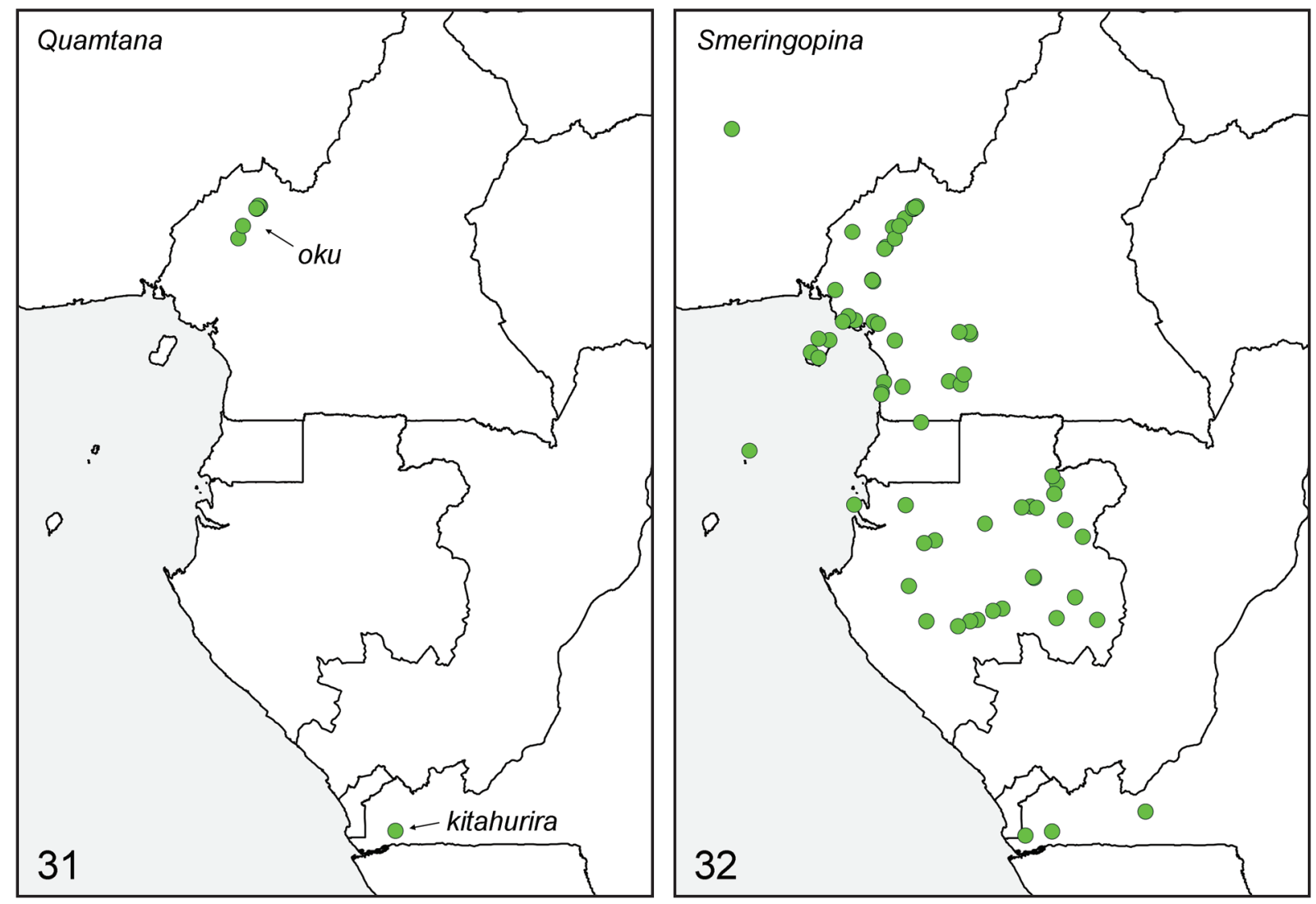

Figs 31-32. Known distributions of the genera Quamtana Huber, 2003 and Smeringopina Kraus, 1957 in Central Africa. For detailed distribution maps of Smeringopina species see Huber (2013). 


\section{New records}

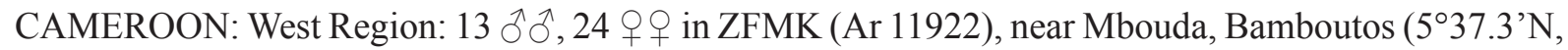
$\left.10^{\circ} 06.7^{\prime} \mathrm{E}\right), 2100 \mathrm{~m}$ a.s.1., underside of leaves, 19 Apr. 2009 (B.A. \& J.C. Huber); 1 ○ in ZFMK (Ar 11923), same data, had died; 5 + 9,6 juvs in pure ethanol, in ZFMK (Cam 153), same data. Northwest

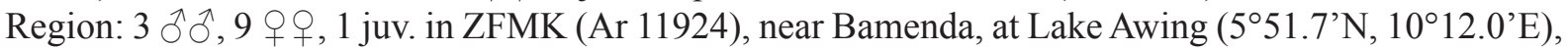
$2100 \mathrm{~m}$ a.s.l., underside of leaves, 15 Apr. 2009 (B.A. \& J.C. Huber); 1 đ, 3 $\circ$, 5 juvs in pure ethanol, in ZFMK (Cam 109), same data. $10^{\wedge}, 8$ 우우 in ZFMK (Ar 11925), near Oku (6² 14.2’ $\left.\mathrm{N}, 10^{\circ} 31.5^{\prime} \mathrm{E}\right)$, $\sim 2200 \mathrm{~m}$ a.s.1., underside of leaves, 17 Apr. 2009 (B.A. \& J.C. Huber); 1 ○े in ZFMK (Ar 11926), same data, had died; 9 우, 8 juvs in pure ethanol, in ZFMK (Cam 85), same data. $1+$ in pure ethanol, in ZFMK (Cam 118), near Oku, 'site 2' ( $\left.6^{\circ} 15^{\prime} \mathrm{N}, 10^{\circ} 30^{\prime} \mathrm{E}\right), \sim 1800 \mathrm{~m}$ a.s.l., underside of banana leaves, 17 Apr. 2009 (B.A. \& J.C. Huber). 1 o in pure ethanol, in ZFMK (Cam 88), at Lake Oku (6 ${ }^{\circ} 12.1^{\prime} \mathrm{N}$, $\left.10^{\circ} 27.6^{\prime} \mathrm{E}\right), 2300 \mathrm{~m}$ a.s.1., underside of leaf, 16. Apr. 2009 (B.A. Huber). 1 $q$ in pure ethanol, in ZFMK (Cam 121), near Lake Oku (6 $\left.{ }^{\circ} 11.2^{\prime} \mathrm{N}, 10^{\circ} 27.9^{\prime} \mathrm{E}\right), 2400 \mathrm{~m}$ a.s.l., underside of leaf, 16 Apr. 2009 (B.A. \& J.C. Huber). $1{ }^{\Uparrow}, 2$ 우 (2 vials) in ZMUC, forest near Lake Oku (6 $\left.{ }^{\circ} 12^{\prime} \mathrm{N}, 10^{\circ} 27^{\prime} \mathrm{E}\right), 2150 \mathrm{~m}$ a.s.l., 7-13 Feb. 1992 (Griswold, Larcher, Scharff, Wanzie).

\section{Smeringopina Kraus, 1957}

The Guineo-Congolian genus Smeringopina has its highest diversity in Central Africa (Huber 2013). Any Central African forest seems to contain one to three representatives of the genus, and places without known records have most probably never been searched adequately (Fig. 32). Of the 44 currently known species, 37 occur in the area considered here. Except for $S$. fon Huber, 2013 (which ranges into West Africa) all of them are endemic to Central Africa.

32. Smeringopina africana (Thorell, 1899). Cameroon (Thorell 1899; Huber 2013).

33. Smeringopina armata (Thorell, 1899). Cameroon (Thorell 1899; Huber 2013).

34. Smeringopina attuleh Huber, 2013. Cameroon (Huber 2013).

35. Smeringopina bamenda Huber, 2013. Cameroon (Huber 2013).

36. Smeringopina bayaka Huber, 2013. Gabon (Huber 2013).

37. Smeringopina belinga Huber, 2013. Gabon (Huber 2013).

38. Smeringopina bioko Huber, 2013. Equatorial Guinea (Bioko) (Huber 2013).

39. Smeringopina bwiti Huber, 2013. Gabon (Huber 2013).

40. Smeringopina camerunensis Kraus, 1957. Cameroon (Kraus 1957; Huber 2013).

41. Smeringopina chaillu Huber, 2013. Gabon (Huber 2013).

42. Smeringopina cornigera (Simon, 1907). Cameroon (Simon 1907; Huber 2013).

43. Smeringopina djidji Huber, 2013. Gabon (Huber 2013).

44. Smeringopina ebolowa Huber, 2013. Cameroon (Huber 2013).

45. Smeringopina essotah Huber, 2013. Cameroon (Huber 2013).

46. Smeringopina etome Huber, 2013. Cameroon (Huber 2013).

47. Smeringopina fang Huber, 2013. Gabon (Huber 2013).

48. Smeringopina fon Huber, 2013. Nigeria, São Tomé and Príncipe (Huber 2013).

49. Smeringopina iboga Huber, 2013. Gabon (Huber 2013). 
50. Smeringopina kala Huber, 2013. Cameroon, Equatorial Guinea (Huber 2013).

51. Smeringopina kikongo Huber, 2013. Congo D.R. (Huber 2013).

52. Smeringopina kinguele Huber, 2013. Gabon (Huber 2013).

53. Smeringopina kribi Huber, 2013. Cameroon (Huber 2013).

54. Smeringopina lekoni Huber, 2013. Gabon (Huber 2013).

55. Smeringopina luki Huber, 2013. Congo D.R. (Huber 2013).

56. Smeringopina mayebout Huber, 2013. Gabon (Huber 2013).

57. Smeringopina mbouda Huber, 2013. Cameroon (Huber 2013).

58. Smeringopina mohoba Huber, 2013. Gabon (Huber 2013).

59. Smeringopina moudouma Huber, 2013. Gabon (Huber 2013).

60. Smeringopina ndjole Huber, 2013. Gabon (Huber 2013).

61. Smeringopina ngungu Huber, 2013. Congo D.R. (Huber 2013).

62. Smeringopina nyasoso Huber, 2013. Cameroon (Huber 2013).

63. Smeringopina ogooue Huber, 2013. Gabon (Huber 2013).

64. Smeringopina sahoue Huber, 2013. Gabon (Huber 2013).

65. Smeringopina simintang Huber, 2013. Gabon (Huber 2013).

66. Smeringopina simplex Kraus, 1957. Cameroon (Kraus 1957; Huber 2013).

67. Smeringopina tchimbele Huber, 2013. Gabon (Huber 2013).

68. Smeringopina tebe Huber, 2013. Gabon (Huber 2013).

Smeringopus Simon, 1890

Smeringopus is currently the most species-rich African pholcid genus (55 species). It is widespread in Central Africa (Fig. 33), but only seven species are known from the area: the pantropical synanthropic S. pallidus (Blackwall, 1858), which is common in the area but whose previous records from Central Africa are all dubious; the widespread S. cylindrogaster (Simon, 1907), which covers at least the western subregions of the Guineo-Congolian rainforest (Upper and Lower Guinea) (Huber 2012), and its close relative S. luki Huber, 2012; the widespread S. lesserti Kraus, 1957, which covers at least the eastern subregions of the Guineo-Congolian rainforest (Lower Guinea and Congolia) (Huber 2012); and the three species of the thomensis group (S. thomensis Simon, 1907; S. mayombe Huber, 2012; S. principe Huber, 2012), all of which are small scale endemics (Huber 2012).

69. Smeringopus cylindrogaster (Simon, 1907). Cameroon (Huber 2009), Gabon (Huber 2012). Newly recorded for Equatorial Guinea (Bioko) and Central African Republic.

New records

EQUATORIAL GUINEA: Bioko: 1 + in CAS, Arena Blanca, 7 km N of Luba (331.3’ $\left.\mathrm{N}, 8^{\circ} 35^{\prime} \mathrm{E}\right), 14$ Oct. 1998 (M. Boko et al.).

CENTRAL AFRICAN REPUBLIC: Sangha-Mbare: $3 q q, 1$ juv. in CAS (9027099), Parc National Dzanga-Ndoki $\left(2^{\circ} 22.2^{\prime} \mathrm{N}, 16^{\circ} 10.3^{\prime} \mathrm{E}\right), 360 \mathrm{~m}$ a.s.l., rainforest, beating low vegetation, 20-28 May 2001 (B.L. Fisher). 
70. Smeringopus lesserti Kraus, 1957. Congo D.R. (Lessert 1930; Kraus 1957; Huber 2012), Cameroon, Gabon, São Tomé and Príncipe (Huber 2012).

71. Smeringopus luki Huber, 2012. Congo D.R. (Huber 2012).

72. Smeringopus mayombe Huber, 2012. Congo D.R. (Huber 2012).

73. Smeringopus pallidus (Blackwall, 1858). Congo D.R. (Simon 1877, sub Pholcus excavatus; see Huber 2011b); Congo R. (Lawrence 1958; doubtful record, only juveniles); newly recorded for Cameroon and Gabon.

\section{New records}

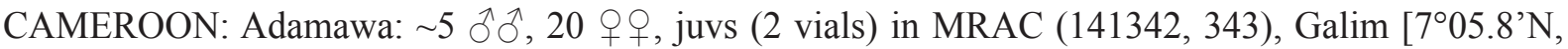

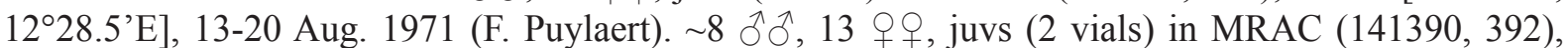
Djohong [6 $\left.6^{\circ} 50.2^{\prime} \mathrm{N}, 14^{\circ} 41.6^{\prime} \mathrm{E}\right], 1-5$ Sep. 1971 (F. Puylaert). West Region: 1 đo in MRAC (148377),

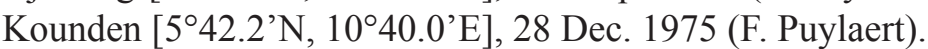

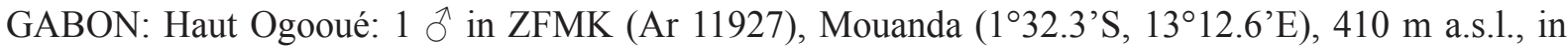

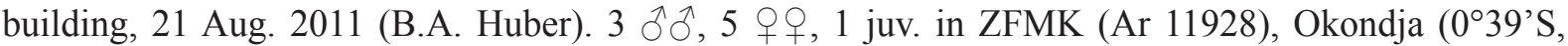
$\left.13^{\circ} 40.5^{\prime} \mathrm{E}\right), 350 \mathrm{~m}$ a.s.1., in building, 17 Aug. 2011 (B.A. \& S.R. Huber). Ogooué-Ivindo: 1 đ, 2 + 9 in

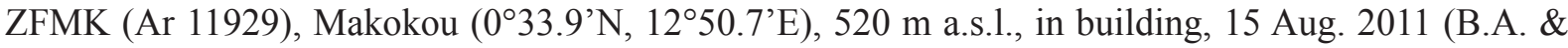
S.R. Huber); 1 , 1 juv. in pure ethanol, in ZFMK (Gab 218), same data.
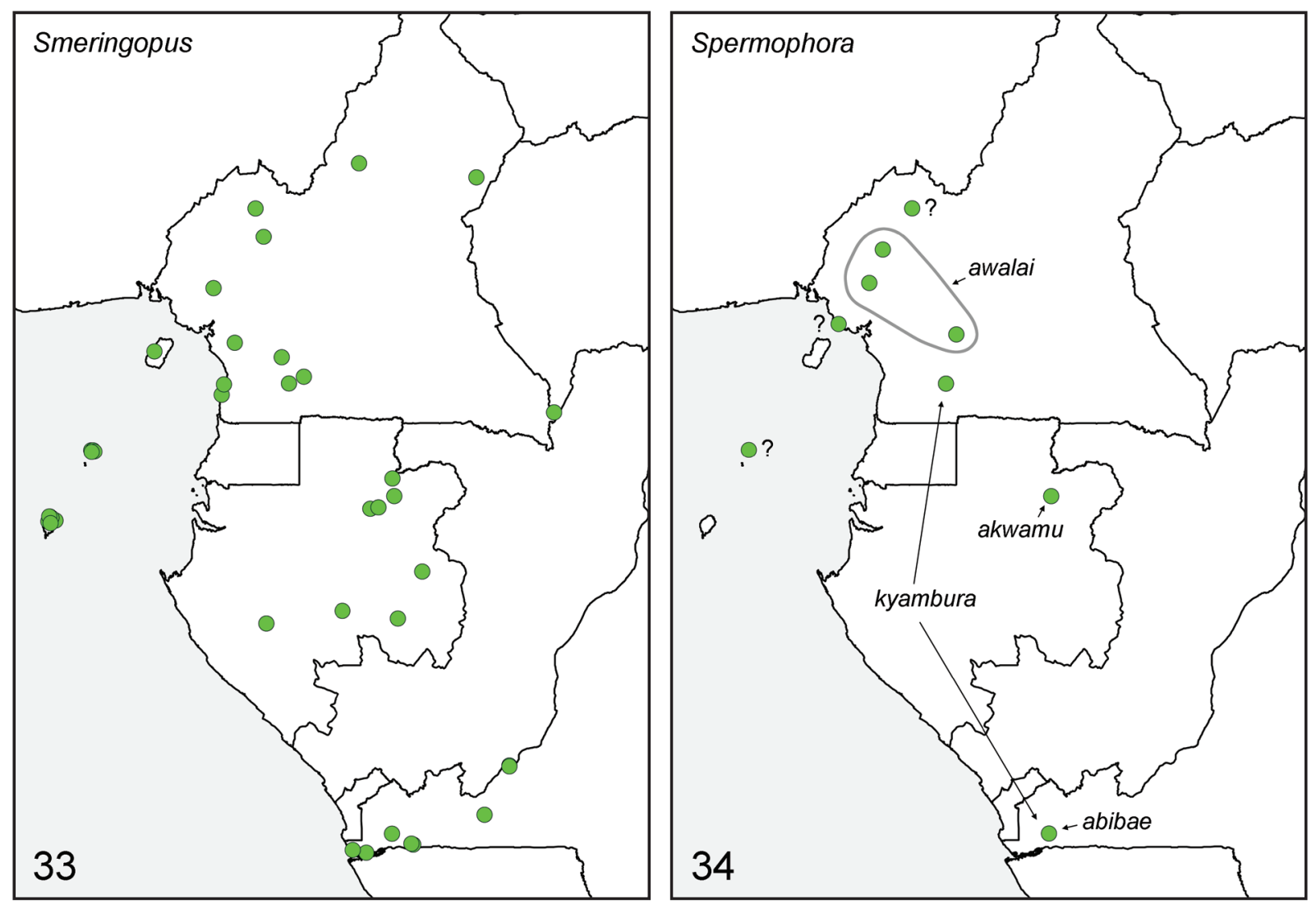

Figs 33-34. Known distributions of the genera Smeringopus Simon, 1890 and Spermophora Hentz, 1841 in Central Africa. For detailed distribution maps of Smeringopus species see Huber (2012). Question marks denote uncertain identifications (females from Cameroon; one pair from Príncipe Island). 


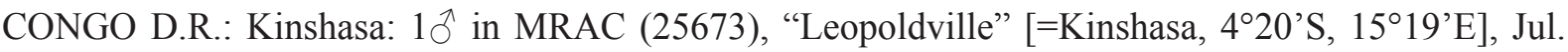
1945 (Bureau); 2 우, 1 juv. in MRAC (59225-30), same locality, Feb. 1947 (E. Dartevelle). 1 ㅇ in MRAC (26834), Matadi [549.3’S, 13²8.0’E], Feb. 1937 (E. Dartevelle).

74. Smeringopus principe Huber, 2012. São Tomé and Príncipe (Príncipe) (Huber 2012).

75. Smeringopus thomensis Simon, 1907. São Tomé and Príncipe (São Tomé) (Simon 1907; Huber 2012).

\section{Spermophora Hentz, 1841}

With currently 25 species, Spermophora is quite diverse in sub-Saharan Africa and Madagascar, but only the widespread S. kyambura Huber \& Warui, 2012 has previously been reported from Central Africa (Huber \& Warui 2012). Three additional species are here reported from Central Africa (Fig. 34). Of these, S. abibae sp. nov. and S. akwamu Huber \& Kwapong, 2013 are very similar to each other and to the West African S. dieke Huber, 2009. Spermophora awalai sp. nov. appears most similar to a group of East African species (node 5 in Appendix 4 in Huber 2003a). A further undescribed species seems to occur on São Tomé and Príncipe (NW of Santo Antonio, 1 § , $1+$ deposited in CAS). Females from Cameroon (Mt. Etinde, 1 i in USNM; near Oku, 1 क in pure ethanol in ZFMK, Cam 117) might represent further undescribed species.

76. Spermophora abibae sp. nov. (see below). Congo D.R.

77. Spermophora akwamu Huber \& Kwapong, 2013. Newly recorded for Central Africa.

\section{New record}

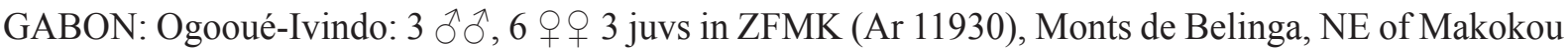
$\left(0^{\circ} 47.0^{\prime} \mathrm{N}, 13^{\circ} 08.3^{\prime} \mathrm{E}\right), 530 \mathrm{~m}$ a.s.l., degraded forest along road, 15 Aug. 2011 (B.A. \& S.R. Huber); same data, 4 juvs in pure ethanol, in ZFMK (Gab 222).

\section{Note}

The new specimens are tentatively assigned to this species because the palps appear identical and the clypeus apophyses are at most minimally different (Figs 95-96). There is some slight difference in the color pattern but this has also been found among different populations in Ghana (Huber \& Kwapong 2013).

78. Spermophora awalai sp. nov. (see below). Cameroon.

79. Spermophora kyambura Huber \& Warui, 2012. Cameroon, Congo D.R. (Huber \& Warui 2012).

\section{Identification key to Central African pholcid genera}

References to figures in upper case ("Fig.") refer to illustrations herein; figures in lower case ("fig.") have been published previously and are freely accessible online (at http://www.pholcidae.de/). Artema atlanta Walckenaer, 1837 is included as it probably occurs in Central Africa, even though we know of no records.

1 Abdomen worm-shaped ( $>10 \times$ longer than wide; Figs 1, 44); male chelicerae with one pair of small projections in latero-distal position (Fig. 51) ................Leptopholcus Simon, 1893

- Abdomen not worm-shaped $(<10 \mathrm{x}$ as long as wide); male chelicerae different .................

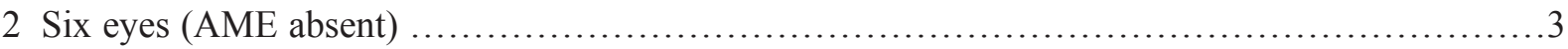

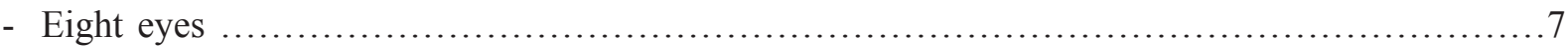


3 Sternum with characteristic pattern of radiating lines (Fig. 36); abdomen dorsally with dark heartmark (Fig. 35)

- Sternum without or with different pattern; abdomen dorsal pattern different

4 Carapace with 2-3 pairs of dark lateral spots; ocular area (especially in males) strongly elevated, in male with frontal hairy pocket; male chelicerae without proximal lateral projections (figs 2-4 in Huber 1996)

Modisimus culicinus (Simon, 1893)

- Carapace without lateral spots; ocular area not elevated; male chelicerae with proximal lateral projections

5 Male palpal bulb with three processes: embolus, uncus, appendix (Fig. 69). Epigynum sclerotized (at least posterior rim), with knob-shaped structure (Fig. 64) ...Pholcus Walckenaer, 1805 (part)

- Male palpal bulb with only one or two processes (embolus, bulbal apophysis); epigynum unsclerotized, without knob-shaped structure

6 Procursus with highly complex system of transparent lamellae (fig. 14 in Huber 2007); male chelicerae narrowing distally, with pair of simple frontal apophyses close to median line (fig. 15 in Huber 2007) Nyikoa limbe Huber, 2007

- Procursus and male chelicerae different Spermophora Hentz, 1841

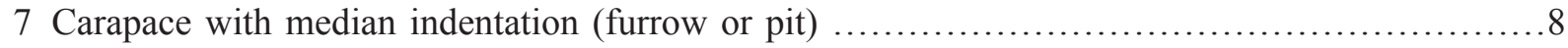

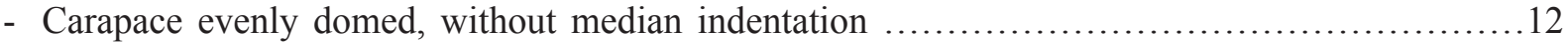

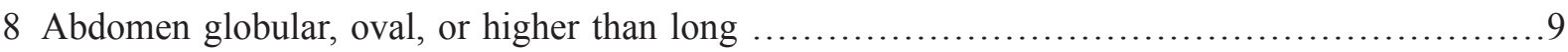

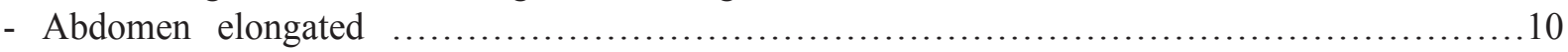

9 Procursus with prominent distal spine; female carapace with posterior median cone acting against frontal plate on abdomen; epigynum with median anterior process

Physocyclus globosus (Taczanowski, 1874)

- Procursus short, without distal spine; female carapace without posterior cone; epigynum without median anterior process Artema atlanta Walckenaer, 1837

10 Legs with many small black marks; abdomen angular in lateral view (posteriorly high) Crossopriza lyoni (Blackwall, 1867)

- Legs without small black marks, abdomen not angular in lateral view (posteriorly tapering) ...11

11 Male chelicerae with proximal lateral projections, either without or with several modified hairs on each side

Smeringopina Kraus, 1957

- Male chelicerae without proximal lateral projections, with single modified hair on each distal apophysis (fig. 47 in Huber 2009) Smeringopus Simon, 1890

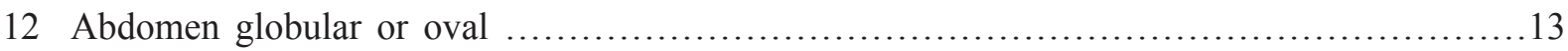

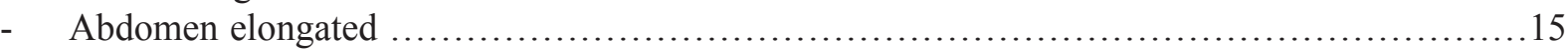

13 Procursus very short and simple (Fig. 58), male chelicerae without proximal lateral apophyses (Fig. 60); epigynum sclerotized

Ninetis Simon, 1890

- Procursus long and/or complex, male chelicerae with proximal lateral apophyses; epigynum barely sclerotized

14 Procursus with long dorsal hinged process, female genitalia with internal U-shaped structure visible through cuticle anteriorly (figs 83-89 in Huber 2011b) ...Micropholcus fauroti (Simon, 1887) 
- Procursus widely curved, without long dorsal process (figs 200, 205 in Huber 2003c); epigynum weakly sclerotized, no internal structure visible through cuticle

Quamtana Huber, 2003

15 Abdomen drawn into cone dorso-posteriorly (fig. 29 in Huber 2011b); male chelicerae with pair of lateral unsclerotized projections in distal position (fig. 130 in Huber 2009); epigynum weakly sclerotized .........Pehrforsskalia conopyga Deeleman-Reinhold \& van Harten, 2001

- Abdomen rounded posteriorly; male chelicerae with pair of lateral unsclerotized projections in proximal position (Fig. 82); epigynum strongly sclerotized at least at rim, with knob-shaped structure (Figs 76, 83)

Pholcus Walckenaer, 1805 (part)

Taxonomy

\section{Anansus kamwai Huber sp. nov. urn:1sid:zoobank.org:act:716ECD2B-4969-4FF5-9A36-FA7CD47F9B08}

Figs 10, 20, 35-43

\section{Diagnosis}

Distinguished from known congeners by shape of procursus (Figs 40, 41; distinctive distal elements); from $A$. atewa also by unpaired process on male clypeus (Figs 36, 42; paired in $A$. atewa); from other species also by more pointed apophyses frontally on male chelicerae (Fig. 42). Females in this genus are difficult to distinguish (except $A$. atewa, which has the epigynal pockets more anteriorly).
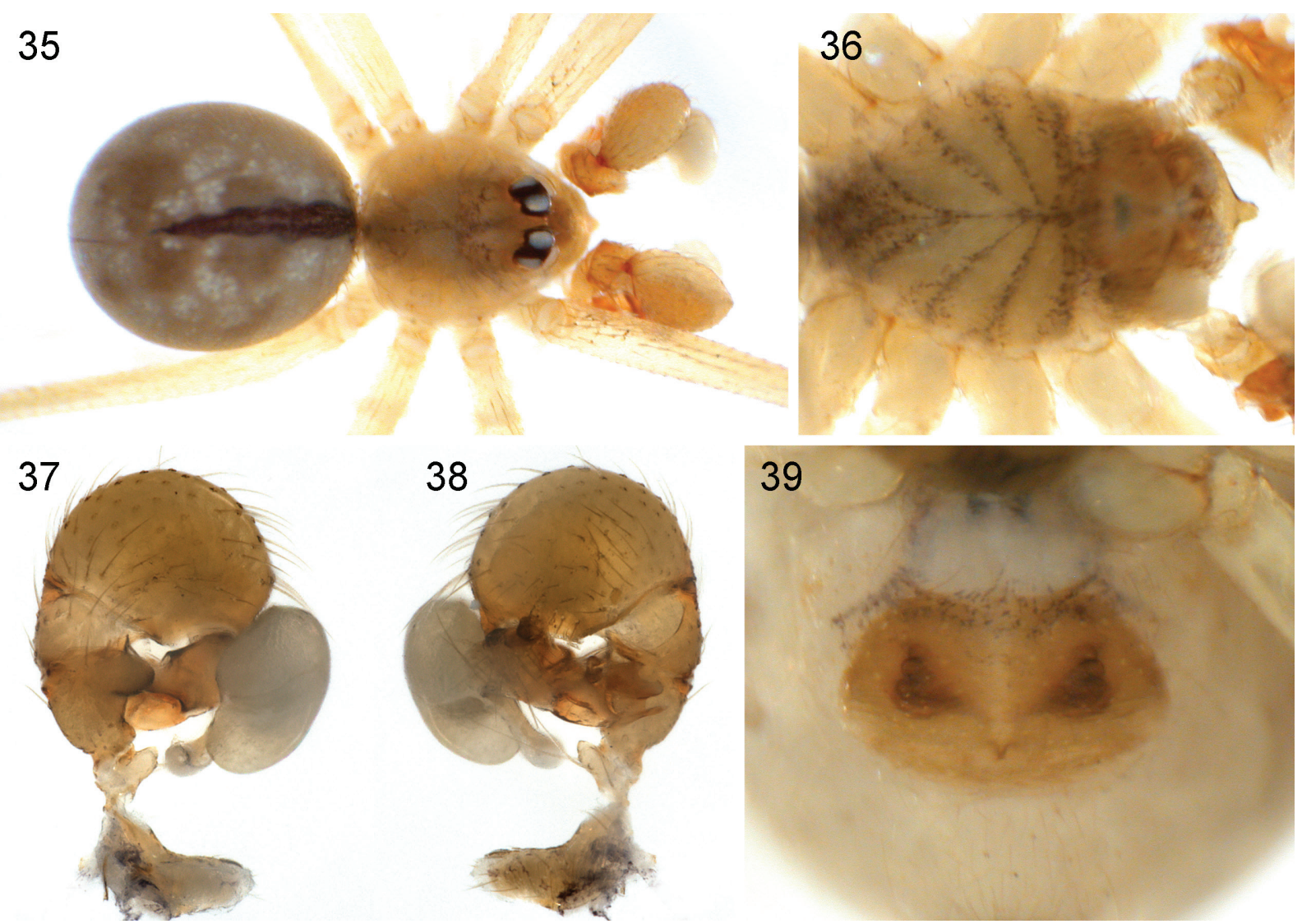

Figs 35-39. Anansus kamwai sp. nov. 35. $\widehat{\partial}$, dorsal view. 36. $\widehat{\partial}$ sternum, ventral view. 37-38. Left $\widehat{\partial}$ palp, prolateral and retrolateral views. 39. + epigynum, ventral view. 

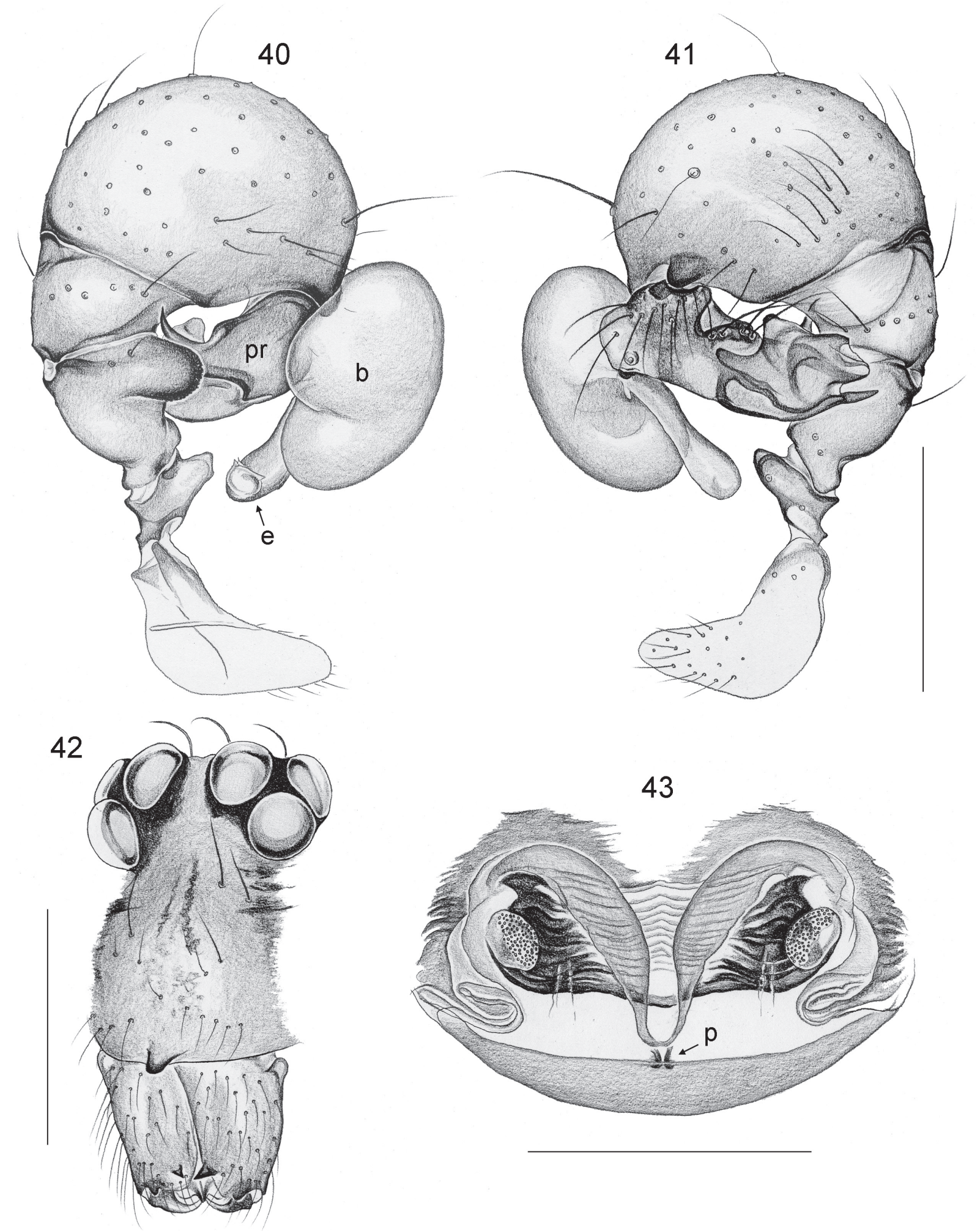

Figs 40-43. Anansus kamwai sp. nov. 40-41. Left $\widehat{\partial}$ palp, prolateral and retrolateral views. 42. $\widehat{\partial}$ ocular area, clypeus and chelicerae, oblique frontal view. 43. Cleared $q$ genitalia, dorsal view. $\mathrm{b}=\mathrm{bulb} ; \mathrm{e}=$ embolus; $\mathrm{p}=$ pocket; $\mathrm{pr}=$ procursus. Scale lines: $0.3 \mathrm{~mm}$. 


\section{Etymology}

Named for Cameroonian filmmaker Daniel Kamwa (born 1943), director of the 1981 film Notre Fille.

\section{Type material}

Holotype ô, in ZFMK (Ar 11931).

\section{Type locality}

CAMEROON, Northwest Region, near Bamenda, under trash and logs at roadside $\left(6^{\circ} 00.5^{\prime} \mathrm{N}, 10^{\circ} 18.1^{\prime} \mathrm{E}\right)$, 1750 m a.s.1., 16 Apr. 2009 (B.A. Huber).

\section{Other material examined}

CAMEROON: Northwest Region: $1 \hat{\partial}, 1$ q in ZFMK (Ar 11931), same data as and together with holotype; 1 $\widehat{\lambda}, 1$,, 2 juvs in pure ethanol, in ZFMK (Cam 76), same data.

\section{Description}

\section{Male (holotype)}

Measurements. Total body length 1.6, carapace width 0.60. Leg 1: $6.00(1.50+0.20+1.63+1.90+$ 0.77), tibia 2: 1.07, tibia 3: 0.80, tibia 4: 1.20; tibia $1 \mathrm{~L} / \mathrm{d}: 23$. Distance PME-PME $45 \mu \mathrm{m}$, diameter PME $60 \mu \mathrm{m}$, distance PME-ALE $20 \mu \mathrm{m}$; AME absent.

COLOR. Carapace ochre-yellow with irregular internal black pigment, sternum light brown with median dark line and four pairs of posteriorly diverging lines (Fig. 36); legs ochre-yellow without distinct dark rings; abdomen ochre-gray, with distinct dark heart-mark and thin dark line above spinnerets, dorsally with some white internal spots.

BoDy. Habitus as in Fig. 35; ocular area not elevated; carapace without median furrow; clypeus with rounded median process at rim (Fig. 42$)$; sternum wider than long $(0.48 / 0.36)$, unmodified. Chelicerae as in Fig. 42, with pair of lateral processes proximally and pair of pointed distal frontal apophyses without modified hairs; without stridulatory ridges.

PaLPS. As in Figs 37-38 and 40-41, coxa unmodified, trochanter with short ventral apophysis, femur small, with prominent distal apophysis prolaterally, tibia very large, procursus complex, with pointed ventral process, sclerotized retrolateral area set with several stronger hairs, distinctive tip; bulb with only one process (embolus, curved in dorsal view towards prolaterally).

LEGS. Without spines and curved hairs, few vertical hairs; retrolateral trichobothrium on tibia 1 at $27 \%$; prolateral trichobothrium absent on tibia 1, present on other tibiae; tarsus 1 with $\sim 10$ pseudosegments.

VARIATION. Tibia 1 in two other males: 1.37, 1.67.

\section{Female}

In general similar to male but clypeus unmodified; one female with darker chelicerae, clypeus, and sternum; tibia 1: 1.63 (missing in second female). Epigynum simple wide plate with pair of tiny pockets close together near posterior rim (Fig. 39), internal structures visible through cuticle; internal genitalia as in Fig. 43.

\section{Distribution}

Known from type locality in Cameroon only (Fig. 20). A poorly preserved male specimen from eastern Cameroon (Mbam near Koupoupi, MRAC 167.984) may also belong to this species. 
Leptopholcus gabonicus Huber, sp. nov. urn:Isid:zoobank.org:act:3CA8906E-7688-405E-AEDE-0A365C40281A

Figs 1, 22, 44-52

\section{Diagnosis}

Distinguished from only other Leptopholcus species known from Gabon [L. tipula (Simon, 1907); cf. figs 82-86 in Huber 2009] by shapes of uncus (Fig. 49; much wider in L. tipula, with narrower semitransparent flap), appendix (Fig. 49; short and wide in L. tipula), and procursus (Fig. 50; wider tip in L. tipula); females of these two species are not easily distinguished. Distinguished from $L$. obo Huber, 2011 (São Tomé and Príncipe) by shapes of trochanter apophysis, procursus, uncus, appendix, and longer epigynum (cf. figs 324-327 in Huber 2011b); from other Central African species (L. dschang Huber, 2011; L. signifer Simon, 1893; L. debakkeri Huber, 2011) by absence of clypeus modification in male (Fig. 45).

\section{Etymology}

Named for the country of Gabon, where this species is endemic.

\section{Type material}

Holotype ${ }^{\lambda}$, in ZFMK (Ar 11932).
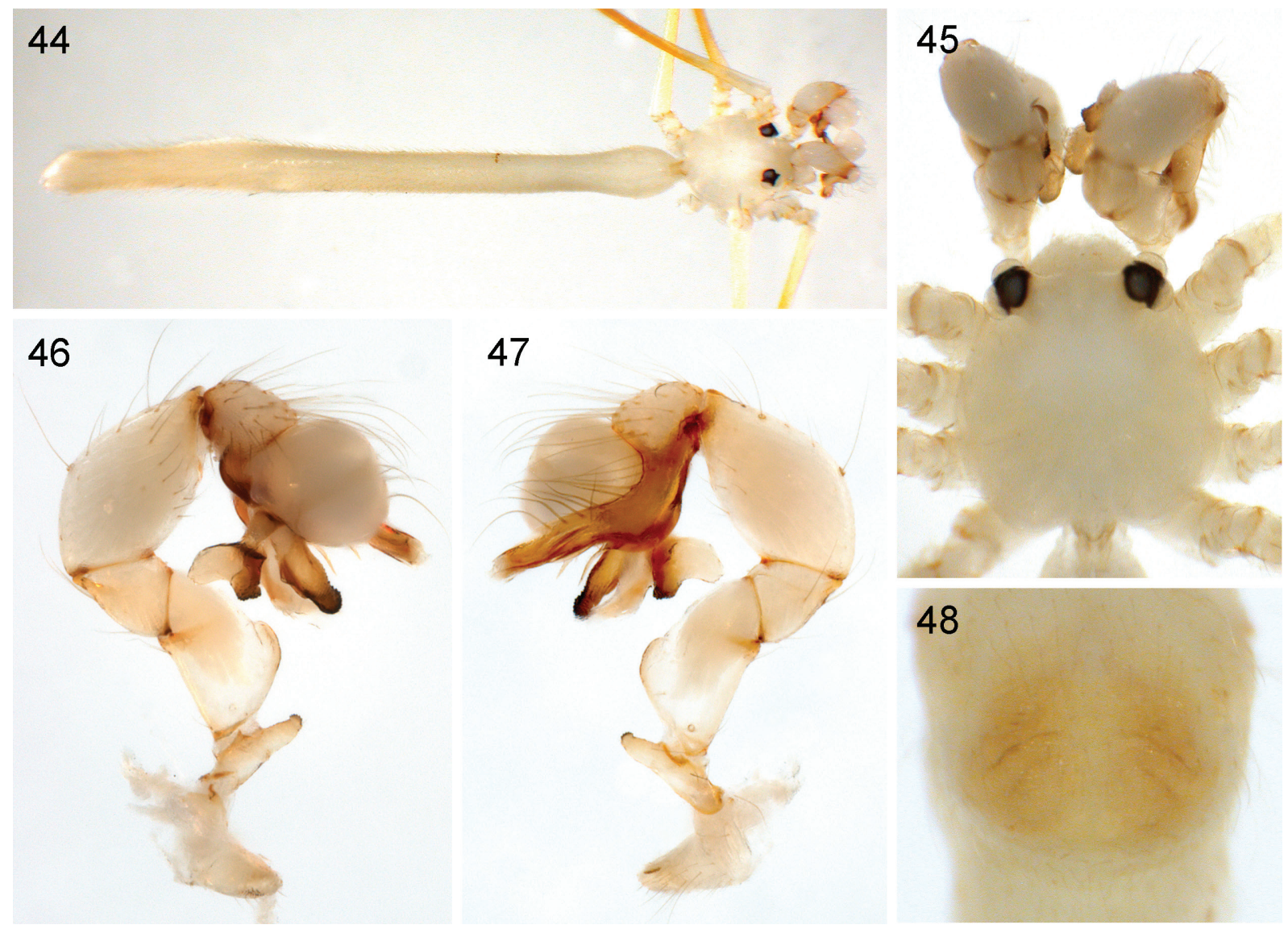

48

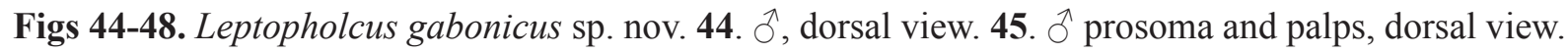
46-47. Left $\widehat{o}$ palp, prolateral and retrolateral views. 48. + epigynum, ventral view. 


\section{Type locality}

GABON, Ogooué-Ivindo, Monts de Belinga, forest near Mayebout ( $\left.1^{\circ} 06.7^{\prime} \mathrm{N}, 13^{\circ} 06.6^{\prime} \mathrm{E}\right), 500 \mathrm{~m}$ a.s.1., 13-14 Aug. 2011 (B.A. \& S.R. Huber).
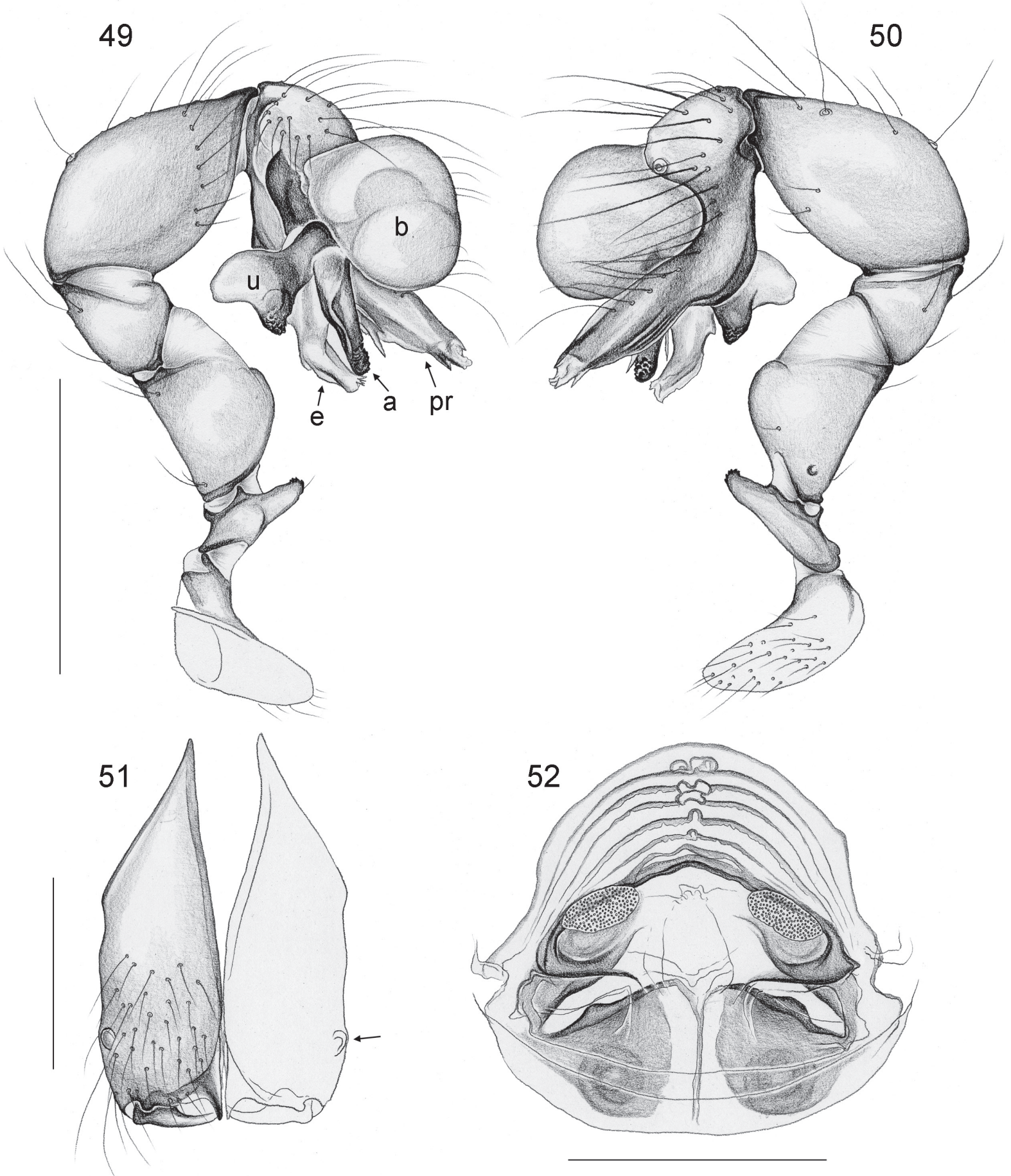

Figs 49-52. Leptopholcus gabonicus sp. nov. 49-50. Left ð̊ palp, prolateral and retrolateral views. 51. $\delta$ chelicerae, frontal view (arrow points at lateral apophysis). 52. Cleared $q$ genitalia, dorsal view. $\mathrm{a}=$ appendix; $\mathrm{b}=$ bulb; $\mathrm{e}=$ embolus; $\mathrm{pr}=$ procursus; $\mathrm{u}=$ uncus. Scale lines: $49-50,52=0.3 \mathrm{~mm} ; 51=0.2 \mathrm{~mm}$. 


\section{Other material examined}

GABON: Ogooué-Ivindo: 3 $\widehat{\partial}, 4$ $q$ in ZFMK (Ar 11933), same data as holotype; 2 우, 3 juvs in pure ethanol, in ZFMK (Gab 160, 200), same data. 1 त in ZFMK (Ar 11934), near Mohoba Mozeye $\left(0^{\circ} 16.8^{\prime} \mathrm{N}, 13^{\circ} 20.9^{\prime} \mathrm{E}\right), 510 \mathrm{~m}$ a.s.1., forest along road, 17 Aug. 2011 (B.A. \& S.R. Huber); 1 juv. in pure ethanol, in ZFMK (Gab 170), same data. Moyen-Ogooué: 1 ô in ZFMK (Ar 11935), near Ndjolé, 'site 2' (005.9'S, 10 52.4'E), $140 \mathrm{~m}$ a.s.1., forest near brook, 11 Aug. 2011 (B.A. \& S.R. Huber). 1 q in ZFMK (Ar 11936), near Ndjolé, 'site 1' ( $\left.0^{\circ} 09.0^{\prime} \mathrm{S}, 10^{\circ} 40.0^{\prime} \mathrm{E}\right), 120 \mathrm{~m}$ a.s.l., forest near brook, 11 Aug. 2011 (B.A. \& S.R. Huber); 1 juv. in pure ethanol, in ZFMK (Gab 229), same data. Estuaire: $2 \hat{\jmath} \widehat{\jmath}, 1$ + in ZFMK (Ar 11937), Monts de Cristal, near Kinguélé ( $\left.0^{\circ} 27.8^{\prime} \mathrm{N}, 10^{\circ} 16.7^{\prime} \mathrm{E}\right), 100 \mathrm{~m}$ a.s.1., forest, 10 Aug. 2011 (B.A. \& S.R. Huber); 2 우 in pure ethanol, in ZFMK (Gab 190), same data.

\section{Description}

\section{Male (holotype)}

Measurements. Total body length 6.0, carapace width 0.77. Leg 1: $33.4(8.5+0.4+7.7+13.3+3.5)$, tibia 2: 5.8, tibia 3: 3.8, tibia 4: 6.4; tibia 1 L/d: 116. Distance PME-PME $290 \mu \mathrm{m}$, diameter PME $80 \mu \mathrm{m}$, distance PME-ALE $25 \mu \mathrm{m}$, AME absent.

CoLor. Entire animal pale whitish to ochre-yellow, only patella area and tibia-metatarsus joints darker.

Body. Habitus as in Fig. 44; ocular area not elevated, each triad on low hump; carapace without median furrow; clypeus unmodified; sternum wider than long (0.64/0.46), unmodified. Chelicerae as in Fig. 51, with pair of small lateral processes barely visible in dissecting microscope; without stridulatory ridges.

PALPS. As in Figs 46-47 and 49-50, coxa unmodified, trochanter with ventral apophysis with serrated tip, femur with large ventral hump and small retrolateral process proximally, procursus rather simple, with two membranous ventral processes, one arising from ventral 'knee', the other more distally; bulb with weakly sclerotized embolus, rod-shaped appendix with small scales, uncus consisting of sclerotized part with small scales and lighter dorsal flap.

LeGs. Without spines and curved hairs, few vertical hairs; retrolateral trichobothrium on tibia 1 at 3\%; prolateral trichobothrium absent on tibia 1, present on other tibiae; tarsus 1 pseudosegments not seen.

VARIATION. Tibia 1 in 6 other males: 7.1-7.7 (mean 7.3).

\section{Female}

In general similar to male; tibia 1 in 6 females: 6.2-7.0 (mean 6.6). Epigynum very simple, weakly sclerotized plate, without 'knob', internal structures visible through cuticle (Fig. 48); internal genitalia as in Fig. 52.

\section{Natural history}

All specimens were found on the undersides of leaves.

\section{Distribution}

Known from various localities in Gabon (Fig. 22). 


\section{Ninetis faro Huber, sp. nov. urn:1sid:zoobank.org:act:C0D5E7FB-BB45-4921-BCBE-75FC4197FF02}

Figs 25, 53-62

\section{Diagnosis}

Easily distinguished from most known congeners (especially from N. subtilissima Simon, 1890 which has a similar male palp) by shape of male cheliceral apophyses (Figs 60-61); from N. russellsmithi Huber, 2002 (which has similar male chelicerae) by shorter embolus and presence of procursus (Figs 58-59). From other species by shapes of bulbal projections (both projections of same length in $N$. toliara Huber \& El Hennawy, 2007) or by shape of procursus (larger and not pointed in N. minuta (Berland, 1919) and N. namibiae Huber, 2000). Females are not easily distinguished (epigynum wider in N. namibiae, narrower in N. minuta; similar in other species).

\section{Etymology}

The name is a noun in apposition, derived from the type locality.

\section{Type material}

Holotype $\hat{\jmath}$, in MRAC (221178).

\section{Type locality}

CAMEROON, North Region, Faro Game Reserve [ $8^{\circ} 24^{\prime} \mathrm{N}, 12^{\circ} 49^{\prime} \mathrm{E}$ ], pitfall in gallery forest, 5 May 2007 (R. Jocqué, K. Loosveldt, L. Baert, M. Alderweireldt).
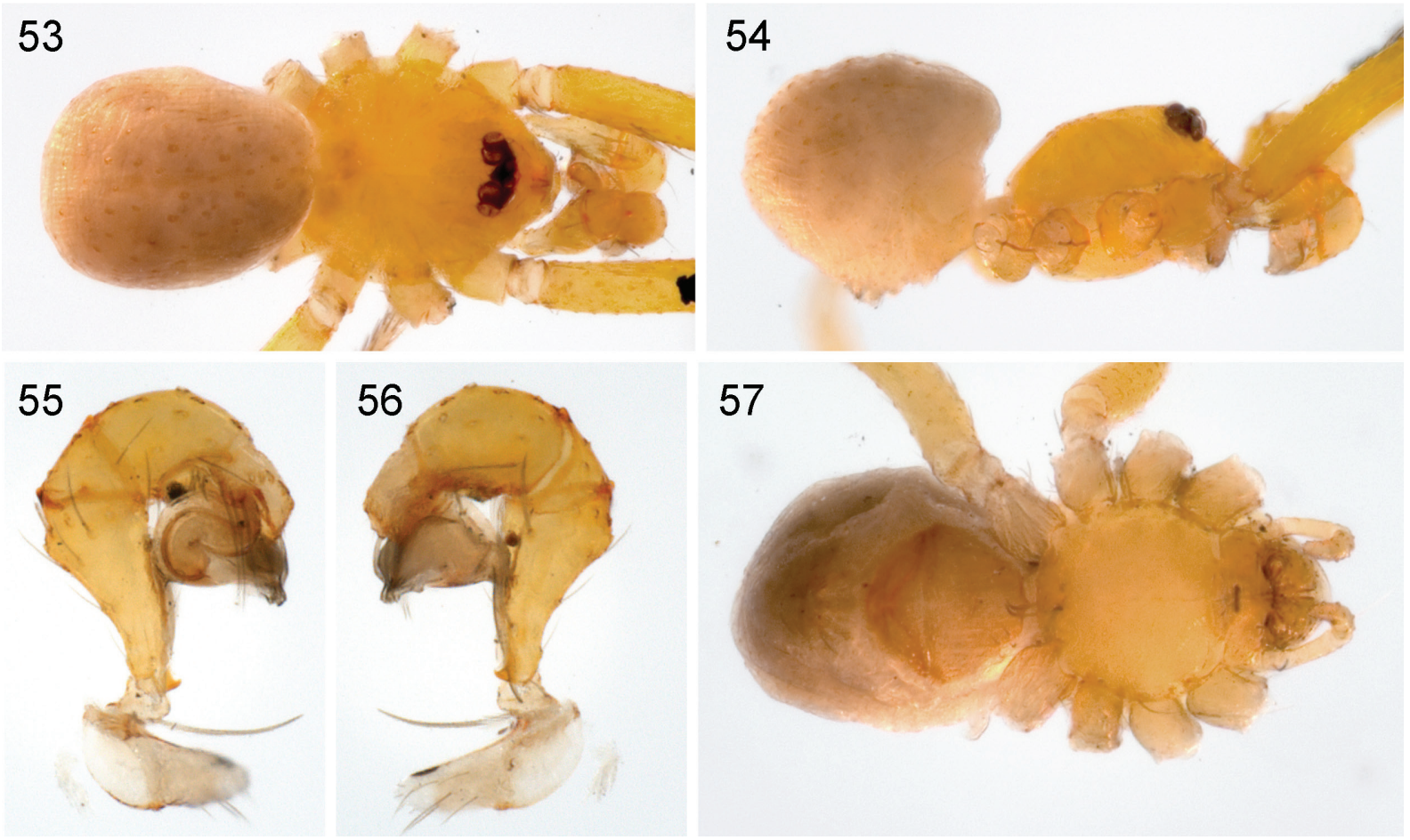

Figs 53-57. Ninetis faro sp. nov. 53-54. $\partial$, dorsal and lateral views. 55-56. Left $\widehat{\jmath}$ palp, prolateral and retrolateral views. 57. + , ventral view. 

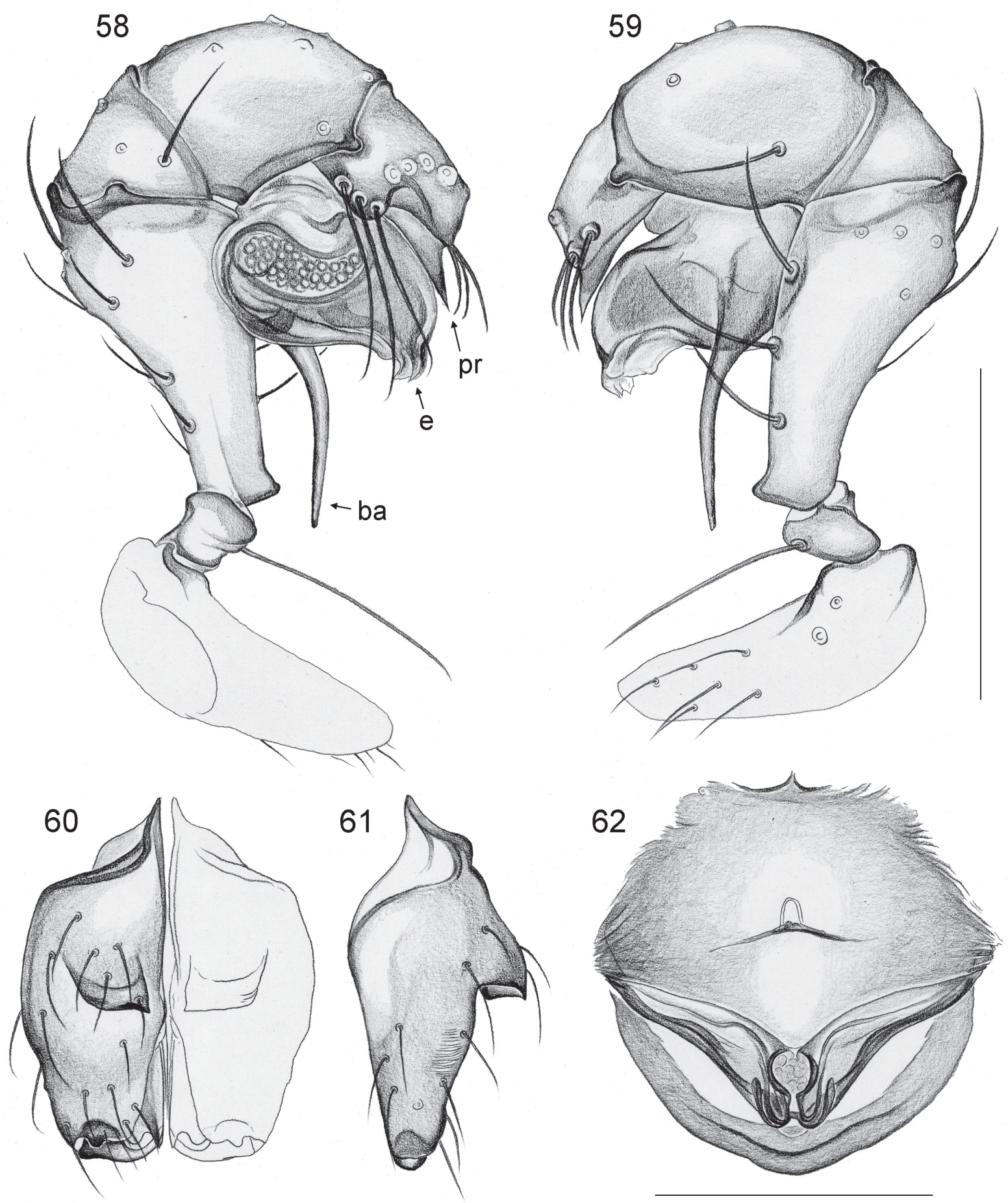

Figs 58-62. Ninetis faro sp. nov. 58-59. Left $\widehat{\partial}$ palp, prolateral and retrolateral views. 60-61. $\widehat{\jmath}$ chelicerae, frontal and lateral views. 62. Cleared + genitalia, dorsal view. ba $=$ bulbal apophysis; e = embolus; $p r$ $=$ procursus. Scale lines: $0.2 \mathrm{~mm}$. 


\section{Other material examined}

CAMEROON: North Region: $1 \delta$ in MRAC (221178), same data as and together with holotype; 2 §ô, 1 ㅇ (2 vials) in MRAC $(221136,221208)$, same data but pitfall in wooded savanna, 3-4 May 2007. 1 in MRAC (221401), same data but sieving in gallery forest, 17 Apr. 2007. $2 \hat{\jmath} \widehat{\jmath}, 4$ q $\propto$ in MRAC (221463), Hossere Gare [ $8^{\circ} 30^{\prime} \mathrm{N}, 13^{\circ} 08^{\prime} \mathrm{E}$ ], sieving of litter among rocks, 4 May 2007 (Jocqué, Loosveldt, Baert, Alderweireldt).

\section{Description}

\section{Male (holotype)}

MEASUREMENTS. Total body length 1.2, carapace width 0.50. Leg 1: $2.96(0.80+0.20+0.80+0.73+$ 0.43 ), tibia 2: 0.67, tibia 3: 0.50, tibia 4: 0.80; tibia $1 \mathrm{~L} / \mathrm{d}: 12$. Distance PME-PME $35 \mu \mathrm{m}$, diameter PME $40 \mu \mathrm{m}$, distance PME-ALE $25 \mu \mathrm{m}$, diameter AME $20 \mu \mathrm{m}$, distance AME-AME $20 \mu \mathrm{m}$.

CoLor. Entire animal ochre-yellow to ochre-grey.

BoDy. Habitus as in Figs 53-54; ocular area not elevated; carapace without median furrow; clypeus more sclerotized at rim and medially slightly protruding; sternum about as wide as long $(0.38 / 0.37)$, with distinct humps near leg coxae 1. Chelicerae as in Figs 60-61, with distinctive pair of frontal apophyses; with very fine stridulatory ridges.

PALPS. As in Figs 55-56 and 58-59, coxa and trochanter unmodified, femur with small retrolatero-ventral apophysis, tarsus with small pointed procursus; bulb with long ventral process and short membranous dorsal embolus.

Legs. Without spines and curved hairs, few vertical hairs; retrolateral trichobothrium on tibia 1 at $67 \%$; prolateral trichobothrium apparently absent on tibia 1 , present on other tibiae; tarsus 1 with $\sim 6$ pseudosegments.

VARIATION. Tibia 1 in 5 other males: 0.63-0.73 (mean 0.69).

\section{Female}

In general similar to male but clypeus, sternum, and chelicerae unmodified; tibia 1 in 5 females: 0.500.60 (mean 0.53). Epigynum simple oval sclerotized area consisting of large anterior and smaller posterior plate; internal structures poorly visible through cuticle (Fig. 57); unclear if complex internal structures are part of anterior plate (as appears in dorsal view; Fig. 62) or posterior plate (as appears in ventral view); anterior plate with transversal ridge apparently connected to median pocket. Pore plates not seen (Fig. 62).

\section{Distribution}

Known from two localities in the North Region of Cameroon (Fig. 25).

Pholcus punu Huber, sp. nov. urn:1sid:zoobank.org:act:C721A4A8-5D18-467B-A433-7E526A641082

Figs 12-13, 27, 63-74

\section{Diagnosis}

Distinguished from P. moca Huber, 2011 (the most similar species and probably closest known relative) by shape of procursus (longer retrolateral process; absence of distinct ridge between retrolateral process and tip; compare Fig. 70 with fig. 946 in Huber 2011b); also by shape of uncus (not bilobed as in 
P. moca), presence of proximal frontal processes on male chelicerae and slightly different shape of epigynal plate (narrower in P. moca; compare Fig. 64 with fig. 921 in Huber 2011b).

\section{Etymology}

Named for the Punu (or Bapunu, Bapounou), one of the four major peoples of Gabon; noun in apposition.

\section{Type material}

Holotype đ̊, in ZFMK (Ar 11938).

\section{Type locality}

GABON, Haut Ogooué, forest above Canyon rose near Lékoni (1³8.6’’, $\left.14^{\circ} 17.5^{`} \mathrm{E}\right), 600 \mathrm{~m}$ a.s.1., 19 Aug. 2011 (B.A. \& S.R. Huber).

\section{Other material examined}

GABON: Haut Ogooué: 2 $\widehat{\jmath}, 10$ q $q$ in ZFMK (Ar 11939), same data as holotype; 2 q $q, 2$ juvs in pure ethanol, in ZFMK (Gab 209), same data. $1 \partial^{\wedge}$ in ZFMK (Ar 11940), forest at Lékoni River (1¹0.7'S, 13³2.3’E), 305 m a.s.1., 18 Aug. 2011 (B.A. \& S.R. Huber); 1 o, 1 juv. in pure ethanol, in ZFMK

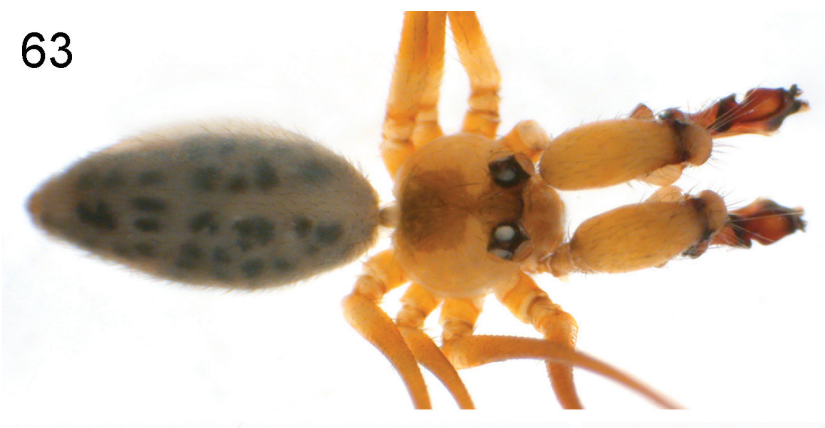

66

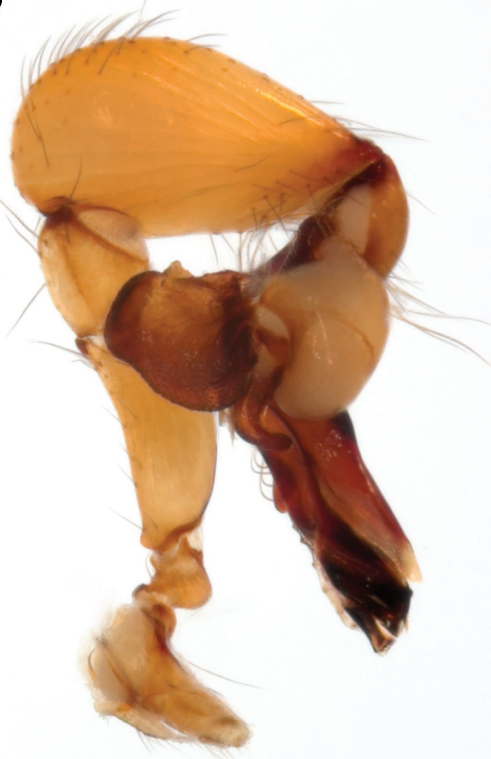

67

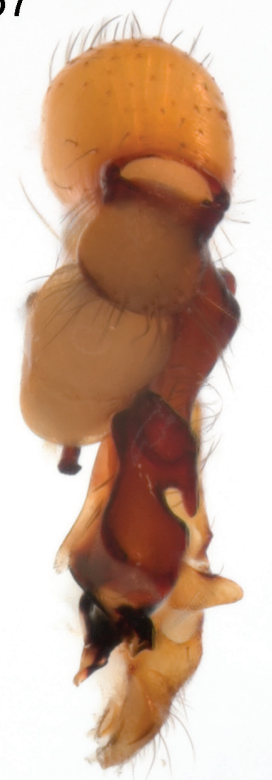

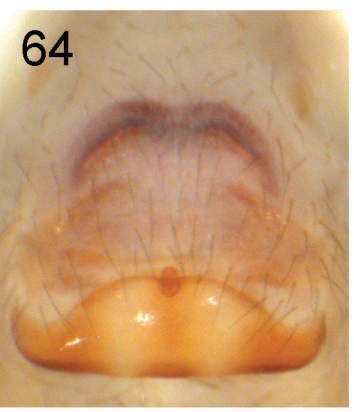

65

68

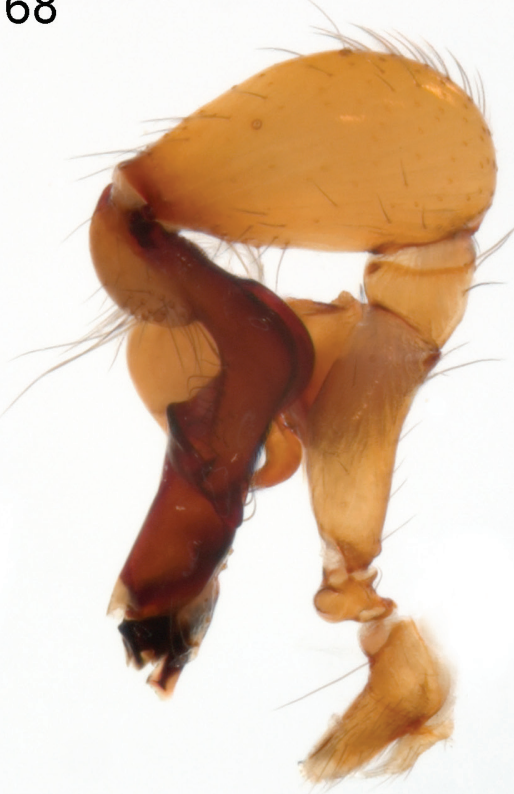

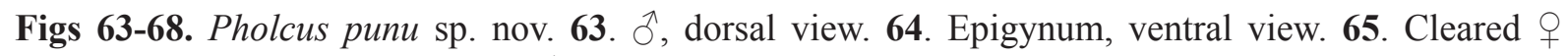
genitalia, dorsal view. 66-68. Left ồ palp, prolateral, dorsal, and retrolateral views. 


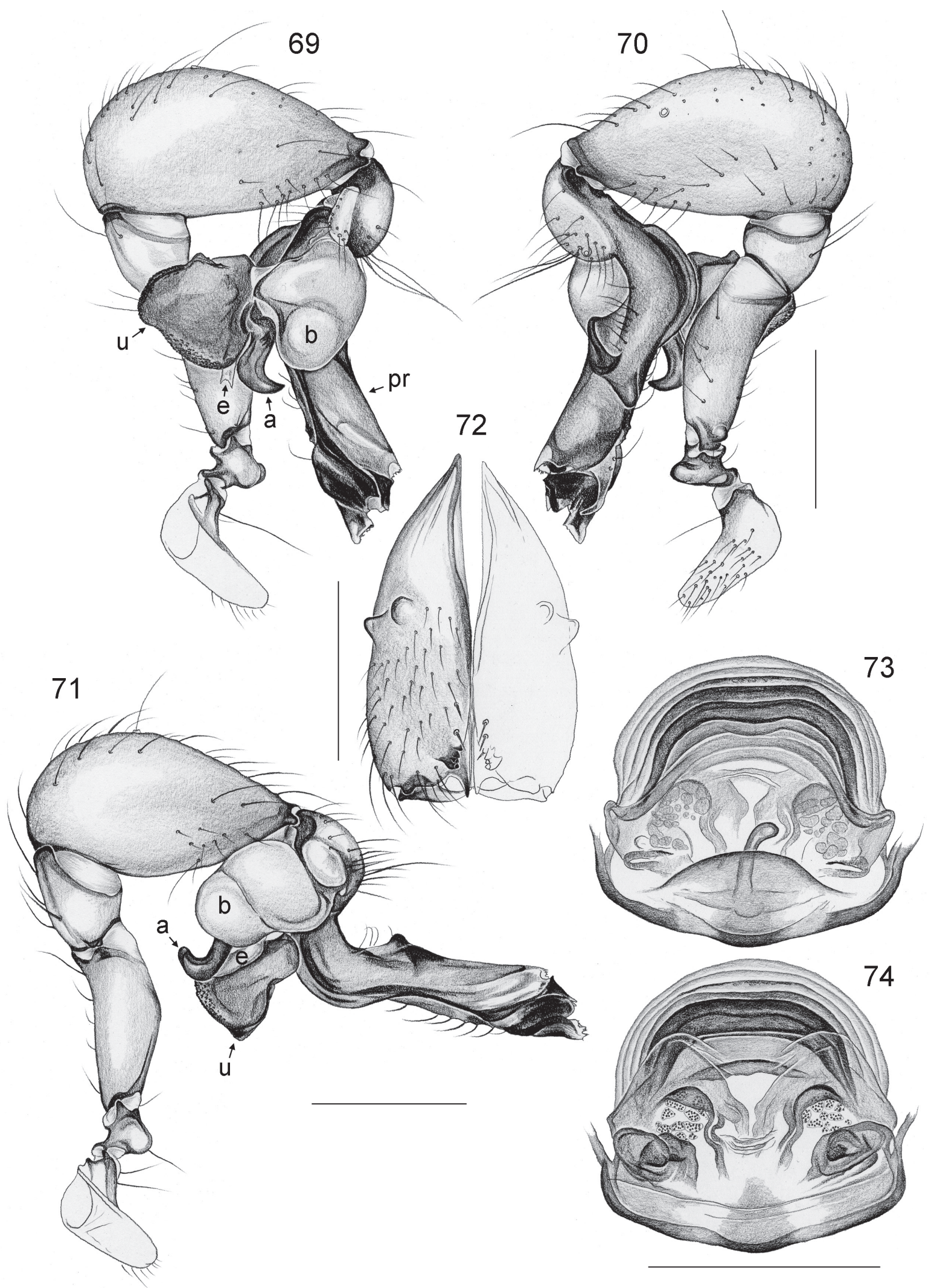

Figs 69-74. Pholcus punu sp. nov. 69-70. Left $\partial$ palp, prolateral and retrolateral views. 71. Extended palp with rotated bulb. 72. 0 chelicerae, frontal view. 73-74. Cleared $q$ genitalia, ventral and dorsal views. $\mathrm{a}=$ appendix; $\mathrm{b}=$ bulb; $\mathrm{e}=$ embolus; $\mathrm{pr}=$ procursus; $\mathrm{u}=$ uncus. Scale lines: $69-71,73-74=0.5 \mathrm{~mm}$; $72=0.3 \mathrm{~mm}$. 
(Gab 213), same data. 1 ``, 3 우 in ZFMK (Ar 11941), forest near Bongoville (1 $\left.{ }^{\circ} 36.7^{\circ} \mathrm{S}, 13^{\circ} 57.4^{\prime} \mathrm{E}\right)$, 600-650 m a.s.1., 20 Aug. 2011 (B.A. Huber); 2 juvs in pure ethanol, in ZFMK (Gab 207), same data.

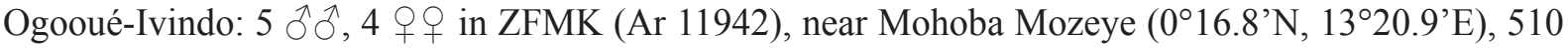
$\mathrm{m}$ a.s.l., forest along road, 17 Aug. 2011 (B.A. \& S.R. Huber); 2 우, 3 juvs in pure ethanol, in ZFMK (Gab 169), same data. Ogooué-Lolo: 1 đ, 1 क in ZFMK (Ar 11943), forest at brook near Lastoursville,

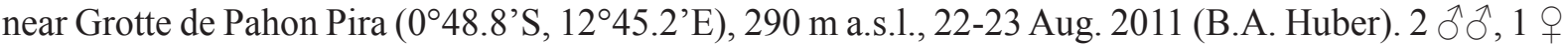

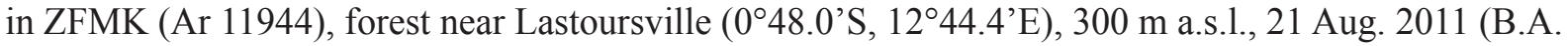
Huber); 3 juvs in pure ethanol, in ZFMK (Gab 221), same data. 1 đo, 1 우 in ZFMK (Ar 11945), near Moudouma ( ${ }^{\circ} 23.5^{\prime}$ 'S, $12^{\circ} 09.6^{\prime}$ E), 475 m a.s.l., forest along brook, 24 Aug. 2011 (B.A. \& S.R. Huber); 1 juv in pure ethanol, in ZFMK (Gab 157), same data. Ngounié: 2 §ิ $\sigma^{\lambda}, 4$ 우우 in ZFMK (Ar 11946), Massif du Chaillu, 'site 2', near Moukabou (1'36.6'S, $\left.11^{\circ} 40.7^{\prime} \mathrm{E}\right), 560 \mathrm{~m}$ a.s.1., forest, 25 Aug. 2011 (B.A. \& S.R. Huber); 3 juvs in pure ethanol, in ZFMK (Gab 174), same data. $4 \hat{\jmath} \sigma^{\lambda}, 7 q q$ in ZFMK (Ar 11947), Massif du Chaillu, 'site 3', between Mimongo \& Yéno (1³8.1'S, 11³2.6’E), 570-650 m a.s.l., forest, 26 Aug. 2011 (B.A. \& S.R. Huber); 3 juvs in pure ethanol, in ZFMK (Gab 233), same data. $1 \delta^{\top}$ in ZFMK (Ar 11948), Massif du Chaillu, 'site 4', between Yéno and Mouila (1²43.7'S, $1^{\circ} 18.4^{\prime}$ 'E), $650 \mathrm{~m}$ a.s.1., forest along river, 26 Aug. 2011 (B.A. \& S.R. Huber). 3 ${ }^{\lambda}, 7$ 7 in ZFMK (Ar 11949), near Moulandoufouala ( $1^{\circ} 38.1^{\prime}$ S, $\left.10^{\circ} 42.5^{\prime} \mathrm{E}\right), 110 \mathrm{~m}$ a.s.l., forest along road, 27 Aug. 2011 (B.A. \& S.R.

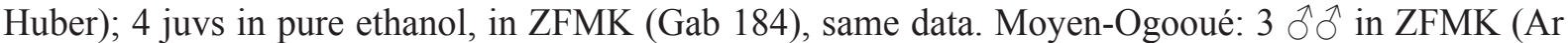
11950), $\mathrm{S}$ of Lambaréné near Tchad (058.1'S, 10²2.7’E), 165 m a.s.1., forest, 27 Aug. 2011 (B.A. \& S.R. Huber).

\section{Description}

Male (holotype)

MeAsurements. Total body length 3.0, carapace width 0.9. Leg 1: $27.0(6.4+0.4+6.5+11.5+2.2)$, tibia 2: 4.5, tibia 3: 2.7, tibia 4: 4.1; tibia $1 \mathrm{~L} / \mathrm{d}$ : 82. Distance PME-PME $265 \mu \mathrm{m}$, diameter PME $95 \mu \mathrm{m}$, distance PME-ALE $45 \mu \mathrm{m}$, AME absent (only black spots without lenses).

CoLOR. Carapace ochre-orange with large brown median mark, ocular area also brown, sternum medially slightly darkened; legs with dark rings on femora subdistally, patellae plus tibiae proximally, and tibiae subdistally; abdomen grey with internal black and whitish spots dorsally and laterally.

BoDy. Habitus as in Fig. 63; ocular area slightly elevated, each triad on short hump directed laterally; carapace without median furrow; clypeus unmodified; sternum wider than long $(0.66 / 0.52)$, unmodified. Chelicerae as in Fig. 72, with pair of lateral processes proximally, pair of frontal apophyses proximally, and pair of frontal apophyses distally provided with two modified hairs each; without stridulatory ridges.

PaLPS. As in Figs 66-71, coxa unmodified, trochanter with short and wide retrolatero-ventral apophysis, femur with short retrolatero-dorsal process proximally, procursus complex, with distinctive sclerotized and membranous elements; bulb with large uncus, simple weakly sclerotized embolus, and hooked appendix.

LEGs. Without spines and curved hairs, few vertical hairs; retrolateral trichobothrium on tibia 1 at 3\%; prolateral trichobothrium absent on tibia 1, present on other tibiae; tarsus 1 with $>20$ pseudosegments, only distally fairly distinct.

VARIATION. Tibia 1 in 22 other males: 6.7-8.8 (mean 7.9). Clypeus variably dark; AME spots sometimes fused. In most males the palps are extended and the bulbs rotated as in Fig. 71. 


\section{Female}

In general similar to male; tibia 1 in 36 females: 5.3-7.1 (mean 6.3). Epigynum with distinct plate and 'knob', anterior area weakly sclerotized, 'valve' and other internal structures visible through cuticle (Fig. 64); internal genitalia as in Figs 65 and 73-74.

\section{Natural history}

The spiders were mostly found in the leaf litter and in cavities in the ground (Fig. 12), sometimes sharing the microhabitat with a representative of Smeringopina (e.g. S. moudouma Huber, 2013 in forest near Lastoursville; S. fang Huber, 2013 between Yéno and Mouila; S. lekoni Huber, 2013 at Lékoni River). The two specimens from Moudouma were found at the rock surface (Fig. 13) close to a small brook.

\section{Distribution}

Known from various localities in Gabon south of the Ogooué-Ivindo Rivers (Fig. 27; the closely related P. moca Huber, 2011 seems to be confined to the north of these rivers).

Pholcus rawiriae Huber, sp. nov. urn:Isid:zoobank.org:act:54111E6C-353C-45DC-B72C-AC7D01382709

Figs 14-15, 28, 75-83

\section{Diagnosis}

Easily distinguished from known congeners by morphology of male palp (large trochanter apophysis; ventral femur apophyses; procursus with distal hinged sclerite strongly bent towards prolateral; bent embolus with spine-like processes; shape of appendix; Figs 80-81); from putative close relatives (bamboutos and circularis species groups) also by distinctive pattern on carapace (Fig. 75; transversal band on carapace; compare with figs. 892-918 in Huber 2011b), and by female external and internal genitalia (narrow sclerotized rim and distinctive shape of 'valve'; long pore plates; Figs 76, 83).

\section{Etymology}

Named for Gabonese novelist Angèle Ntyugwetondo Rawiri (1954-2010).

\section{Type material}

Holotype đે, in ZFMK (Ar 11951).

\section{Type locality}

GABON, Ogooué-Ivindo, near Mohoba Mozeye ( $\left.0^{\circ} 16.8^{\prime} \mathrm{N}, 13^{\circ} 20.9^{\prime} \mathrm{E}\right), 510 \mathrm{~m}$ a.s.l., forest along road, 17 Aug. 2011 (B.A. \& S.R. Huber).

\section{Other material examined}

GABON: Ogooué-Ivindo: 2 + $q$ in ZFMK (Ar 11951), same data as and together with holotype. $2 \widehat{\partial} \widehat{\partial}, 3$ 우 으 in ZFMK (Ar 11952), Monts de Belinga, forest near Mayebout ( $\left.1^{\circ} 06.7^{\prime} \mathrm{N}, 13^{\circ} 06.6^{\prime} \mathrm{E}\right), 500 \mathrm{~m}$ a.s.l., 13-14 Aug. 2011 (B.A. \& S.R. Huber); 2 우 in pure ethanol, in ZFMK (Gab 199), same data. Estuaire: 1 , 3 juvs in pure ethanol, in ZFMK (Gab 191), Monts de Cristal, between Tchimbélé and Kinguélé $\left(0^{\circ} 33.8^{\prime} \mathrm{N}, 10^{\circ} 18.8^{\prime} \mathrm{E}\right), 520 \mathrm{~m}$ a.s.l., forest near river, 10 Aug. 2011 (B.A. \& S.R. Huber). 


\section{Description}

Male (holotype)

Measurements. Total body length 5.0, carapace width 1.4. Leg 1: $39.1(9.6+0.5+9.3+17.5+2.2)$, tibia 2: 6.4, tibia 3: 4.2, tibia 4: 6.0; tibia $1 \mathrm{~L} / \mathrm{d}$ : 62. Distance PME-PME $365 \mu \mathrm{m}$, diameter PME $140 \mu \mathrm{m}$, distance PME-ALE $45 \mu \mathrm{m}$, diameter AME $90 \mu \mathrm{m}$, distance AME-AME $70 \mu \mathrm{m}$.

CoLor. Carapace ochre-yellow with distinctive dark pattern, clypeus not darkened, sternum with darker brown margins; legs with distinct dark rings on femora subdistally, patellae plus tibiae proximally, tibiae subdistally, and metatarsi proximally, tips of femora and tibiae lighter; abdomen dorsally and laterally with internal black marks.

Body. Habitus as in Fig. 75; ocular area slightly elevated, each triad on short hump directed laterally; carapace without median furrow; clypeus unmodified; sternum wider than long $(0.92 / 0.70)$, unmodified. Chelicerae as in Fig. 82, with pair of small lateral processes proximally, directed slightly towards posterior, pair of low frontal humps, and pair of distal frontal apophyses provided with two modified hairs each; without stridulatory ridges.
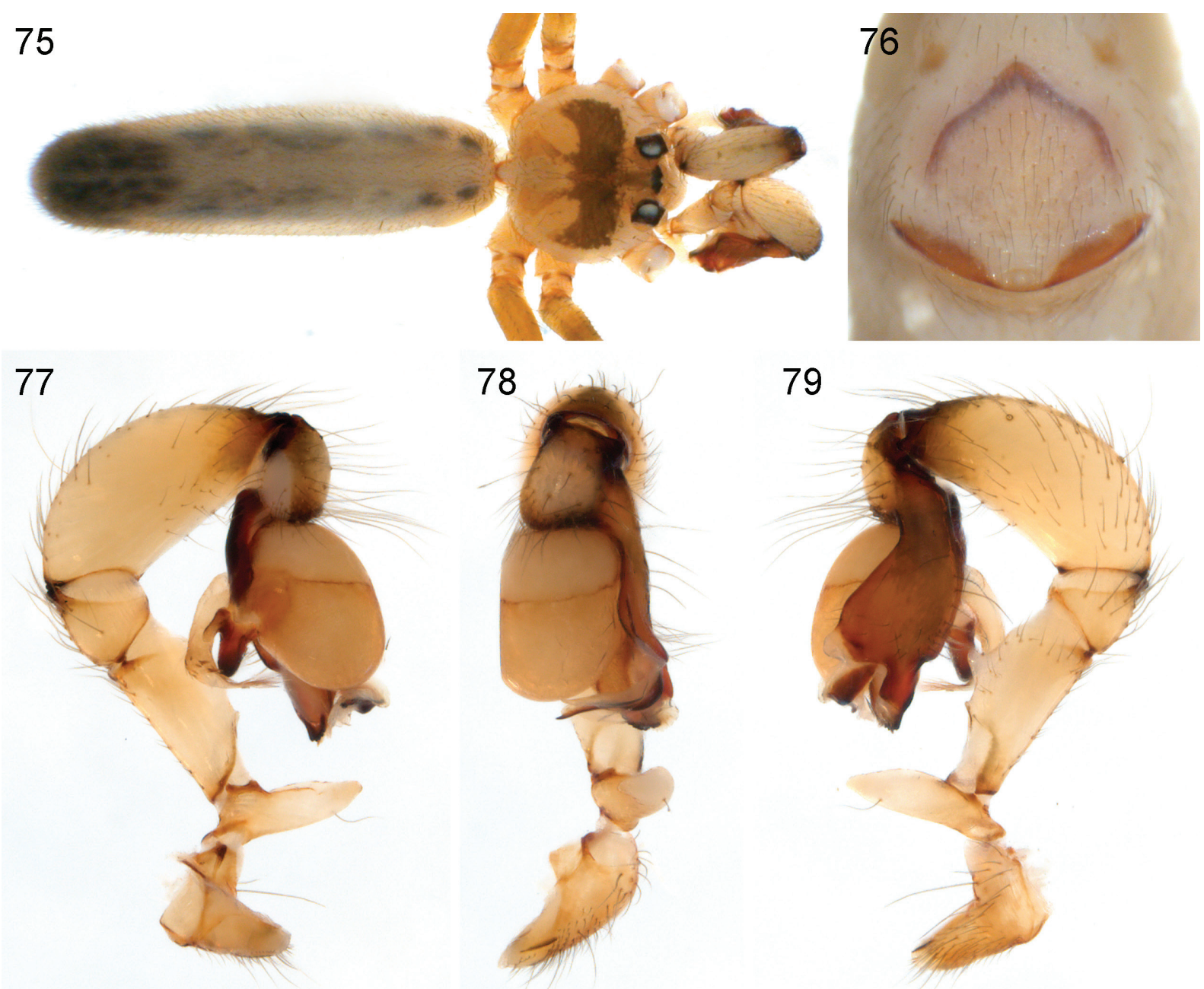

Figs 75-79. Pholcus rawiriae sp. nov. 75. $ð$, dorsal view. 76. + epigynum, ventral view. 77-79. Left $\curvearrowright$ palp, prolateral, dorsal, and retrolateral views. 

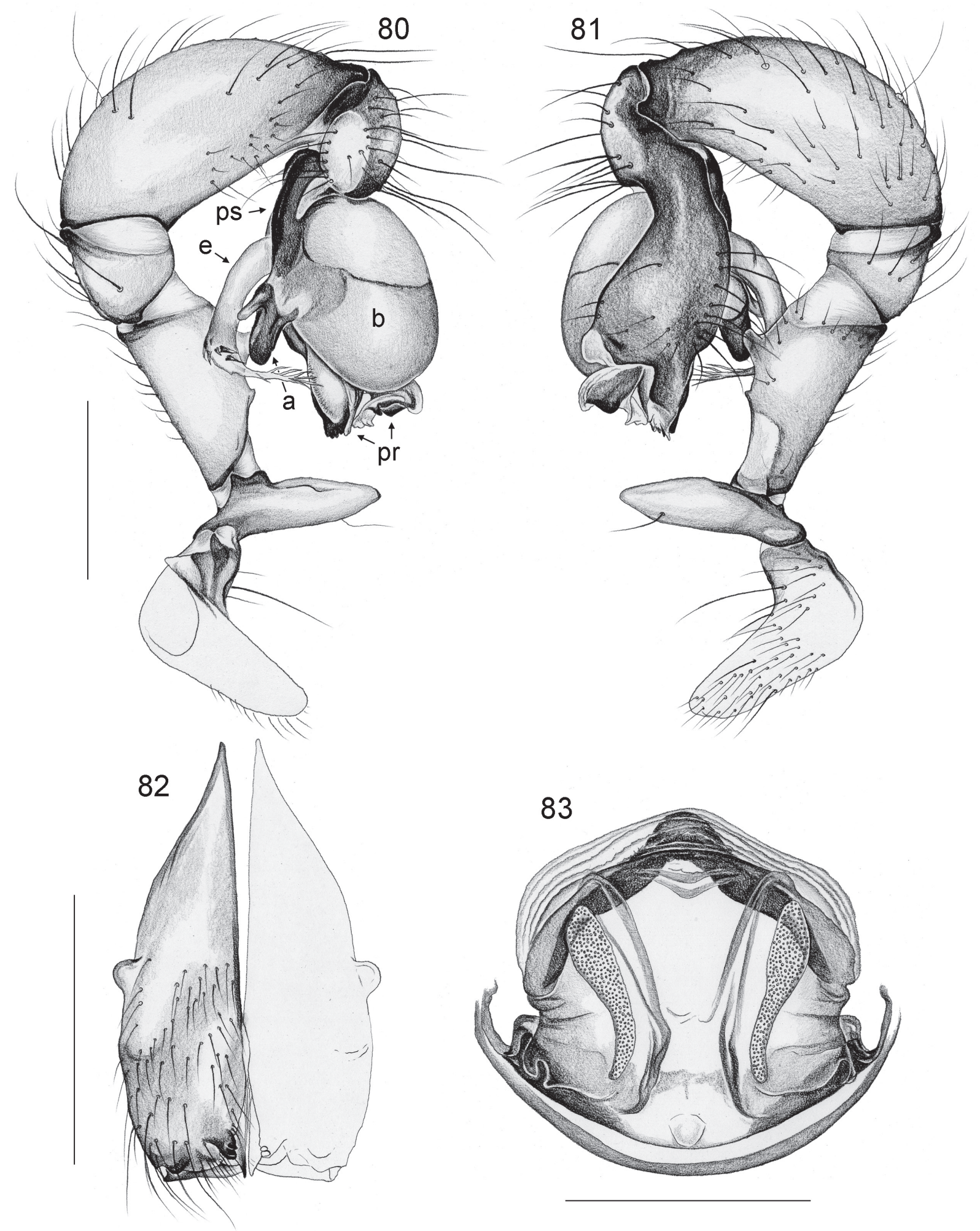

Figs 80-83. Pholcus rawiriae sp. nov. 80-81. Left $\widehat{\partial}$ palp, prolateral and retrolateral views. 82. $\widehat{\sigma}$ chelicerae, frontal view. 83. Cleared $\circ$ genitalia, dorsal view. $a=$ appendix; $b=$ bulb; $\mathrm{e}=$ embolus; $\mathrm{pr}=$ procursus; $\mathrm{ps}=$ proximal sclerite of bulb. Scale lines: $0.5 \mathrm{~mm}$. 
PALPS. As in Figs 77-81, coxa unmodified, trochanter with very large ventral apophysis, weakly sclerotized and distally curved towards prolateral, femur with one small and one larger distinctive ventral projection, procursus with distinctive hinged process distally strongly curved towards prolateral; bulb with long proximal sclerite, strongly bent embolus provided with several spine-like processes and distal fringes, without uncus, appendix with weakly sclerotized basal process.

LEGS. Without spines and curved hairs, few vertical hairs; retrolateral trichobothrium on tibia 1 at $4 \%$; prolateral trichobothrium absent on tibia 1, present on other tibiae; tarsus 1 with $>20$ pseudosegments, only distally fairly distinct.

VARIATION. Not seen. Tibiae 1 missing in other males.

\section{Female}

In general similar to male; tibia 1 in 5 females: 6.6-8.1 (mean 7.2). Epigynum with narrow sclerotized rim posteriorly, median 'knob', anterior area weakly sclerotized, 'valve' visible through cuticle (Fig. 76); internal genitalia as in Fig. 83.

\section{Natural history}

Most specimens were found at tree trunks, with their bodies and legs tightly pressed against the bark and thus barely visible (Figs 14-15).

\section{Distribution}

Known from three localities in northern Gabon (Fig. 28).

Spermophora abibae Huber, sp. nov. urn:Isid:zoobank.org:act:85A657B7-245E-4943-881F-A86BEC8B934A

Figs 34, 84-96

\section{Diagnosis}

Distinguished from the very similar S. dieke Huber, 2009 and S. akwamu Huber \& Kwapong, 2013 by bifid process on male clypeus (Figs 85, 92; only one median process in $S$. dieke; two processes in $S$. akwamu; cf. Figs 94-96), and by pore plates in female internal genitalia (Fig. 93; longer and in different position than in $S$. dieke and $S$. akwamu).

\section{Etymology}

The species name commemorates the 11-year old girl, who was purchased for six handkerchiefs by James Jameson, a member of Henry Stanley's Emin Pasha Relief Expedition, who gave her to cannibals so he could watch her being killed, cooked and eaten. Her name is not known. Abiba is an African name, meaning beloved.

\section{Type material}

Holotype $\widehat{\partial}$, in MRAC (separated from 224303).

\section{Type locality}

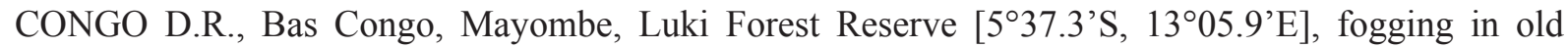
secondary rainforest, 17 Sep. 2007 (D. De Bakker, J.P. Michiels). 


\section{Other material examined}

CONGO D.R.: Bas Congo: $7 \hat{\jmath} \widehat{\partial}, 9$ qq+ in MRAC (224303 part), same data as holotype; $80 \hat{\jmath} \widehat{\partial}, 107$ 우, juvs (8 vials) in MRAC (224304-11 part), same data but 18-25 Sep. 2007 (D. De Bakker, J.P.

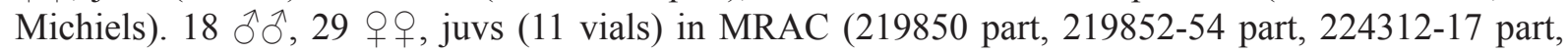
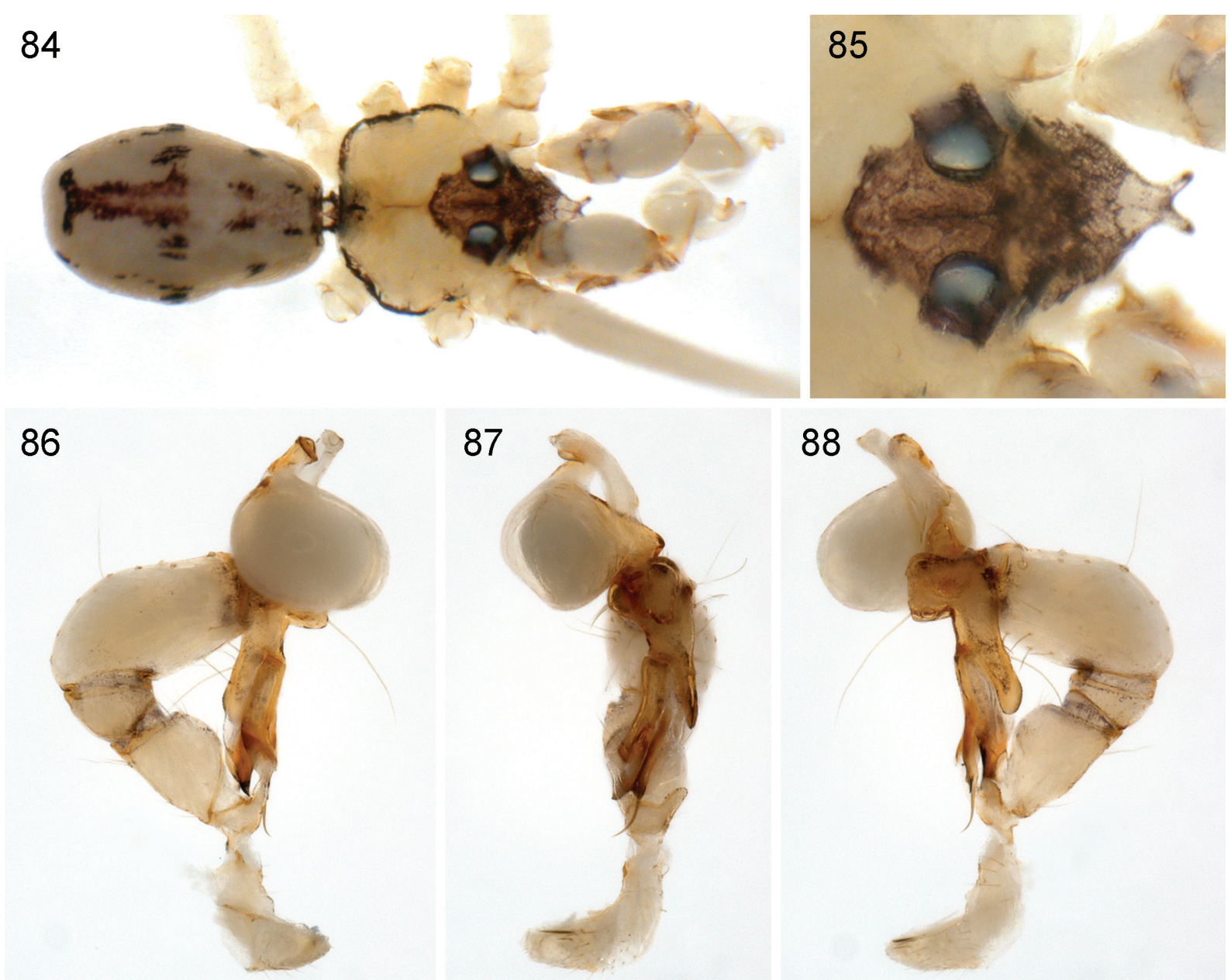

88
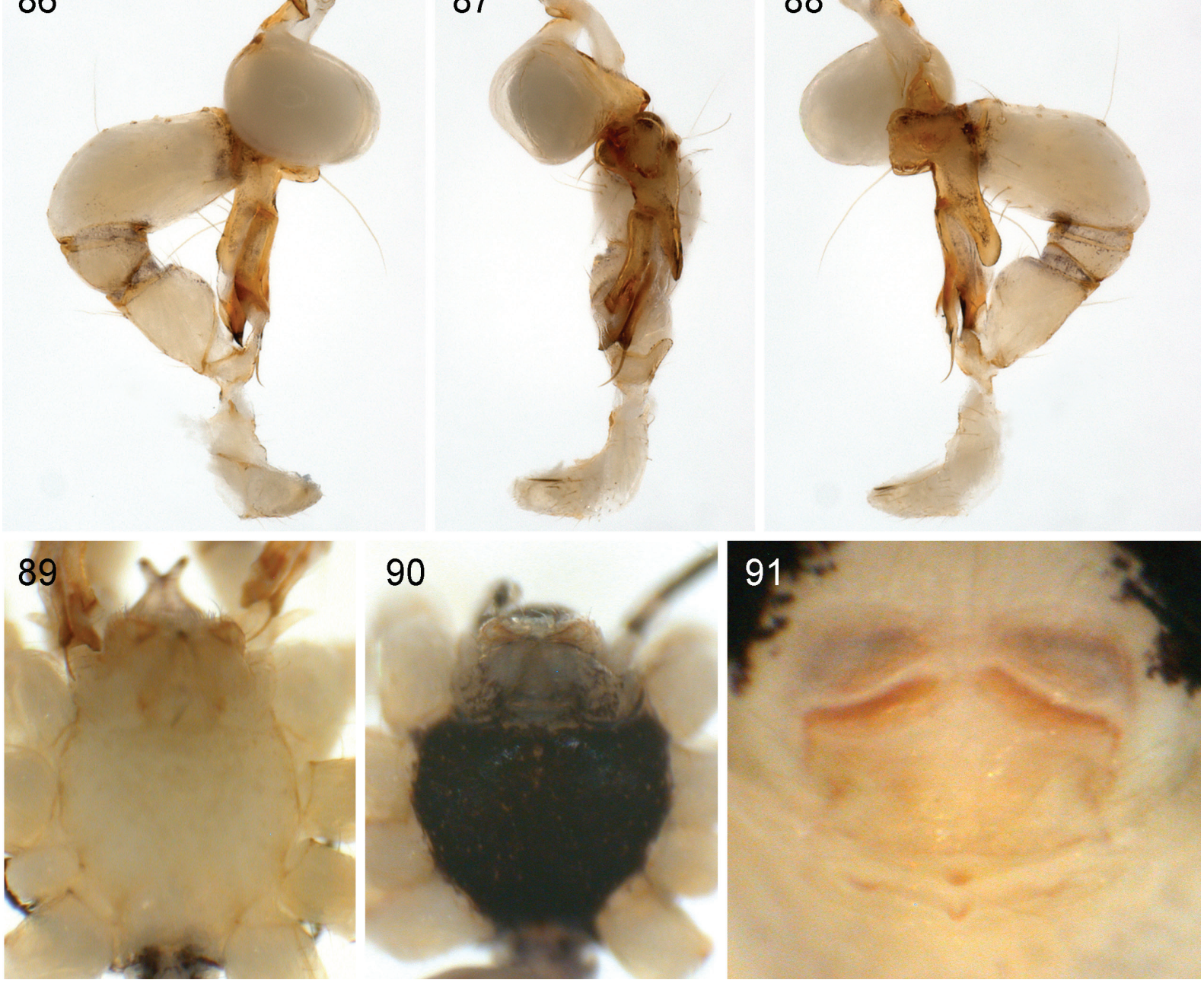

Figs 84-91. Spermophora abibae sp. nov. 84. đ̂, dorsal view. 85. đo ocular area and clypeus, dorsal view. 86-88. Left $\delta$ palp, prolateral, dorsal, and retrolateral views. 89-90. $\delta$ and $q$ prosomata, ventral views. 91. + epigynum, ventral view. 
224319 part), same locality, fogging in primary rainforest, 4-12 Nov. 2006 and 26 Sep.-4 Oct. 2007 (D. De Bakker, J.P. Michiels). 1 in MRAC (219999), same locality, beating along trail near guest house, 14 Nov. 2006 (D. De Bakker, J.P. Michiels). 4 ふึત 5 우우 (7 vials) in MRAC (222026 part, 222062, 223589,223605 part, 223616, 223628 part, 223635 part), same locality, beating in primary rainforest,

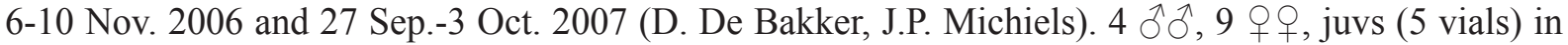
MRAC (222167, 222190 part, 222994 part, 223457 part, 223679 part), same locality, beating in old secondary rainforest, 18-23 Sep. 2007 (D. De Bakker, J.P. Michiels). 1 ㄱ, 3 우 ㅇ in MRAC (221619), same locality, beating along trail in planted and regenerated forest near guest house, 9 Nov. 2006 (D. De Bakker, J.P. Michiels). 2 juvs in MRAC (223113 part), same locality, beating in young secondary forest, 16 Sep. 2007 (D. De Bakker, J.P. Michiels).

\section{Description}

Male (holotype)

MEASUREMENTS. Total body length 2.1, carapace width 0.7. Leg 1: $4.7+0.3+4.8+7.9$, tarsus missing, tibia 2: 2.7, tibia 3: 1.8, tibia 4: 2.7; tibia $1 \mathrm{~L} / \mathrm{d}$ : 68. Distance PME-PME $135 \mu \mathrm{m}$, diameter PME $80 \mu \mathrm{m}$, distance PME-ALE $25 \mu \mathrm{m}$, AME absent.

Color. Carapace pale ochre-yellow with narrow black margins and indistinct median line (Fig. 84), ocular area and clypeus with dark pattern, sternum whitish (Fig. 89), legs ochre-yellow, with indistinct
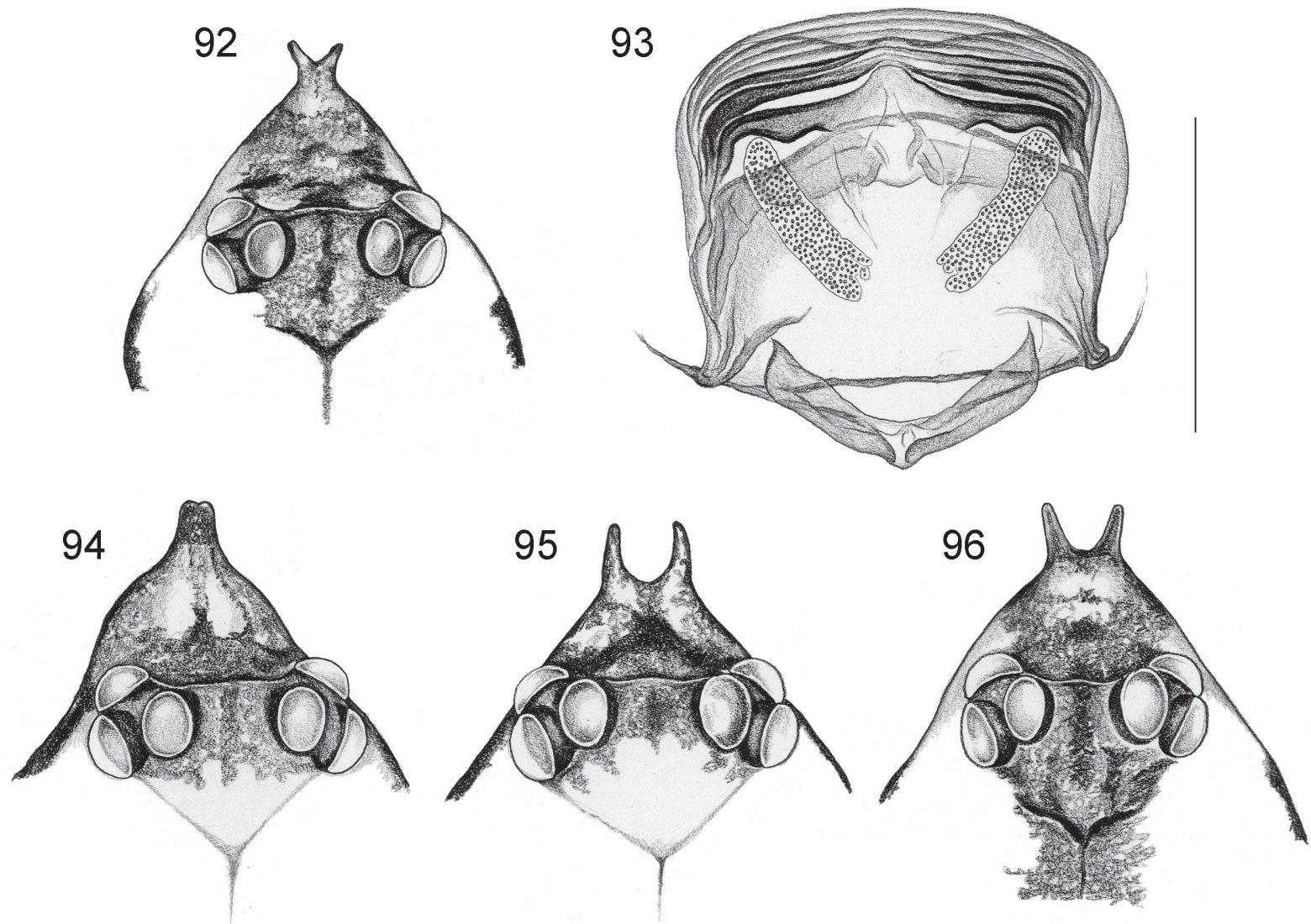

Figs 92-96. Spermophora abibae sp. nov. and putative close relatives. 92-93. Spermophora abibae sp. nov. ô ocular area and clypeus, dorsal view (92) and cleared $q$ genitalia, dorsal view (93). 94-96. $\delta^{\lambda}$ ocular area and clypeus, dorsal view of S. dieke Huber, 2009 (94) and of S. akwamu Huber \& Kwapong, 2013 (95: Ghana; 96: Gabon). Scale line: $93=0.3 \mathrm{~mm}$. 
dark rings subdistally on femora and tibiae, abdomen mostly pale gray, with distinct dark pattern dorsally and laterally, ventrally only pair of marks at booklung covers.

Body. Habitus as in Fig. 84; ocular area slightly elevated, each triad on low hump; carapace without median furrow (only dark line); clypeus with distinctive bifid process, about $120 \mu \mathrm{m}$ long (Figs 85, 92); sternum wider than long (0.52/0.44), unmodified. Chelicerae as in S. dieke and S. akwamu (cf. fig. 89 in Huber \& Kwapong 2013), with pair of weakly sclerotized processes proximally, distally without modification, without stridulatory ridges.

PALPS. As in Figs 86-88, apparently indistinguishable from S. dieke and S. akwamu; coxa with indistinct ventral process, trochanter with long ventral and shorter retrolateral apophyses, procursus with ventral sclerotized flap, prolatero-dorsal hinged process and thin distal flagellum; bulb with hooked apophysis and long weakly sclerotized embolus.

Legs. Without spines and curved hairs, few vertical hairs; retrolateral trichobothrium on tibia 1 at 10\%; prolateral trichobothrium absent on tibia 1, present on other tibiae.

VARIATION. Tibia 1 in 30 other males: 4.8-5.9 (mean 5.3), in one exceptional but otherwise indistinguishable male: 3.0 .

\section{Female}

In general similar to male but sternum in most females dark brown or black (Fig. 90), clypeus unmodified, carapace with small median process acting against indistinct sclerotized plate above pedicel. Tibia 1 in 30 females: 3.7-4.9 (mean 4.3). Epigynum simple rectangular plate, anteriorly with dark transversal internal structure, without pockets (Fig. 91); internal genitalia as in Fig. 93.

\section{Relationships}

Judging from the very similar morphology (including the most probably derived median process on the female carapace), this species is probably closely related to $S$. dieke from Guinea and the GuineoCongolian S. akwamu.

\section{Distribution}

Known from type locality in Congo D.R. only (Fig. 34).

Spermophora awalai Huber, sp. nov. urn:1sid:zoobank.org:act:0F2AB0B0-5E64-4F4E-9C10-D62EBE8BEAFA

Figs 5-6, 34, 97-107

\section{Diagnosis}

Easily distinguished from most congeners by procursus (Figs 102-103; strongly bent towards ventral; with large hinged ventral process); from similar (East African) species (S. morogoro Huber, 2003; S. usambara Huber, 2003; S. masisiwe Huber, 2003; cf. figs 222, 239, 245 in Huber 2003b) by long apophyses on male chelicerae (Figs 104-105); from these and other congeners also by distinctive pair of round structures with concentric rings in female internal genitalia (Figs 98, 106).

\section{Etymology}

Named for the Cameroonian writer Alexandre Biyidi Awala (1932-2001), known as Mongo Beti.

\section{Type material}

Holotype $\widehat{~}$, in ZFMK (Ar 11953). 


\section{Type locality}

CAMEROON, Southwest Region, near Dschang, Attuleh, 'site 2' (5'27.9’ N, 956.5'E), $1800 \mathrm{~m}$ a.s.1., underside of leaves, 20 Apr. 2009 (B.A. \& J.C. Huber).

\section{Other material examined}

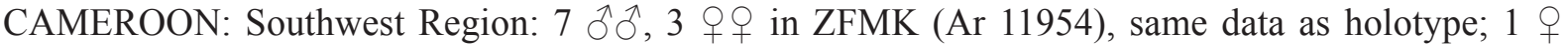
in pure ethanol, in ZFMK (Cam 125), same data. 5 ऽิ $\sigma^{\lambda} 4$ 우 0 in ZFMK (Ar 11955), near Dschang, Attuleh, 'site 1' (5'27.7’ N, 9'56.5'E), $1880 \mathrm{~m}$ a.s.l., underside of leaves, 20 Apr. 2009 (B.A. \& J.C. Huber); 1 in pure ethanol, in ZFMK (Cam 128), same data. 1 §, 1 q in ZFMK (Ar 11956), Mt. Koupé above Nyasoso (449.6’ N, 941.1'E), 1600 m a.s.l., near ground, 23 Apr. 2009 (B.A. Huber); 3 우 in pure ethanol, in ZFMK (Cam 145), same data. Centre Region: 1 ऽ, 3 우 in ZFMK (Ar 11957), near

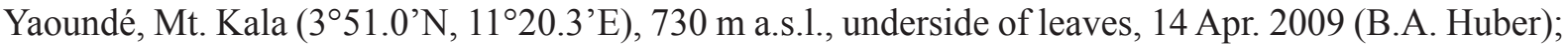
2 우, 2 juvs in pure ethanol, in ZFMK (Cam 106), same data.

\section{Description}

Male (holotype)

MeAsuREMENTs. Total body length 2.2, carapace width 0.8. Leg 1: $21.5(5.2+0.3+5.2+7.9+2.9)$, tibia 2: 3.3, tibia 3: 2.0, tibia 4: 2.9; tibia $1 \mathrm{~L} / \mathrm{d}$ : 73. Distance PME-PME $220 \mu \mathrm{m}$, diameter PME $95 \mu \mathrm{m}$, distance PME-ALE $35 \mu \mathrm{m}$, AME absent.

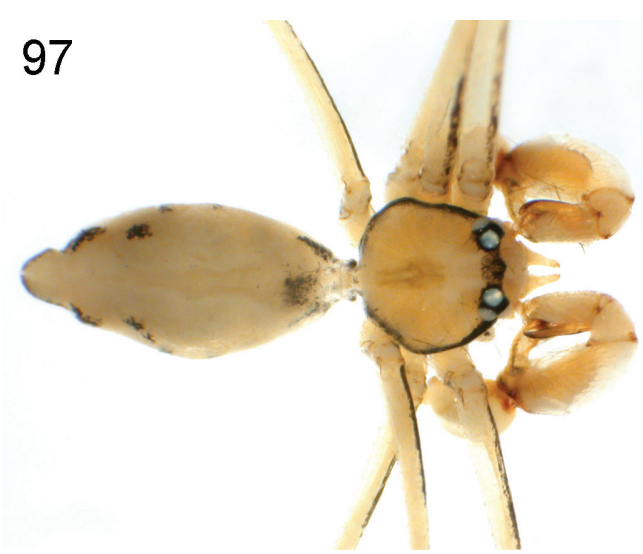

100

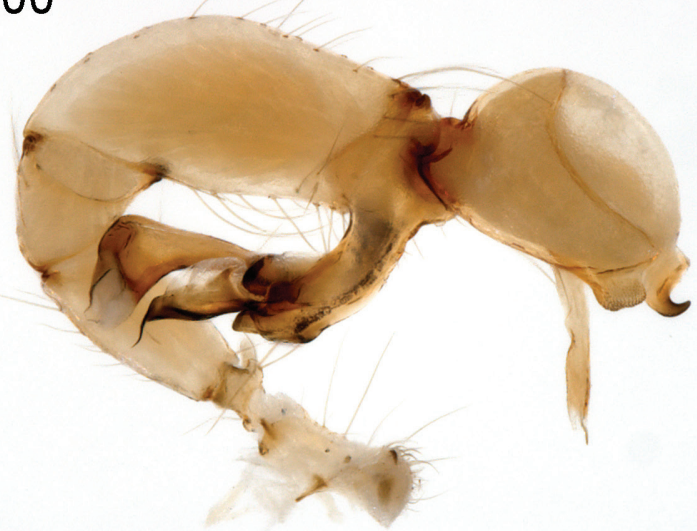

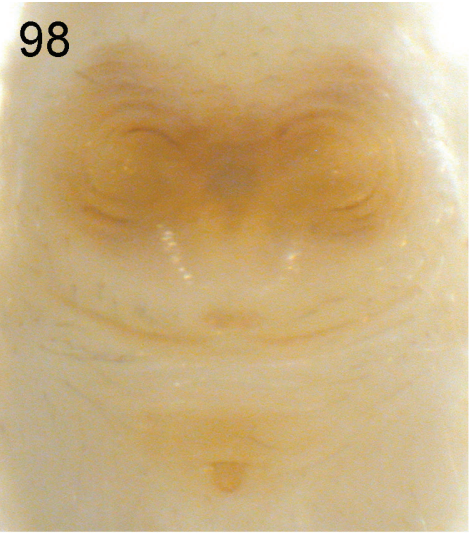

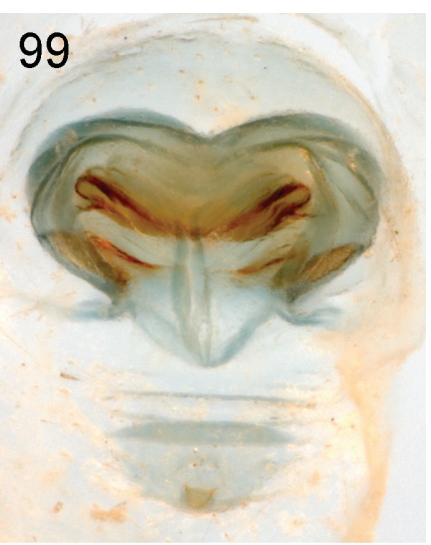

101

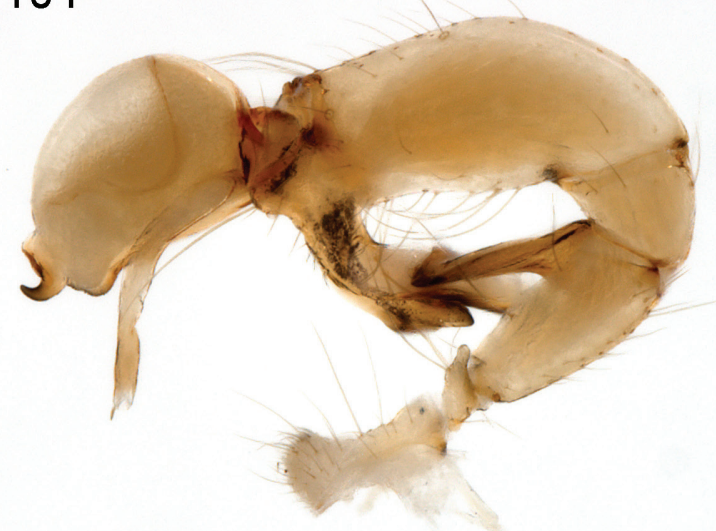

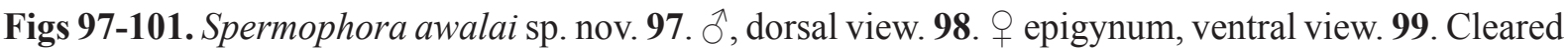
+ genitalia, dorsal view. 100-101. Left $\delta$ palp, prolateral and retrolateral views. 


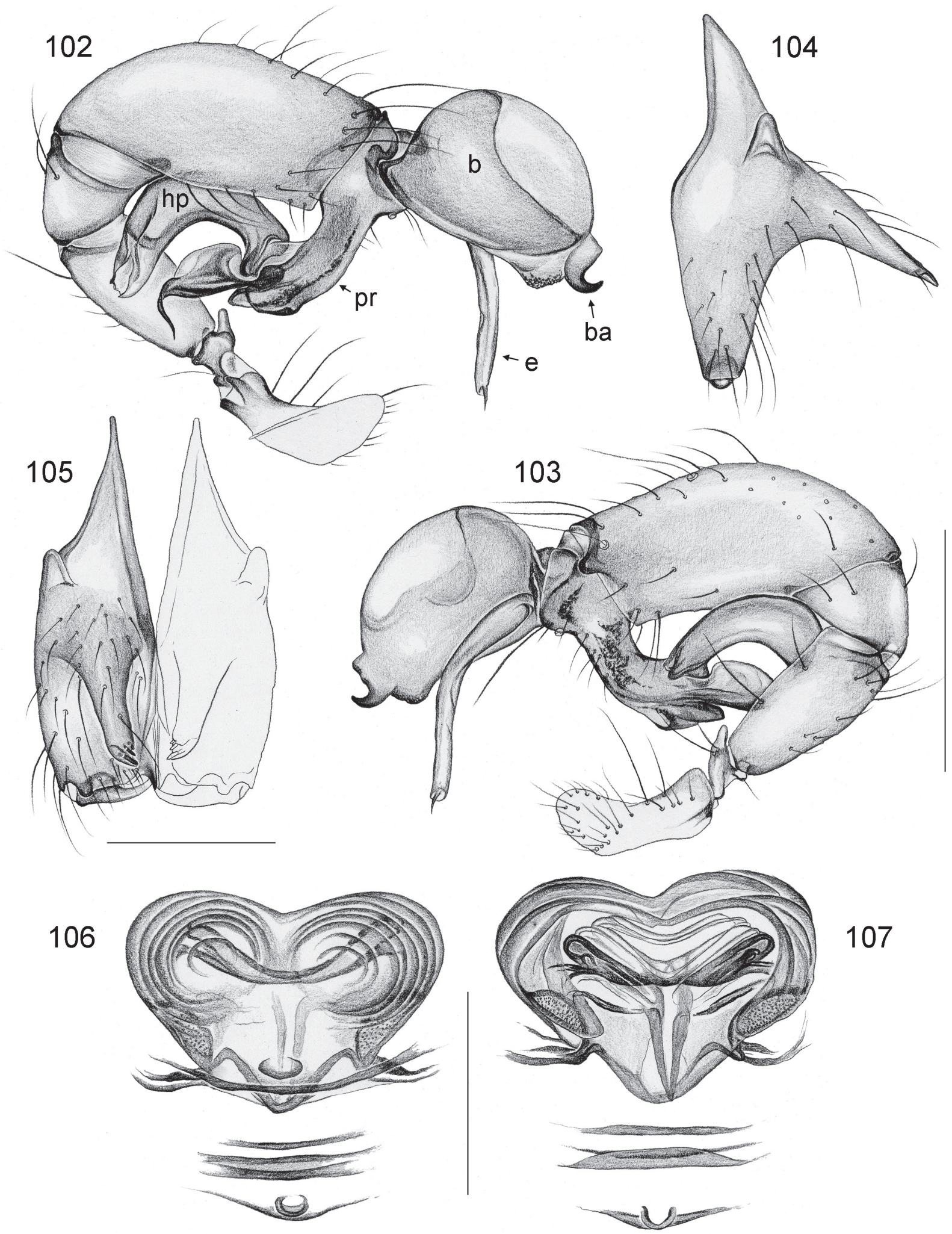

Figs 102-107. Spermophora awalai sp. nov. 102-103. Left $\widehat{\partial}$ palp, prolateral and retrolateral views. 104105. $\delta^{\lambda}$ chelicerae, lateral and frontal views. 106-107. Cleared $q$ genitalia, ventral and dorsal views. $\mathrm{b}=$ bulb; ba = bulbal apophysis; $\mathrm{e}=$ embolus; $\mathrm{hp}=$ hinged process; $\mathrm{pr}=$ procursus. Scale lines: $102-103=$ $0.5 \mathrm{~mm} ; 104-105=0.2 \mathrm{~mm} ; 106-107=0.3 \mathrm{~mm}$. 
Color. Carapace ochre-yellow with black lateral margins and light brown median mark (Fig. 97), ocular area with dark band between eye triads, clypeus with a few black spots, sternum whitish, legs ochreyellow, with black spots on femora proximally, black patellae and tibia-metatarsus joints, dark rings subdistally on femora and tibiae (unusually far from tip), abdomen ochre gray with black marks dorsally and laterally.

Body. Habitus as in Fig. 97; ocular area barely elevated, each triad on low hump; carapace without median furrow; clypeus unmodified; sternum wider than long $(0.58 / 0.42)$, unmodified. Chelicerae as in Figs 104-105, with pair of proximal lateral apophyses and long frontal apophyses provided with three modified hairs each at tips, without stridulatory ridges.

PALPS. As in Figs 100-103, coxa unmodified, trochanter with short retrolatero-ventral apophysis, femur unmodified, procursus strongly bent towards ventral, with complex tip and large ventral hinged process; bulb with long, weakly sclerotized embolus and short, hooked apophysis.

LEGS. Without spines and curved hairs, few vertical hairs; retrolateral trichobothrium on tibia 1 at $8 \%$; prolateral trichobothrium absent on tibia 1 , present on other tibiae. Tarsus 1 with $>20$ pseudosegments, only distally fairly distinct.

VARIATION. Tibia 1 in 12 other males: 4.1-5.5 (mean 4.9). Some specimens with additional indistinct dark ring on each femur and tibia.

\section{Female}

In general similar to male; tibia 1 in 10 females: 3.6-4.6 (mean 4.2). Epigynum light brown area with pair of distinctive internal structures with concentric rings visible through cuticle (Figs 98, 106), with median pocket between epigynum and spinnerets; internal genitalia as in Figs 99 and 107.

\section{Distribution}

Known from several localities in Southwest and Centre Regions, Cameroon (Fig. 34).

\section{Discussion}

\section{Distribution patterns}

Except for some synanthropic and widespread species, the large majority of Central African Pholcidae are highly endemic. Considering just the two neighboring countries that were relatively well sampled (Cameroon and Gabon), the number of endemic species is considerably higher than the number of nonendemic species in each country. In Cameroon, 21 of the 35 currently recorded species (i.e. $60 \%$ ) are not known from any other country, not even neighboring Gabon. The numbers for Gabon are almost identical (21 of 33 species endemic, i.e. 64\%). Diversity and endemism are especially high in the genus Smeringopina, with 13 of the 14 Cameroonian species and all 18 Gabonese species known from only Cameroon and Gabon, respectively.

Most of the species listed above (62, i.e. $84 \%$ if the five synanthropic species are discounted from the total number of 79) are endemics of the Lower Guinean subregion of the Guineo-Congolian center of endemism. Similar percentages of endemics have been found in West Africa (68\%; value differs from that in Huber \& Kwapong 2013 because Anansus atewa is no longer considered an endemic of West Africa) and East Africa (84\%; calculated from data in Huber \& Warui 2012). This is reflected in the fact that few species (again, discounting synanthropics) are shared among these regions. Only three species occur in all three regions: Pehrforsskalia conopyga Deeleman-Reinhold \& van Harten, 2001; Quamtana kitahurira Huber, 2003 and Spermophora kyambura Huber \& Warui, 2012. Three additional species are shared between Upper and Lower Guinea (i.e., West and Central Africa): Smeringopina fon Huber, 
2013; Smeringopus cylindrogaster (Simon, 1907); and Spermophora akwamu Huber \& Kwapong, 2013 (a fourth, Pholcus kakum Huber, 2009, is likely to occur in Lower Guinea but has not yet been documented from there). Two Central African species range deeply into Congolia (Pholcus baka Huber, 2011 and Smeringopus lesserti Kraus, 1957), the latter reaching the western limits of East Africa (Huber 2011b, 2012).

A comparison of the genera represented by endemic species in each of the three regions studied (Fig. 108) reveals significant differences between East and Central Africa but smaller differences between Central and West Africa. This is mainly due to the species-rich genera Buitinga Huber, 2003 and Smeringopina Kraus, 1957, the first being endemic to East Africa, the second to West and Central Africa. By contrast, the percentages of endemic species of Pholcus Walckenaer, 1805 are relatively homogeneous across tropical Africa. This is noteworthy because Pholcus has no endemic species in southern Africa or on Madagascar (Huber 2011b).

\section{Diversity patterns}

From a simple comparison of total species numbers, pholcid diversities in Central and East Africa appear to be similar (79 and 86 species respectively), while West Africa seems to be significantly less diverse (38 species; Fig. 109). This is not simply a result of different surface areas considered in each case. The land area of West Africa considered in Huber \& Kwapong $\left(2013 ; \sim 2.3 \times 10^{6} \mathrm{~km}^{2}\right)$ was actually larger than that of East Africa in Huber \& Warui $\left(2012 ; \sim 2.1 \times 10^{6} \mathrm{~km}^{2}\right)$ and that of Central Africa considered herein $\left(\sim 1.6 \times 10^{6} \mathrm{~km}^{2}\right)$. On the other hand, there is some evidence that the total numbers are biased against Central Africa because it seems most poorly collected. Figure 110 shows species numbers collected by the first author during expeditions of very similar durations and with very similar collecting efforts (West Africa: Guinea, Ghana; Central Africa: Cameroon, Gabon; East Africa: Kenya, Uganda). The much higher number of new species found in Central Africa suggests that this region is in fact undersampled relative to West and East Africa. Recent evidence on forest-dwelling insects suggests that the diversity is higher in Central Africa (and in particular in Cameroon) than in any other part of Africa (P. Le Gall, unpublished).

Diversity is also high at individual localities (with 'locality' roughly defined as the area that can be covered in one day by walking). Few localities worldwide are known to contain more than 10 species of
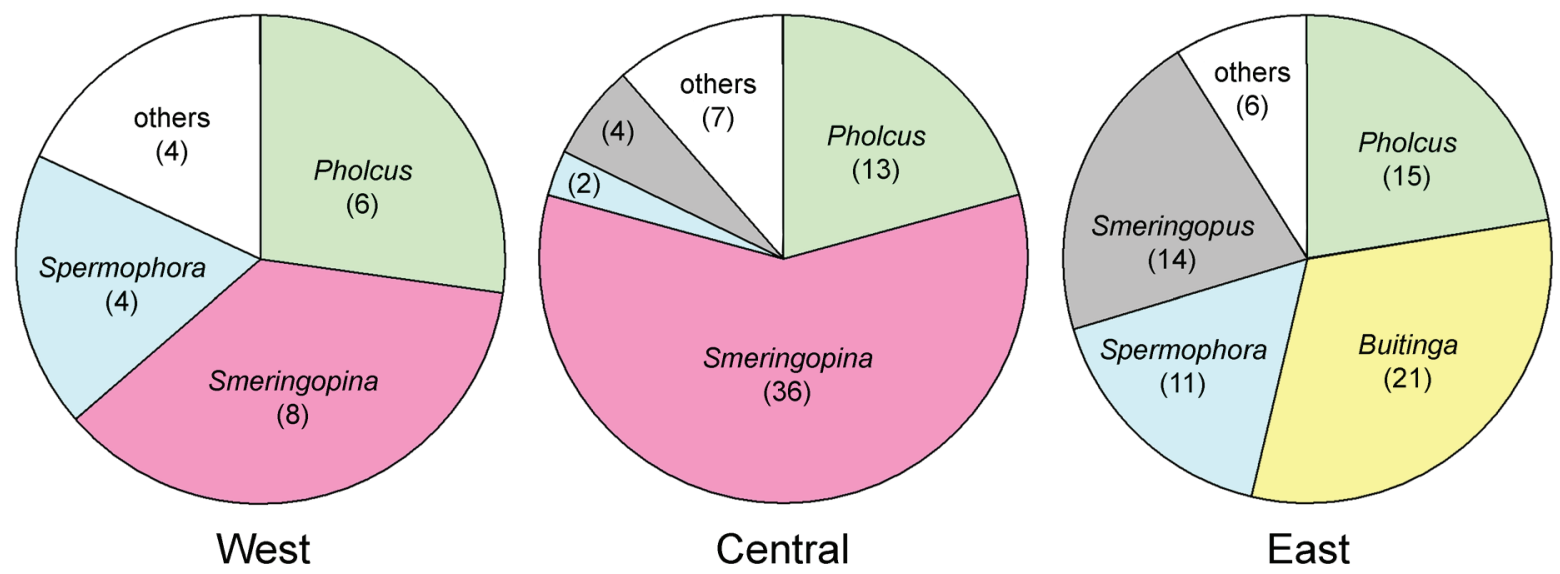

Fig. 108. Pholcid genera represented by endemic species (total numbers of endemic species in parentheses) in each region (West, Central, and East Africa), illustrating the distinctness of East Africa as compared to West and Central Africa. Data on East and West Africa from Huber \& Warui (2012) and Huber \& Kwapong (2013), respectively. White: genera that are not represented by more than four endemic species in any of the three regions. 
Pholcidae each, most of them in Brazil's Atlantic Forest (Huber \& Rheims 2011; B.A. Huber, unpublished data). Luki Forest Reserve in Central Africa is currently the most diverse locality in Africa for this family. Eleven of its 13 known species (the last of which is described herein), have been described within the last decade: Anansus debakkeri Huber, 2007; Leptopholcus debakkeri Huber, 2011; L. tipula (Simon, 1907); Pholcus luki Huber, 2011; P. soukous Huber, 2011; Quamtana kitahurira Huber, 2003; Smeringopina kikongo Huber, 2013; S. luki Huber, 2013; Smeringopus luki Huber, 2012; S. mayombe Huber, 2012; Spermophora abibae sp. nov.; S. kyambura Huber \& Warui, 2012; Nyikoa limbe Huber, 2007. Since Luki Forest Reserve is probably among the best sampled African localities as far as spiders are concerned (as a result of two major campaigns by MRAC focusing on this single forest), it is likely that increased effort will reveal more such diverse localities in Central Africa. The fact that 10 species were collected at Mayebout (Gabon) within two days by only two collectors (one of them inexperienced) also points in that direction.

\section{Outlook}

Two recent expeditions to Cameroon and Gabon resulted in a total of 54 pholcid species, 42 of which (78\%) were still undescribed a decade ago. All this material and most of the Central African material deposited in other major arachnological collections is now described. However, the high percentage of undescribed species collected during about seven weeks in the field also illustrates the relative ease with which new pholcid species can still be discovered in this region. This is probably a general pattern, as suggested by recent studies on arthropods in lowland forests in Cameroon (e.g., Larsen 2005) and on

\section{9}

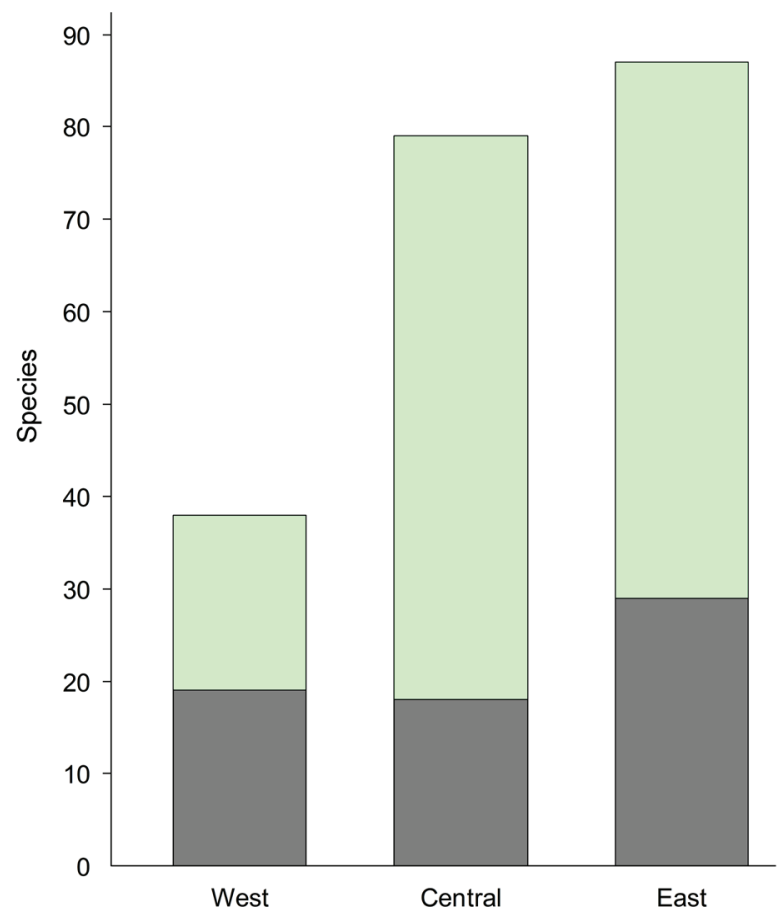

110

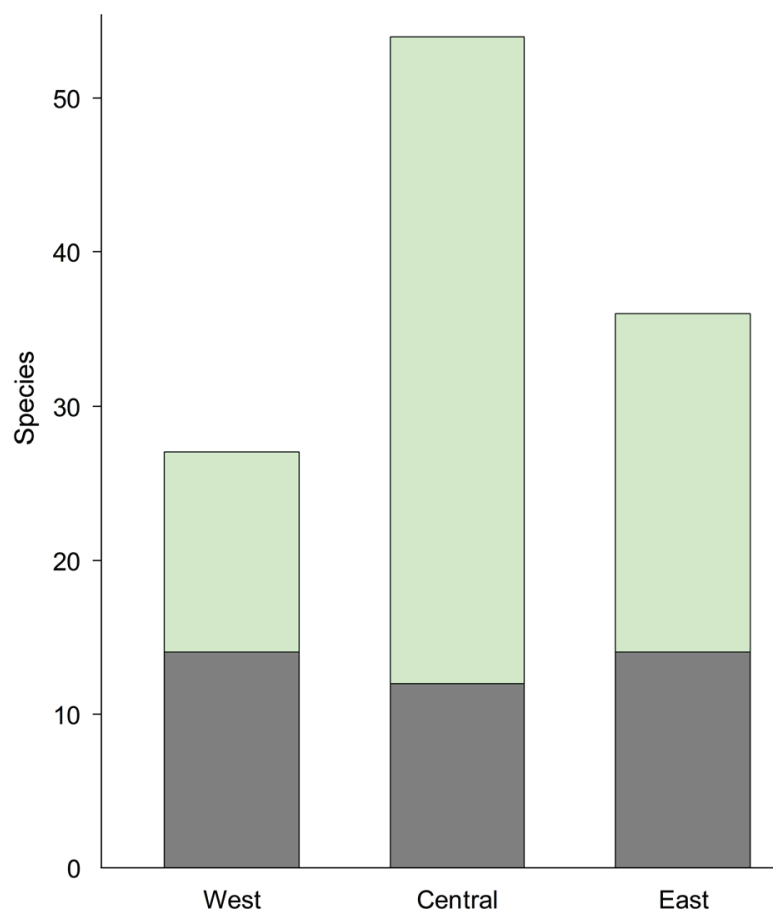

Figs 109-110. Pholcid species from West, Central, and East Africa, divided into 'old' species (grey; described before 2003) and 'new' species (green; described since 2003). 109. Current totals as listed in Huber \& Warui (2012), Huber \& Kwapong (2013) and herein, suggesting lower diversity in West than in Central and East Africa. 110. Species collected by the first author during six expeditions (two to each region) of very similar durations and with very similar collecting efforts, suggesting that Central Africa may be more severely undersampled than West and East Africa. 
the biodiversity of the Volcanic Line of Cameroon (Bergl et al. 2007). Species distribution patterns also suggest that even in areas relatively well sampled (western Cameroon, Gabon, western Congo D.R.), many undiscovered species may remain. Of the 79 Central African species listed above, 33 (42\%) are known from their type localities only. Denser sampling across seasons and altitudes will probably reveal not only more realistic distribution patterns, but also additional new species even in these areas.

On the other hand, large areas within Lower Guinea remain almost entirely unexplored with respect to spiders and to Pholcidae in particular (Fig. 19). Congo Republic is among the few countries worldwide from which the first author has never seen even a single pholcid specimen. Only a single (doubtful) record seems to exist in the literature (a juvenile Smeringopus pallidus cited in Lawrence 1958). With large parts of its moist tropical forests remaining (over $60 \%$ as of 1992; Naughton-Treves \& Weber 2001), Congo Republic is likely to have similar numbers of species as neighboring Gabon (currently 33). The same is true for large parts of southeastern Cameroon, eastern Nigeria, and southwestern Central African Republic (Fig. 19).

\section{Acknowledgements}

BAH thanks all the people who kindly sent specimens used in this study: J. Beccaloni, J. Coddington, C.E. Griswold, R. Jocqué and N. Scharff. BAH thanks R.A. Nkomo and R. Kamga for their invaluable and friendly assistance in the field. F.J. Muafor, J.C. Huber and S.R. Huber provided further help in the field. E. Gavish-Regev and an anonymous reviewer provided helpful comments on the manuscript. The German Research Foundation provided financial support (DFG, HU 980/9-1).

\section{References}

Bergl R.A., Oates J.F., \& Fotso R. 2007. Distribution and protected area coverage of endemic taxa in West Africa's Biafran forests and highlands. Biological Conservation 134: 195-208. http://dx.doi. org/10.1016/j.biocon.2006.08.013

Dimitrov D., Astrin J.J. \& Huber B.A. 2013. Pholcid spider molecular systematics revisited, with new insights into the biogeography and the evolution of the group. Cladistics 29: 132-146. http://dx.doi. org/10.1111/j.1096-0031.2012.00419.x

Dowsett-Lemaire F. \& Dowsett R.J. 2001. African forest birds. In: Weber W., White L.J.T., Vedder A. \& Naughton-Treves L. (eds) African Rain Forest Ecology and Conservation: 233-262. Yale University Press, New Haven and London.

Grubb P. 2001. Endemism in African rain forest mammals. In: Weber W., White L.J.T., Vedder A. \& Naughton-Treves L. (eds) African Rain Forest Ecology and Conservation: 88-100. Yale University Press, New Haven and London.

Huber B.A. 1996. On the distinction between Modisimus and Hedypsilus (Pholcidae; Araneae), with notes on behavior and natural history. Zoologica Scripta 25: 233-240. http://dx.doi. org/10.1111/j.1463-6409.1996.tb00164.x

Huber B.A. 2000. New World pholcid spiders (Araneae: Pholcidae): a revision at generic level. Bulletin of the American Museum of Natural History 254: 1-348. http://dx.doi.org/10.1206/00030090(2000)254<0001:NWPSAP>3E2.0.CO;2

Huber B.A. 2002. Ninetis russellsmithi n. sp., an unusual new pholcid spider species from Malawi (Araneae: Pholcidae). Journal of Insect Science 2.4: 1-3. http://www.insectscience.org/2.4/

Huber B.A. 2003a. Cladistic analysis of Malagasy pholcid spiders reveals generic level endemism: revision of Zatavua n. gen. and Paramicromerys Millot (Pholcidae, Araneae). Zoological Journal of the Linnean Society 137: 261-318. http://dx.doi.org/10.1046/j.1096-3642.2003.00046.x 
Huber B.A. 2003b. High species diversity in one of the dominant groups of spiders in East African montane forests (Araneae: Pholcidae: Buitinga n. gen., Spermophora Hentz). Zoological Journal of the Linnean Society 137: 555-619. http://dx.doi.org/10.1046/j.1096-3642.2003.00053.x

Huber B.A. 2003c. Southern African pholcid spiders: revision and cladistic analysis of Quamtana n. gen. and Spermophora Hentz (Araneae: Pholcidae), with notes on male-female covariation. Zoological Journal of the Linnean Society 139: 477-527. http://dx.doi.org/10.1046/j.0024-4082.2003.00082.x

Huber B.A. 2005. The pholcid spiders of Africa (Araneae: Pholcidae): state of knowledge and directions for future research. In: Huber B.A., Sinclair B.J. \& Lampe K.-H. (eds) African Biodiversity: Molecules, Organisms, Ecosystems: 181-186. Springer Verlag.

Huber B.A. 2007. Two new genera of small, six-eyed pholcid spiders from West Africa, and first record of Spermophorides for mainland Africa (Araneae: Pholcidae). Zootaxa 1635: 23-43.

Huber B.A. 2009. Life on leaves: leaf-dwelling pholcids of Guinea, with emphasis on Crossopriza cylindrogaster Simon, a spider with inverted resting position, pseudo-eyes, lampshade web, and tetrahedral egg-sac (Araneae: Pholcidae). Journal of Natural History 43: 2491-2523. http://dx.doi. org/10.1080/00222930903207876

Huber B.A. 2011a. Phylogeny and classification of Pholcidae (Araneae): an update. Journal of Arachnology 39: 211-222. http://dx.doi.org/10.1636/CA10-57.1

Huber B.A. 2011b. Revision and Cladistic Analysis of Pholcus and Closely Related Taxa (Araneae, Pholcidae). Bonner zoologische Monographien 58, Zoologisches Forschungsmuseum Alexander Koenig, Bonn.

Huber B.A. 2012. Revision and cladistic analysis of the Afrotropical endemic genus Smeringopus Simon, 1890 (Araneae: Pholcidae). Zootaxa 3461: 1-138.

Huber B.A. 2013. Revision and cladistic analysis of the Guineo-Congolian spider genus Smeringopina Kraus (Araneae, Pholcidae). Zootaxa 3713: 1-160. http://dx.doi.org/10.11646/zootaxa.3713.1.1

Huber B.A. In press. Progress and prospects in taxonomy: what is our goal and are we ever going to reach it? Journal of Arachnology.

Huber B.A. \& El Hennawy H. 2007. On Old World ninetine spiders (Araneae: Pholcidae), with a new genus and species and the first record for Madagascar. Zootaxa 1635: 45-53.

Huber B.A. \& Kwapong P. 2013. West African pholcid spiders: an overview, with descriptions of five new species (Araneae, Pholcidae). European Journal of Taxonomy 59: 1-44. http://dx.doi.org/10.5852/ ejt.2013.59

Huber B.A. \& Rheims C.A. 2011. Diversity and endemism of pholcid spiders in Brazil's Atlantic Forest, with descriptions of four new species of the Atlantic Forest endemic genus Tupigea (Araneae: Pholcidae). Journal of Natural History 45: 275-301. http://dx.doi.org/10.1080/00222933.2010.524319

Huber B.A. \& Warui C.M. 2012. East African pholcid spiders: an overview, with descriptions of eight new species (Araneae, Pholcidae). European Journal of Taxonomy 29: 1-44. http://dx.doi.org/10.5852/ ejt.2012.29

Kraus O. 1957. Araneenstudien 1. Pholcidae (Smeringopodinae, Ninetinae). Senckenbergiana biologica 38(3/4): 217-243.

Larsen, T.B. 2005. Butterflies of West Africa. Apollo Books, Vester Skerninge, Denmark.

Lawrence R.F. 1958. A collection of cavernicolous Arachnida from French Equatorial Africa. Revue suisse de Zoologie 65: 857-866. 
Lawson D.P. \& Klemens M.W. 2001. Herpetofauna of the African rain forest. In: Weber W., White L.J.T., Vedder A. \& Naughton-Treves L. (eds) African Rain Forest Ecology and Conservation: 291-307. Yale University Press, New Haven and London.

Le Gall P., Silvain J.F., Nel A. \& Lachaise D. 2010. Les insectes actuels témoins des passés de l'Afrique: essai sur l'origine et la singularité de l'entomofaune de la région afrotropicale. Annales de la Société entomologique de France 46: 297-343.

Lessert R. de 1930. Araignées du Congo recueillies au cours de l'expédition organisée par l'American Museum (1909-1915). Quatrième et dernière partie. Revue suisse de Zoologie 37: 613-672.

Lessert R. de 1938. Araignées du Congo Belge. Revue de Zoologie et de Botanique Africaines 30: 424457.

Maley J. 2001. The impact of arid phases on the African rain forest through geological history. In: Weber W., White L.J.T., Vedder A. \& Naughton-Treves L. (eds) African Rain Forest Ecology and Conservation: 68-87. Yale University Press, New Haven and London.

Naughton-Treves L. \& Weber W. 2001. Human dimensions of the African rain forest. In: Weber W., White L.J.T., Vedder A. \& Naughton-Treves L. (eds) African Rain Forest Ecology and Conservation: 30-43. Yale University Press, New Haven and London.

Norris K., Asase A., Collen B., Gockowksi J., Mason J., Phalan B. \& Wade A. 2010. Biodiversity in a forest-agriculture mosaic - The changing face of West African rainforests. Biological Conservation 143: 2341-2350. http://dx.doi.org/10.1016/j.biocon.2009.12.032

Simon E. 1877. Etude sur les Arachnides du Congo (suite) (1). Bulletin de la Société zoologique de France 2: 482-485.

Simon E. 1893. Histoire Naturelle des Araignées. 2nd edition., 1(2): 256-488. Paris.

Simon E. 1907. Arachnides recueillis par L. Fea sur la côte occidentale d'Afrique. Annali del Museo civico di storia naturale di Genova 43: 218-323.

Thorell T. 1899. Araneae camerunenses. Bihang till Kongliga Svenska Vetenkaps-Akademien Handlingar 25: $1-105$.

Voelker G., Marks B.D., Kahindo C., A’Genonga U., Bapeamoni F., Duffie L.E., Huntley J.W., Mulotwa E., Rosenbaum S.A. \& Light J.E. 2013. River barriers and cryptic biodiversity in an evolutionary museum. Ecology and Evolution 3: 536-545. http://dx.doi.org/10.1002/ece3.482

White L.J.T. 2001. The African rain forest. In: Weber W., White L.J.T., Vedder A. \& Naughton-Treves L. (eds) African Rain Forest Ecology and Conservation: 3-29. Yale University Press, New Haven and London.

Manuscript received: 6 December 2013

Manuscript accepted: 1 April 2014

Published on: 25 April 2014

Topic editor: Rudy Jocqué

Desk editor: Kristiaan Hoedemakers

Printed versions of all papers are also deposited in the libraries of the institutes that are members of the EJT consortium: Muséum National d'Histoire Naturelle, Paris, France; Botanic Garden Meise, Belgium; Royal Museum for Central Africa, Tervuren, Belgium; Natural History Museum, London, United Kingdom; Royal Belgian Institute of Natural Sciences, Brussels, Belgium; Natural History Museum of Denmark, Copenhagen, Denmark. 